$$
\begin{aligned}
& \text { 震 }
\end{aligned}
$$

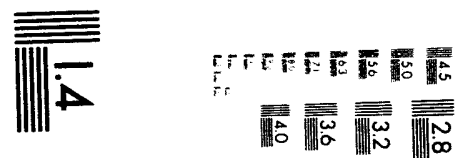

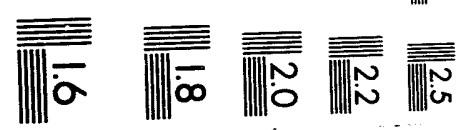



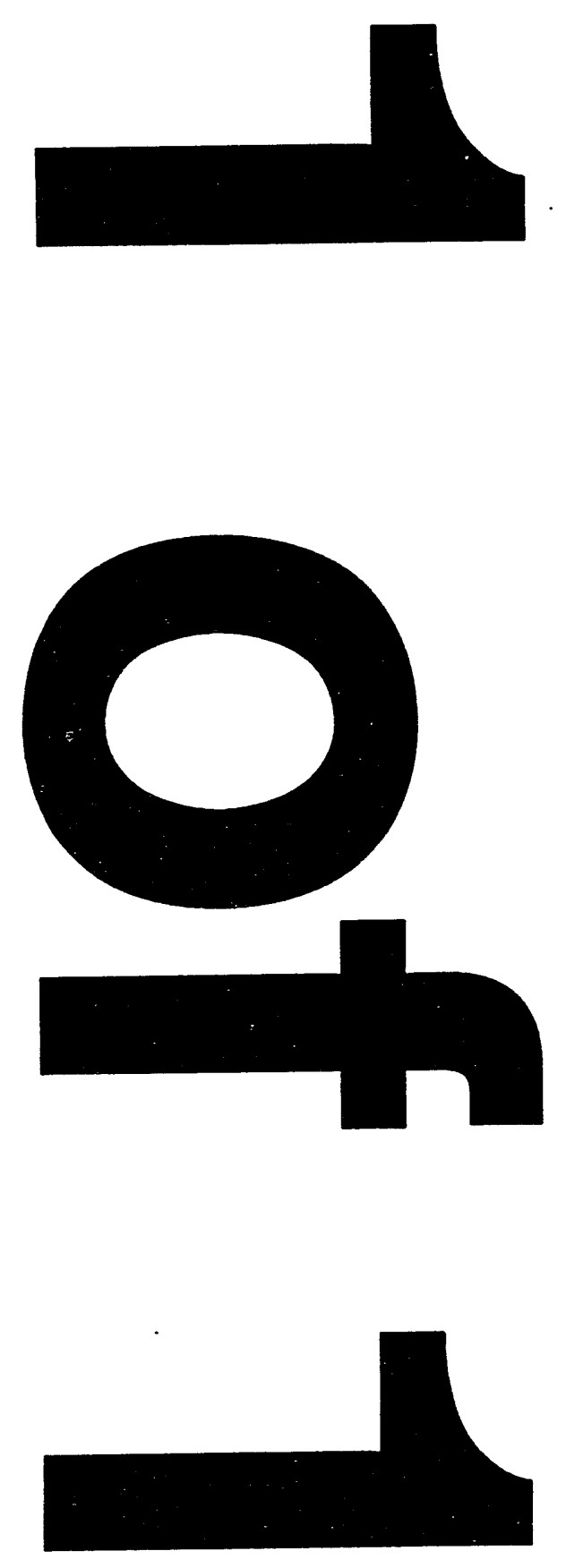


\title{
VITRIFICATION DEVELOPMENT PLAN \\ FOR U.S. DEPARTMENT OF ENERGY MIXED WASTES
}

\author{
Richard Peters \\ Pacific Northwest Laboratory \\ Battelle \\ Joe Lucema \\ EG\&G Rocky Flats \\ M. John Plodinec \\ Westinghouse Savannah River Company
}

October 1993

\author{
Prepared for the \\ MIXED WASTE INTEGRATED PROGRAM \\ U.S. DEPARTMENT OF ENERGY \\ OFFICE OF TECHNOLOGY DEVELOPMENT \\ Washington, D.C. 20585 \\ Prepared by the \\ PACIFIC NORTHWEST LABORATORY \\ under contract DE-AC06-76RLO 1830 \\ operated for the \\ U.S. DEPARTMENT OF ENERGY \\ bY BATTELLE MEMORIAL INSTITUTE
}




\section{CONTENTS}

SUMMARY

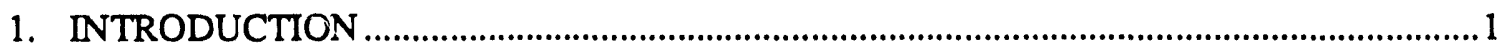

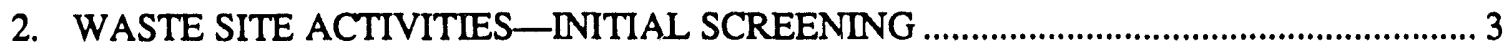

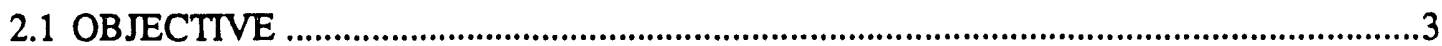

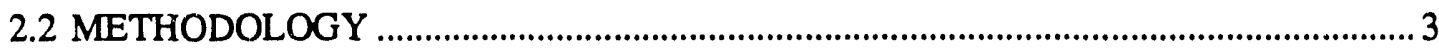

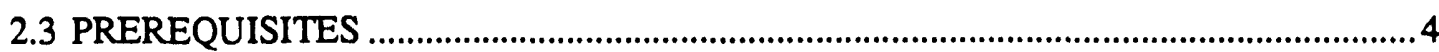

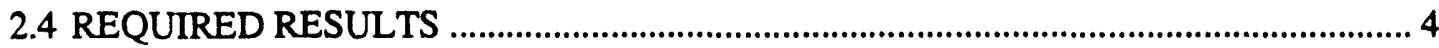

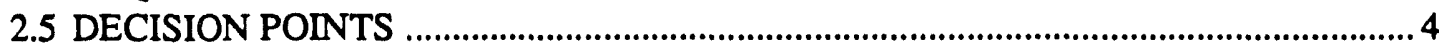

3. VITRIFICATION DEVELOPMENT FOR MIXED WASTES …....................................

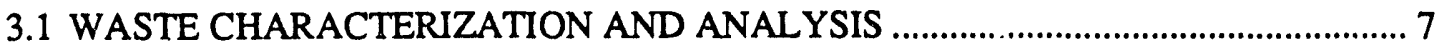

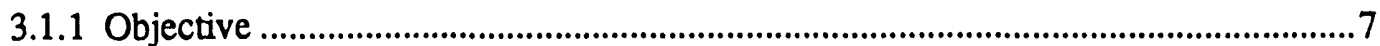

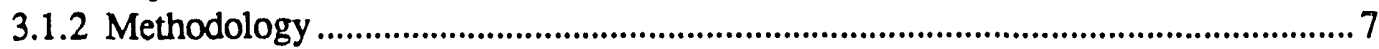

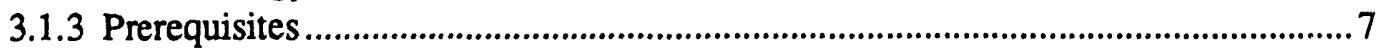

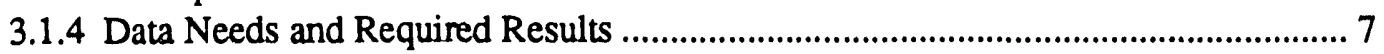

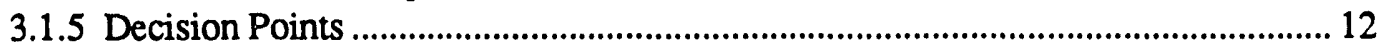

3.2 WASTE FORM DEVELOPMENT AND TREATABILITY STUDIES .......................13

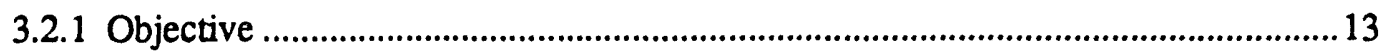

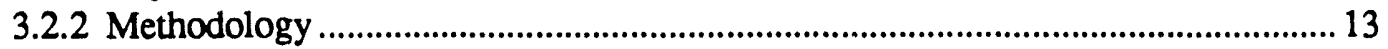

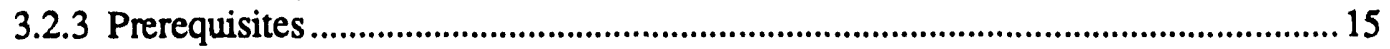

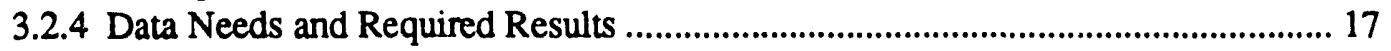

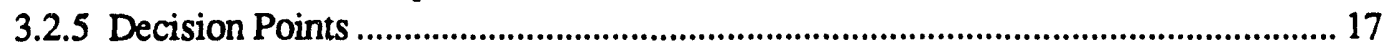

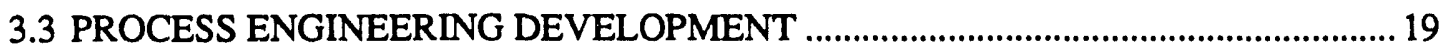

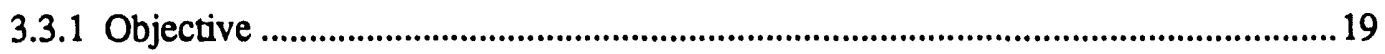

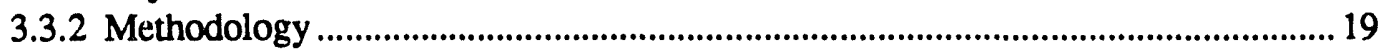

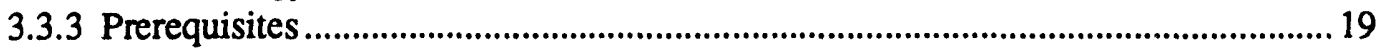

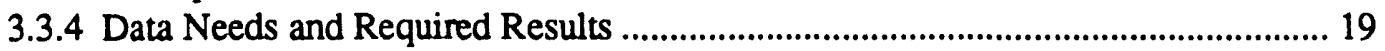

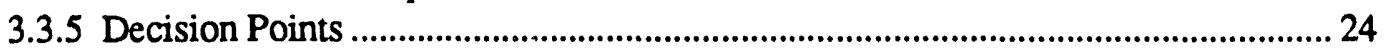

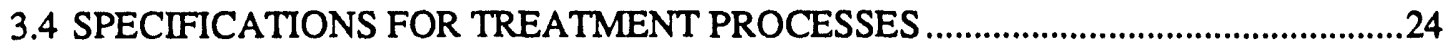

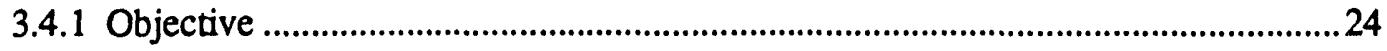

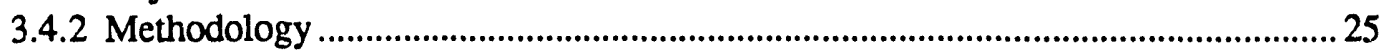

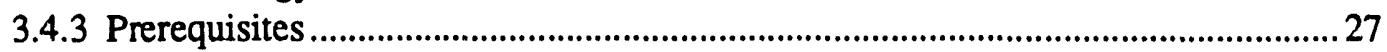

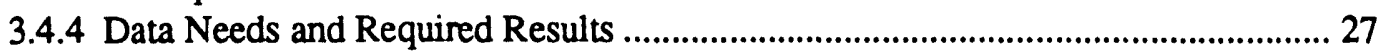

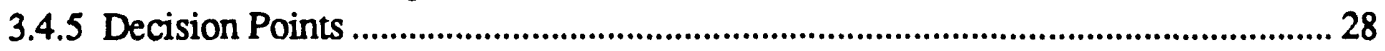

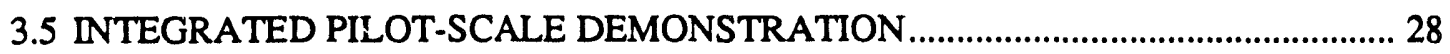

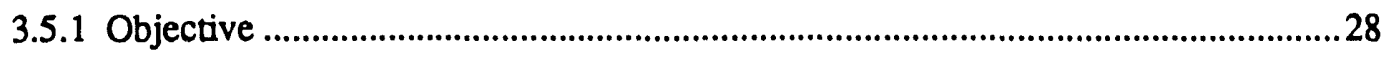

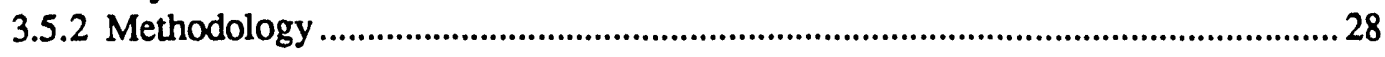

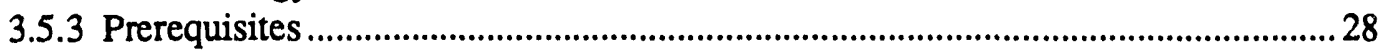

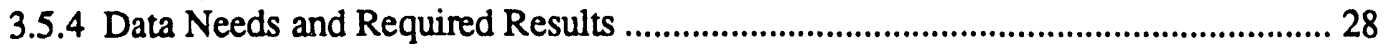

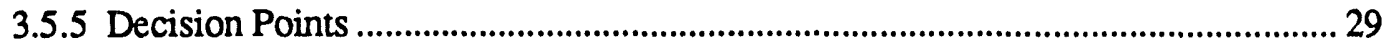

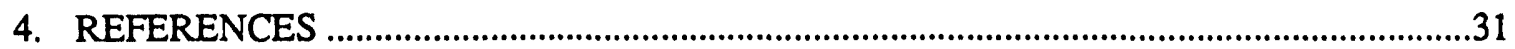


Appendix A: Sample Characterization Procedure for Waste Vitrification Studies-

Density, Moisture Content, Combustible Content

Appendix B: Sample Test Plan for Bench-Scale Vitrification Studies / Crucible

Melt Studies

Appendix C: Sample Test Plan for Engineering-Scale Vitrification Studies

Appendix D: Sample Test Plan Outline for Pilot-Scale Melter Studies

Figure 1. General Glass Formulation Procedure ........................................................................ 16

Table 1. Data Needs: Waste Characterization and Analysis ........................................................... 8

Table 2. Formulation of Glass for Oak Ridge West Tank Farm Sludge......................................... 14

Table 3. Data Needs: Waste Form Development and Treatability Studies.................................... 18

Table 4. Data Needs: Process Engineering Development ................................................................... 20

Table 5. Data Needs: Pilot-Scale Testing ....................................................................................... 30 


\section{SUMMARY}

This document is a general plan for conducting vitrification development for application to mixed wastes owned by the U.S. Department of Energy. The emphasis is a description and discussion of the data needs to proceed through various stages of development. These stages are (1) screening at a waste site to determine which streams should be vitrified, (2) waste characterization and analysis, (3) waste form development and treatability studies, (4) process engineering development, (5) flowsheet and technical specifications for treatment processes, and (6) integrated pilot-scale demonstration. Appendices provide sample test plans for various stages of the vitrification development process.

This plan is directed at thermal treatments which produce waste glass. However, the study is still applicable to the broader realm of thermal treatment since it deals with issues such as off-gas characterization and waste characterization that are not necessarily specific to vitrification. The purpose is to provide those exploring or considering vitrification with information concerning the kinds of data that are needed, the way the data are obtained, and the way the data are used. This will provide guidance to those who need to prioritize data needs to fit schedules and budgets. Knowledge of data needs also permits managers and planners to estimate resource requirements for vitrification development.

Vitrification has already been developed for high-level waste and other types of radioactive and industrial waste. Based on this experience, development for mixed waste should also be feasible. One distinguishing aspect of mixed waste, however, is variability and uncertainty in composition. Production of a glass acceptable for land disposal will require some knowledge of the waste composition so that appropriate glass-forming chemicals can be added where necessary. Process safety will also be a factor when vitrifying unknown waste materials. Another special feature of mixed waste is that it consists of regulated hazardous materials as well as radionuclides. Vitrification development should thus result in equipment systems and process chemistry flowsheets that satisfy regulatory requirements for waste form product consistency, product quality, worker safety, equipment performance, and environmental discharges. The required product quality is not yet defined beyond certain minimal limits. Through vitrification development, the glass waste form can be tailored to any desired level of quality. 


\section{INTRODUCTION}

The U.S. Department of Energy (DOE) is actively investigating methods for treating mixed waste to yield enhanced waste forms through the Mixed Waste Integrated Program (MWIP). To this end, various treatment alternatives are being explored, including vitrification, which results in a glass waste form. Vitrification is attractive because hazardous organic compounds are destroyed at the high process temperatures (typically $1000-1500^{\circ} \mathrm{C}$ ), and toxic metals and radionuclides can be incorporated in the leach-resistant glass waste form. Vitrification has been successfully applied to high-level wastes from the nuclear fuel cycle in France and Germany (Chapman and McElroy 1989). DOE is planning to use vitrification on its high-level waste (HLW) at West Valley (New York), Hanford, and Savannah River. Similarly, it is expected that vitrification can be deployed for mixed waste, although the equipment configurations and glass compositions may be different from those used for HLW.

The purpose of this report is to lay out a plan for development of vitrification technology to treat mixed low-level radioactive wastes (mixed waste). The waste being considered is located at DOE sites and is the responsibility of DOE. The report provides a description of the data needs for bringing vitrification technology to the deployment stage for mixed waste.

The term vitrification means "conversion to glass." The waste glass, however, can include crystalline phases as minor constituents. The plan described in this report covers production of a glass waste form, with the understanding that the waste may not be entirely vitreous because of process conditions. The results are thus relevant to glass-producing technologies including the joule-heated melter, fuel-fired melter, and in-can melter.

The study begins with a description of initial screening activities at the waste site to determine which wastes should be considered for vitrification. This is followed by a vitrification development plan covering waste characterization, waste form development, process engineering, technical specifications for treatment processes, and integrated pilot-scale demonstration. The emphasis of the study is to generally identify and discuss the data needs in a vitrification development program. The appendices provide examples of test plans and data-gathering procedures for treatability/glass development, small-scale melter testing, and pilot-scale testing. These cover both mixed waste vitrification development and testing for the HLW vitrification program. 


\section{WASTE SITE ACTIVITIES-INITIAL SCREENING}

This activity covers the selection of waste streams that should be considered for vitrification. The selection process should involve site staff and those familiar with the technology.

\subsection{OBJECTIVE}

The main objective of this section of the plan is to describe the process for selection of those low-level mixed waste streams that are potentially amenable to vitrification. The selected wastes will be candidates for further study during vitrification development at a treatment site. An additional purpose of this task is to describe the requirements and issues that must be addressed by the project from the generator-site perspective. The screening exercise initially covers stored and newly generated wastes; remedial and decontamination and decommissioning waste treatment needs will be determined when these waste streams are better defined.

The objective of the initial phases of characterization is to gain sufficient compositional data to determine applicability of the waste forms to vitrification. This information should include the Resource Conservation and Recovery Act (RCRA)-listed constituents, radionuclide analysis, and as much detail as possible about the chemical composition. Knowledge about the processes which generated the waste can be used if there is sufficient documentation. By using the results of the characterization activity, a screening process will provide a selection and prioritization of those low-level mixed waste streams that have the highest potential for treatment by vitrification. This screening will include the advantages and disadvantages of vitrification when compared to other technologies such as incineration, grouting, and polymer encapsulation.

The following steps are discussed in this phase of the plan:

- Screening and selection of the mixed wastes for vitrification or vitrification testing development

- Preliminary characterization of the waste to allow for estimates of process chemistry and process equipment design and preparation of surrogate materials for testing

- Packaging and shipment of waste samples for treatability studies on actual waste at the vitrification site or the vitrification testing site if different from the waste originator site

\subsection{METHODOLOGY}

Each DOE site has completed at least a preliminary listing of the compositions and amounts of its mixed waste streams. Compositions of these streams are based on process knowledge in the majority of cases. Process knowledge has been the method of choice in the recent past because of the general lack of analytical capabilities for radioactive mixed wastes. The initial screening activity is planned as a coarse selection process, so the existing process knowledge will be used as the initial information base. Selection criteria will include radionuclide composition, RCRA constituents and U.S. Environmental Protection Agency (EPA) codes, chemical composition, physical form, total amount to be treated, ability to obtain samples, ability to perform analyses, pretreatment requirements, ability to ship, application to other sites, and political interest. After the initial list of candidates has been selected, the limited compositional information known at that point will be shared with those developing vitrification treatment technologies.

Surrogate materials can be identified for preparation of simulated waste streams for use in preliminary glass development and testing. This initial testing is typically performed with nonradioactive material due to cost and schedule constraints. These "cold" tests can be 
accomplished at the vitrification developer sites while additional characterization, testing, and preparation for shipment of samples of the real waste for treatability testing are taking place at the waste originator site.

Characterization will provide information required by the process as well as that needed for shipping. This includes the main constituents, presence of materials that may be an advantage or a disadvantage to vitrification, materials that could cause shipping problems, the RCRA-listed constituents, and a radionuclide analysis. A preliminary test using the toxicity characteristic leaching procedure (TCLP) and possibly other evaluations of the rough waste will provide a basis for comparison to the final waste form. Some type of pretreatment may be required prior to shipment. Finally, the waste samples must be properly packaged in suitable shipping containers that comply with all applicable regulations at the shipping site, the U.S. Department of Transportation (DOT), and the receiving site. This final waste form verification activity will ensure that the waste has been converted into a robust form that complies with all applicable regulations. The minimum compliance is verification that the treated waste is low-level waste (LLW), rather than HLW or TRU (transuranic), and that it meets land disposal restrictions. Further verification may include a compositional analysis to determine hazardous constituents, a radionuclide analysis to determine activity, and a TCLP to verify encapsulation.

\subsection{PREREQUISITES}

In general, a comprehensive inventory of the types and quantities of low-level mixed waste at a particular site will serve as the basis for this portion of the plan. At the Rocky Flats site, the inventory information required as input will be provided by the Comprehensive Treatment and Management Plan (CTMP) and its supporting documents. The CTMP has been prepared as a requirement of the Federal Facilities Compliance Agreement (FFCA) and describes DOE's strategy and commitments for bringing Land Disposal Restricted (LDR) mixed waste at Rocky Flats into compliance with applicable regulations.

\subsection{REQUIRED RESULTS}

The information to be developed as a result of this screening activity is as follows:

- List of wastes under consideration for treatment at the site

- List of selected waste streams to consider for vitrification

- EPA listing and RCRA constituents for the selected wastes

- Description of the waste through process knowledge and documentation, including chemicals and radionuclides, if possible

\subsection{DECISION POINTS}

The key decision in this task is selection of wastes as candidates for vitrification development. The criteria on which this decision will be based are as follows:

- Chemical composition and physical form. This information will be required for process development as well as for shipping. It includes the main constituents; presence of materials that may be an advantage to vitrification (silica, alumina, calcium, etc.) Or that could be a disadvantage (chlorides, sulfates, metals, etc.); materials, like free liquids, that could cause shipping problems; the RCRA-listed constituents; and a radionuclide analysis. Wastes that are predominantly metal or dilute wastewater may not be 
candidates for vitrification; however, the residue from decontaminating the metal or wastewater could be vitrified. Also wastes that contain high levels of volatile material such as mercury are not candidates for vitrification.

- Total amount to be treated. Includes both the backlog and newly generated wastes. This is used for economic analysis and equipment sizing.

- Ability to obtain samples for analysis. It will be much easier to sample current processes as opposed to backlog wastes, which may not be homogeneous and will probably not have current sampling plans.

- Pretreatment requirements and ability to ship. This hinges on good characterization and the ability to package the waste samples in limited-quantity DOT Type A containers.

- Political interest. Some waste streams have gained this interest level for a variety of reasons: perceived hazard, amounts in backlog or being generated, desire for "some action/any action," and individual VIP opinions. There may be site-specific concems and national-need issues to consider. 


\section{VITRIFICATION DEVELOPMENT FOR MIXED WASTES}

The following section describes general activities needed to develop vitrification for waste treatment.

\subsection{WASTE CHARACTERIZATION AND ANALYSIS 3.1.1 Objective}

The objective of this activity is to characterize those waste streams previously selected during the initial screening process (Sect. 2) as being likely candidates for crucible studies. State and federal regulations may require some level of waste characterization prior to engaging in waste management activities such as storage, transportation, treatment, and disposal. Any or all of these data should be made available to those exploring vitrification as a treatment option for a particular waste type.

Beyond the regulatory requirement, there are technical needs associated with characterization. Knowing the constituents in the waste facilitates selection of proper additives to be introduced during vitrification. A target waste glass formulation is sought which has the appropriate processing properties (e.g., viscosity at melt temperature and electrical conductivity) and also yields a final waste form with adequate structural integrity, leach resistance, and other attributes. It is also useful to identify constituents that are not incorporated into glass, such as metals, chlorides, sulfates, and combustible materials. Techniques to manage these materials must be employed, such as combustion, volatilization, and draining of metals. Waste variability information is needed for process design. Finally, some testing will be accomplished using surrogate materials, and characterization will provide the information needed to select and formulate appropriate surrogates. The key deliverable for this activity is sufficient characterization of each waste stream selected in the rough screening process to decide if vitrification studies are warranted.

\subsubsection{Methodology}

Characterization of stored waste occurs by process knowledge or by sampling and analysis. As mentioned above, process knowledge will probably be the only initial information available on the constituents in the majority of mixed wastes. In some cases this information may be enough. Other wastes, such as those with a requirement for determining levels of certain contaminants, may require more detailed analyses, and an analytical laboratory with specific mixed waste capability must be utilized.

\subsubsection{Prerequisites}

To proceed with characterization, a decision on which wastes to consider for vitrification is needed. This should be established in the rough screening exercise.

\subsubsection{Data Needs and Required Results}

Characterization should include information sufficient to select and size waste-handling equipment, formulate glasses, develop a process flowsheet, and define process operating parameters. The information should also be sufficient to allow formulation of surrogate materials for testing of various technologies at the bench or pilot scale. Table 1 lists the principal types of information about waste that can assist in vitrification development. Many of the procedures for chemical analysis are well established and are commonly used in commercial laboratories. To determine water content and combustible content for the purpose of vitrification testing, a specific procedure has been developed at Pacific Northwest Laboratory (PNL) for industrial and institutional wastes and is also applicable to DOE mixed wastes. It is provided in Appendix A. 
Table 1. Data Needs: Waste Characterization and Analysis

Data Objectives

Quantity

\section{General material \\ description}

Physical form

Physical properties

Rough size distribution

Combustibles content

Water content

Primary metal content
Equipment sizing and selection, identify opportunities for blending wastes that are complementary with respect to vitrification, establishing cost and schedule for treatment campaign

Screen waste categories for applicability of vitrification or other thermal processing

Determine materials conveyance requirements, feed systems, melter sizing requirements

Determine materials conveyance requirements, feed systems, melter sizing requirements

Determitie materials convcyance requirements, feed systems, melter sizing requirements

Mclter plenum sizing and design, off-gas system sizing and design, meltcr heat loads, selcction of technologies (incinerator, etc.)

Determine process energy requirements, off-gas sizing, process rate estimates, secondary effluent quantities

Determine materials conveyance requirements, need for soring, feed systems, melter sizing requirements, melter design requirements, treatment technology selection, design of waste glass

\section{Method}

Plant records, inspection (i.e., count number of containers), volume or weight

measurements

Plant processing records, inventory records, visual inspection

Plant records, inventory records,

visual/manual inspection of wastc

Measurement of specific weight, viscometer measurement, handling characteristics

Plant records, inventory records, visual/manual inspection of wastc

Plant rccords, visual/manual inspection, char/oxidation weight change, organic analysis as noeded

Sample and analyze: weight loss on drying, firing

Plant records, inventory records, visual/manual inspection, sorting of waste, analysis for metals as needed using metallurgical or chemical methods

\section{Form of Data}

Mass, volume, and density

Qualitative: sludge, liquid, bulk solid, trash, contaminated metal, general heterogencous matcrial, etc.

Qualitative: flowable solid, liquid, slurry, bulk solid, heterogeneous material, etc.

Density, viscosity, angic of repose

Size distributon: weight pereent versus dimension

Weight percent carbonaccous material or fuel content

Weight percent $\mathrm{H}_{2} \mathrm{O}$

Weight percent metals by metal type 
Table 1. Data Needs: Waste Characterization and Analysis (continued)

\section{Data Objectives}

Volatile metal content

\section{Metal cation/oxide} content

\section{Hazardous organic} compound content

Anion content

Radiochemical analysis

Radiation field

\section{How Data Are Used}

Off-gas system design, plant flowsheet development, sccondary waste cvaluation

Melter decontamination factor (DF) determination, waste glass formulation, additive requirements, flowsheet development

Air quality and other EPA permit requirements, melter plenum sizing and design, destruction and removal efficiency determination, off-gas system sizing and design, melter heat loads, selection of technologies (incinerator, etc.)

Air quality rcquirements, off-gas scrubber design, scrub solution recycle management, secondary effluent quantitics, waste glass formulation, additive requirements

Determine radionuclide reıntion (DF) in melter, evaluate criticality safcty, establish radiation protocols, establish material balances for radionuclides across process, meet air quality requirements

Determine personnel shielding requirements

\section{Method}

Plant records, inventory records,

visual/manual inspection, sorting of waste,

analysis for metals as needed using

metallurgical or chemical methods

Sampling and analysis of waste: inductively coupled plasma (ICP) (EPA 3050, 6010)

Sampling and analysis of waste: gas chromatography/mass spectrometry (EPA 8240, 8270)

Sampling and analysis of waste: anion chromatography

Gross alpha counting, gamma scan

exposure rate measurement using hand-held or remote ion chamber probes

\section{Eorm of Data}

Weight percent metals

Parts per million or weight percent metals, converted to equivalent oxides or glass compounds

Parts per million by compound

Parts per million, weight percent, or mole percent anions, associated with corresponding cations (use ICP data as necessary)

Activity per unit mass (Ci/g) by radionuclide

Exposure rate $(\mathrm{R} / \mathrm{h})$ 
It should be pointed out that not all of the data categories in Table 1 are required. Ideally, there would be minimal requirements to characterize the waste prior to treatment. However, this may not be realistic regardless of the treatment technology for reasons of safety and waste form quality. Blindly treating waste is a safety issue because there may be highly reactive or sealed containers that could explode upon thermal treatment. The safety systems to contain such an event in a radioactive processing facility may be economically unfavorable compared to the altemative of opening containers and conducting sorting/sampling. Waste form acceptance requirements may also prevent treating without some knowledge of the waste. For example, if the waste is dominated by sodium or calcium, then it is necessary to add glass formers in the correct proportions in order to arrive at glass that is not highly soluble in water.

The extent to which waste needs to be characterized depends on the waste form criteria, the uniformity of the waste feedstock, the waste loading, and the treatment process. The need for detailed elemental analysis information about the waste increases with the quality and consistency requirements imposed on the waste glass. This is due to the need to blend appropriate glass formers with the waste. If the waste is highly variable, then the frequency of the sampling and analysis for characterization will correspondingly increase. The sampling and analysis frequency can be reduced if there is a provision in the treatment process for accumulating and batching waste. This dampens out variability and results in a uniform and predictable product. Accumulation and blending can be done in feed preparation tanks prior to vitrification. This is done in the HLW program, where there are stringent requirements for waste glass quality control. Another approach is to utilize a melter with a sufficiently long residence time or a large glass melt bath. Temporary fluctuations in waste composition are dampened by a large inventory of molten glass which is within acceptable composition limits.

A vitrification process can also be chosen that does not depend on the waste for applying heat. The joule-heated melter requires a range of electrical conductivity for heating molten glass. This conductivity is dependent on glass composition. It is thus necessary to analyze the waste to make sure that the material to be vitrified has the appropriate composition to ensure jouleheating. This is avoided by indirect heating such as fuel-fired or arc furnaces. (In the case of arc fumaces, however, it is not clear that homogeneous glass can be produced. This is currently being evaluated by DOE Office of Environmental Restoration and Waste Management programs.) Also, heat applied externally, as with an in-can melter, can be used to vitrify waste without dependence on glass composition or electrical properties.

The extent of characterization for a variable feedstock can also be reduced by formulating a glass with low waste loading. In this case, known glass formers dominate the glass composition. The disadvantage of this approach is that the lower the waste loading is, the higher the amount of waste glass to handle, store, and dispose of.

The distinction between essential versus desirable data will depend on the specifics of the waste in question; the type of vitrification technology being applied; and the criteria for treatment in terms of cost, waste loading, schedule, and perhaps other factors. Some generalities can be made, however, regarding the data types that are needed to proceed with glass development. process design, and evaluation of the performance of the process.

\subsubsection{Glass Development}

The key information needed here is the waste composition in terms of elements that form glass compounds ("metal cation/oxide content" in Table 1). The glass-soluble compounds in the waste determine the ultimate waste glass composition. They also determine whether additives are 
needed to achieve a nonleachable glass and to meet requirements for viscosity and other thermal properties to accommodate processing. The elements that are generally abundant in mixed waste and affect glass composition are $\mathrm{Li}, \mathrm{Na}, \mathrm{K}, \mathrm{Mg}, \mathrm{Ca}, \mathrm{Zr}, \mathrm{Fe}, \mathrm{Al}, \mathrm{Si}, \mathrm{P}, \mathrm{Pb}$, and $\mathrm{F}$. All of these except fluorine are oxides when dissolved in glass. Fluorine can replace oxygen in the glass structure and bind with metal atoms. The elements sulfur and chlorine tend to volatilize when introduced into a thermal process, although they can be incorporated into glass at low percentages. Those that are less abundant but may affect processing constraints include $\mathrm{As}, \mathrm{Cd}, \mathrm{Hg}$, and $\mathrm{Cr}$. Other elements are generally trace contaminants including heavy metals; radionuclides such as Cs, Sr, and Tc; various other fission products; activation products; and transuranics.

\subsubsection{Process Chemistry}

Certain waste constituents do not play a role in glass development since they either vaporize during vitrification or form another phase aside from molten glass. However, these constituents influence process design and operation. Materials that volatilize include compounds with $\mathrm{H}$, $\mathrm{C}$, and N. Nitrate and most organic and combustible materials have no influence on glass composition, but they can affect the process. If nitrates are present in the waste, then it may be necessary to employ $\mathrm{NO}_{x}$ abatement devices, depending on the facility permit requirements and the quantities to be processed. Combustion of organic material will generate heat and gases that must be dealt with in the off-gas system. The presence of organic material in the feed may also affect the redox conditions of the glass. Reducing conditions can result in metal phases that include toxic heavy metals and generate waste form material that would have difficulty passing TCLP.

Some elements have a tendency to form another phase that is not soluble in glass. This includes metals with a tendency to remain in the primary state at vitrification temperatures $\left(>1000^{\circ} \mathrm{C}\right.$ ) such as $\mathrm{Rh}, \mathrm{Pd}, \mathrm{Ag}, \mathrm{Cu}, \mathrm{Cd}, \mathrm{As}$, and $\mathrm{Hg}$. Arsenic and mercury have high vapor pressure, have low solubility in glass, and may volatilize from the melter. These metals would likely require capture in the air pollution control system.

Under reducing conditions, iron can reside as a separate phase in a melter. In the glass industry, iron-rich tramp metal is often found in melters. If there is a potential for molten metal phases, then the design of the melter and its operating temperature must be able to accommodate this. The refractory must be able to resist erosion due to metals. There must be provisions to withdraw metals. An alternative approach is to oxidize the metal using an oxygen lance, in which case the glass formulation will need to be adjusted accordingly.

Depending on the glass and feed chemistry, sulfur can dissolve into the glass, form a separate molten sulfate salt layer in the melter, form a metal sulfide phase, or all of the above. If the concentration of sulfur is low enough, then it may dissolve into the glass completely. Silicate glasses typically can dissolve 1 or 2 wt \% of sulfur (as $\mathrm{SO}_{3}$ in glass). If there is a high level of sulfur in the waste, then provisions for its capture in the air pollution control system and management of a sulfate-bearing scrubber liquid need to be considered. The strategy for managing a molten sulfate layer in the glass melter may be a separate tap from the glass tank or use of a reducing agent to promote conversion to $\mathrm{SO}_{x}$ and volatilization into melter exhaust. Phosphorous in the feed can result in a phosphate salt layer; however, phosphate has a higher tendency to dissolve into glass than sulfate. Phosphate glass compositions have been developed for highlevel waste (Sales and Boatner 1988). Phosphate glasses also have a higher solubility for sulfur than silicate glasses. 


\subsubsection{Subsystem Designs}

To design the feed system, off-gas system, and radiation protection system requires knowledge of the waste stream to be processed in the vitrification facility. The general approach will perhaps be to design systems that can handle most or all of the envisioned mixed waste slated for vitrification, rather than tailor the design to a particular type of waste. This allows the greatest flexibility and may avoid the need to build or retrofit a facility to handle a new waste stream.

The physical form of the waste will determine the waste-handling requirements. If the waste is liquid or slurry, then the feed system will utilize appropriate pumps and piping. If it is a bulk solid, then a conveyer and screw feeder might be used. Large solid objects such as trash or cement blocks may require size reduction prior to feeding.

The radiation field associated with waste is necessary information to determine shielding requirements during handling, storage, shipment, and processing. Typically, this information is easy to obtain with hand-held instruments and is documented for stored radioactive waste. Whatever facility is used for treatment, it will likely be designed for the worst condition in terms of radiation field. Shielding will be inherent in the design, and changes in administrative controls and levels of shielding to accommodate a new waste will be costly. It is therefore important that all available radiation field information be available on potential wastes to be treated so that these data can be considered in the criteria for design of the treatment facility.

The presence of water in the feed material will require additional energy for vaporization. The sizing and design of the off-gas system will depend on the water load because of the steam volume and the necessity to avoid the dew point downstream of the scrubbers. It may be necessary to assume the feed is entirely water as a design basis. Provisions for removal of $\mathrm{NO}_{x}, \mathrm{SO}_{x}$, acid fumes, particulate, and various radionuclide species will be required of the vitrification offgas system. Performance requirements for the off-gas system should be general enough to cover most envisioned mixed waste.

\subsubsection{Process Evaluation}

Determining the quantities of radionuclides, heavy metal contaminants, and hazardous organic compounds in the waste is needed in order to evaluate the overall success of the process and the resultant waste form. The leach resistance of the waste form as compared to the raw waste can be determined. The degree to which the hazardous organic compounds in the waste are destroyed can be assessed. It is also necessary to determine a material balance around the treatment process and individual units. The radionuclide and heavy metal content of the waste glass and the off-gas emissions can be compared to that of the untreated waste to complete a mass balance. During full-scale operations, process evaluations at predetermined intervals can be done to show compliance with permit requirements.

\subsubsection{Decision Points}

Based on knowledge gained from characterization, waste streams need to be selected for glass development and treatability studies. There are some wastes that may not be amenable for vitrification. It is expected that these will be identified in the initial screening (Section 2). This includes contaminated scrap metal, mercury, and brines or sludges with high levels of chloride and sulfate. Each waste stream should be considered on a case-by-case basis, however, rather than by establishing a general policy which either prohibits or requires certain treatment technologies for certain wastes. The decision to proceed with vitrification development on certain wastes will involve consideration of how readily the waste stream chemistry lends itself to 
conversion to glass and how readily the waste glass can be produced in a melter which is available for testing and/or deployment.

\subsection{WASTE FORM DEVELOPMENT AND TREATABILITY STUDIES \\ 3.2.1 Objective}

The objective is to develop glass compositions based on waste compositions selected for vitrification studies. The objective is also to perform crucible-scale tests with the waste or surrogates to determine the feasibility of treatment. The waste glass should have performance standards higher than those required to meet environmental regulations.

At present, the recognized criteria are EPA-TCLP and the general standards identified in DOE Order 5820.2A, which essentially follows those of the U.S. Nuclear Regulatory Commission (10 CFR 61). The DOE standards are qualitative and deal with free liquids, flammable material, reactive material, compressive strength, and other basic criteria. They are met almost automatically by glass waste forms. There is no established leach performance criteria beyond TCLP for mixed waste. TCLP was originally designed as a method to determine whether a substance is hazardous.

There is an incentive to minimize the leach rate of waste forms that is independent of conformance to TCLP or other established criteria. The measured or predicted leach rate will provide the near-field source-term data in a performance assessment model. The lower the rate is, the lower the calculated dose to the biosphere. The desire to minimize leach rate for waste glass must be balanced against other factors such as additive requirements (i.e., low waste loading) and the cost and schedule of the development phase to optimize the glass composition.

\subsubsection{Methodology}

To a first approximation, it is necessary to formulate a glass for every inorganic waste stream to be vitrified. If the waste stream is small (i.e., on the order of the size of the molten glass inventory in the melter), then this development may not be necessary since small waste streams in this case may be dominated by larger waste streams. The steps to develop a waste glass for a specific mixed waste composition are described as an example. Table 2 shows specific data for mixed waste sludge from the Oak Ridge Reservation West Tank Farm sludge (WTFS).

1. Waste composition data are obtained and expressed as chemical analyses. This is shown in the first two columns in Table 2. Note that the parts per million only adds to 271,800 . The glass developer must assume that the balance is water or some other material that does not affect glass composition.

2. The elements in the waste are converted to oxides or other compounds that form glass, as shown in the next two columns. This can be done in the laboratory and the oxide residue analyzed. This is the preferred approach when the waste contains a high mass loading of combustible material. Altematively, given the chemical analysis of the waste, the oxide equivalent composition can be calculated. In the case of the tank farm sludge, the composition is dominated by $\mathrm{CaO}$.

3. Chemical surrogates are used to make an equivalent composition to match the waste with respect to glass compounds. Lanthanum is used in place of uranium so that bench-scale studies can be done without using radioactive material. MIK (methyl isobutyl ketone) is a solvent that is added. (To prepare a surrogate with representative physical and 
Table 2. Formulation of Glass for Oak Ridge West Tank Farm Sludge

\begin{tabular}{|c|c|c|c|c|c|c|c|}
\hline \multicolumn{2}{|l|}{$\begin{array}{l}\text { Average } \\
\text { Waste }\end{array}$} & $\begin{array}{c}\text { Glass } \\
\text { Compound }\end{array}$ & $\begin{array}{l}\text { Dry Oxide } \\
\text { wt \% }\end{array}$ & \multicolumn{2}{|l|}{ Surrogate } & \multicolumn{2}{|l|}{ Waste Glass } \\
\hline $\mathrm{Ba}$ & 500 & $\mathrm{BaO}$ & 0.5 & $\mathrm{Ba}(\mathrm{OH})_{2}$ & 0.24 & $\mathrm{BaO}$ & 0.1 \\
\hline $\mathrm{Ca}$ & 269,200 & $\mathrm{CaO}$ & 96.2 & $\mathrm{Ca}\left(\mathrm{NO}_{3}\right)_{2} 4 \mathrm{H}_{2} \mathrm{O}$ & 92.37 & $\mathrm{CaO}$ & 21.0 \\
\hline $\mathrm{Cd}$ & 100 & $\mathrm{CdO}$ & 0.5 & $\mathrm{CdNO}_{3} 4 \mathrm{H}_{2} \mathrm{O}$ & 0.23 & $\mathrm{CdO}$ & 0.11 \\
\hline $\mathrm{Cr}$ & 400 & $\mathrm{Cr}_{2} \mathrm{O}_{3}$ & 0.8 & $\mathrm{Cr}\left(\mathrm{NO}_{3}\right)_{3} \cdot 9 \mathrm{H}_{2} \mathrm{O}$ & 1.15 & $\mathrm{Cr}_{2} \mathrm{O}_{3}$ & 0.17 \\
\hline $\mathrm{Ni}$ & 1,100 & $\mathrm{NiO}$ & 0.8 & $\mathrm{Ni}(\mathrm{NO} 3)_{2} 6 \mathrm{H}_{2} \mathrm{O}$ & 0.68 & $\mathrm{NiO}$ & 0.17 \\
\hline $\mathrm{Pb}$ & 200 & $\mathrm{PbO}$ & 0.5 & $\mathrm{~Pb}\left(\mathrm{NO}_{3}\right)_{2}$ & 0.17 & $\mathrm{PbO}$ & 0.1 \\
\hline $\mathrm{Zn}$ & 300 & $\mathrm{ZnO}$ & 0.1 & $\mathrm{ZnO}$ & 0.02 & $\mathrm{ZnO}$ & 0.02 \\
\hline $\mathrm{U}$ & 0.14 & $\mathrm{La}_{2} \mathrm{O}_{3}$ & 0.6 & $\mathrm{La}_{2} \mathrm{O}_{3}$ & 0.14 & $\mathrm{La}_{2} \mathrm{O}_{3}$ & 0.13 \\
\hline MIK & 3.7 & --- & & MIK & 5.0 & $\mathrm{Al}_{2} \mathrm{O}_{3}^{*}$ & 14.0 \\
\hline & & & & & & $\mathrm{Na}_{2} \mathrm{O}^{*}$ & 14.0 \\
\hline & & & & & & $\mathrm{SiO}_{2}^{*}$ & 50.2 \\
\hline Total & 271,800 & Tot: & 100.0 & Total & 100.00 & Total & 100 \\
\hline
\end{tabular}

* Additives.

chemical properties of the raw waste, it is necessary to stoichiometrically match cations and anions, if known from the analysis. This detail may not be necessary if the intent is to evaluate the glass, since anions such as carbonate and nitrate are destroyed in the vitrification process.)

4. A glass composition is sought that most closely matches the equivalent oxides shown in the second two columns. Resources are phase diagrams for ceramics; Interglad, which is a commercial glass database; and the PNL Waste Glass Database. In the case of waste dominated by calcium oxide as in Table 2 , it is evident that dilution with glass formers is needed to bring down the melting temperature and to arrive at a nonleachable glass.

5. Melting trials are conducted. The surrogate waste is blended with various glass former combinations and melted in crucibles. Observations on melting temperature, homogeneity, phase separation, foaming behavior, and metals dropout are made. These preliminary stuuies should provide an indication of the feasibility of making a reasonable glass from the waste and can serve as a treatability study. Many candidate glasses are identified based on this exercise. One preliminary glass, WTFS-2, is shown. The glass formers are alumina and silica, which take advantage of the low-melting $\mathrm{CaO}-\mathrm{Al}_{2} \mathrm{O}_{3}-\mathrm{SiO}_{2}$ temary phase.

6. Candidate glasses are evaluated for melt properties such as viscosity and electrical conductivity as a function of temperature. If these parameters are unacceptable, then step 5 is repeated until the acceptable values are obtained. The qualitative effect of various constituents on these thermal properties is known in many cases so that the iteration steps to arrive at the correct viscosity and conductivity ranges can be minimized. The HLW programs within EM-30 have developed computer models over some compositional ranges to predict properties (Piepel et al. 1993).

7. A final selection on candidate glasses is done to evaluate leach resistance. Tests methods that can be used include MCC-1 (Materials Characterization Center 1982) and the Product Consistency Test (PCT) (Bibler and Bates 1990). 
Figure 1 is a logic d.dgram for waste characterization and glass development prepared for a company that treats commercial LLW. The steps mentioned above are illustrated in this diagram, which is applicable to mixed waste as well. Appendix B provides an example of a test plan used to conduct treatability studies on vitrifying Femald OU-4 waste. It includes detailed data sheets for the specific test apparatus used in the study.

Preferred formulations will be developed for various temperatures ranging from 1050 to $1500^{\circ} \mathrm{C}$. This is the temperature range which has been found to dissolve common inorganic oxides found in waste into the glass melt. Other waste compositions available for co-processing will be considered if they offer potential economic or formulation advantages (e.g., mixing in a waste high in silica with one high in alkali). For each temperature, an optimum waste loading will be identified.

The efforts to develop glasses for mixed wastes can benefit from previous investigations and accumulated theoretical and empirical knowledge. Wolf (1984) provides a comprehensive summary of the effects of various elements on commercial and technical glasses. Chick et al. (1981 and 1984) and Piepel et al. (1993) provide data for borosilicate waste glass. Leachability can be compromised when certain alkaline and alkaline earth metals exceed $20-30 \mathrm{wt} \%$ of the glass. This includes mainly $\mathrm{Na}, \mathrm{Li}, \mathrm{K}$, and $\mathrm{Ca}$. Because of solubility, it is difficult to make glass when alumina and magnesia exceed $30 \mathrm{wt} \%$. Silica is the most common glass former but additives are generally needed to bring its fraction to below $95 \%$ to achieve reasonable viscosity at reasonable melt temperature. Chrome oxide is generally insoluble in glass beyond $1-2 \%$, although the steel industry reports molten slags with up to $15 \mathrm{wt} \%$ chrome oxide (Downing and Urban 1965). Zirconia is difficult to dissolve beyond 10-15\%, although it is possible to make high-zirconia glass under certain conditions (Lukacs et al. 1978, J. St-Pierre and Zikovsky 1982). Sulfate is generally only soluble up to about 1 or $2 \mathrm{wt} \%$ in glass. High percentages of phosphate can be incorporated into glasses that are acceptable as waste forms (Sales and Boatner 1988).

\subsubsection{Prerequisites}

The information requirements to proceed with waste form development are as follows:

- Chemical composition of the waste

- General requirements of the treatment process (i.e., operating temperature, materials compatibility)

- Waste form performance requirements

In practice, these three factors may not be completely defined prior to the waste form development phase. Detailed chemical composition of the waste may not be available or may have statistical uncertainties due to limited sample populations. There may be iteration between treatment process design or selection and glass development. Waste form performance requirements may not be fully developed for a particular site or disposal scenario. In this case, the glass developer may need to adopt working standards to proceed with a waste glass composition. 
Characterize the Waste
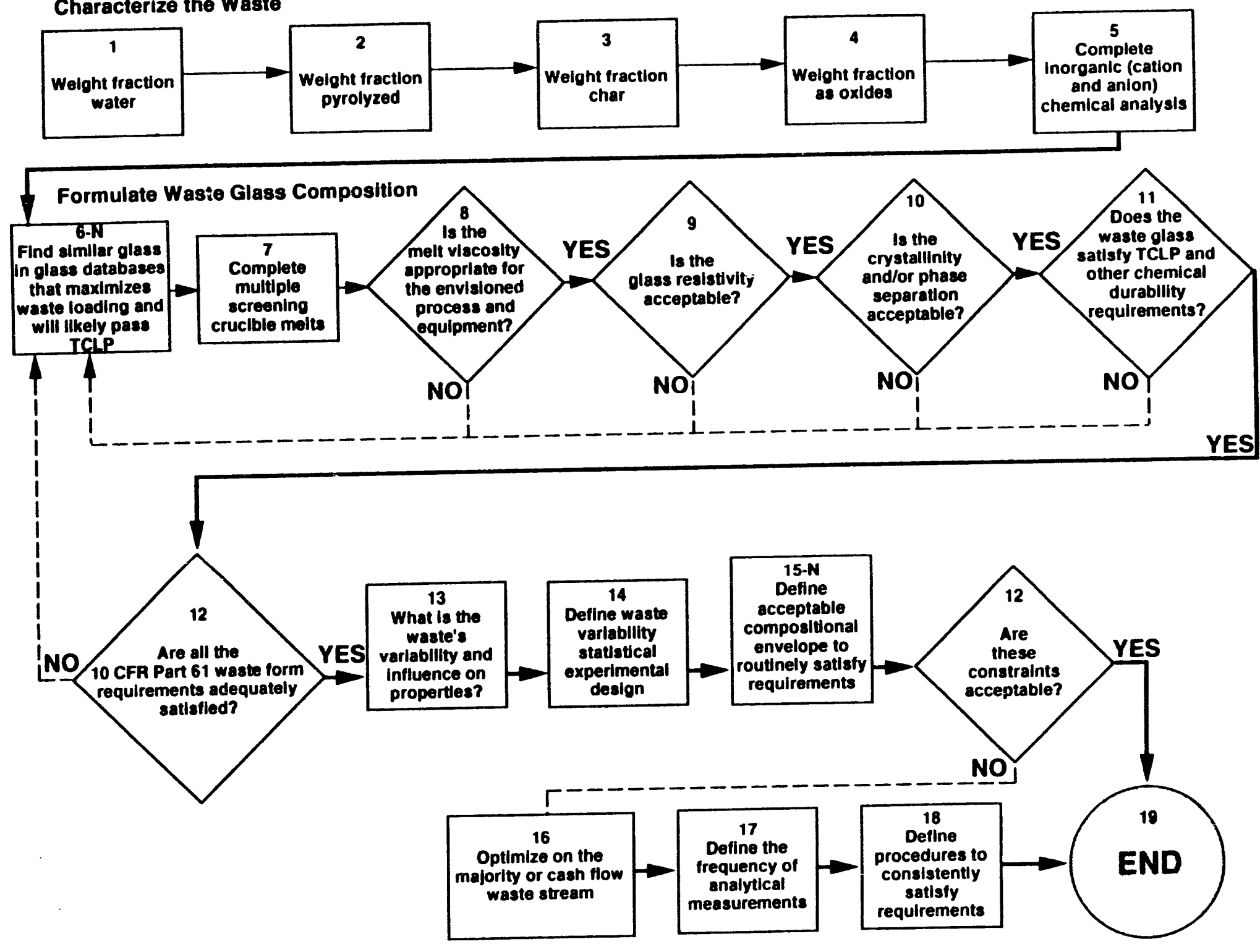

Figure 1. General Glass Formulation Procedure. 


\subsubsection{Data Needs and Required Results}

Table 3 lists general data needs associated with this glass development activity. The results of waste form development should provide a glass composition that optimizes the following factors:

- Waste loading

- Compositional variability

- Melt temperature

- Melt viscosity as a function of temperature

- Foaming/reboil behavior

- Processing rate

- Electrical conductivity (for joule-h^ated melter)

- Leach resistance

- Homogeneity/phase separation

- Devitrification behavior

The ideal situation is to have a glass with $100 \mathrm{wt} \%$ waste loading and with the ability to accommodate variations in composition. The glass would melt at the lowest practical temperature, it would not foam or reboil, and it would have a high processing rate. It would have a viscosity of about 100 poise at process temperature and an electrical conductivity of about $0.3 / \mathrm{hm}-\mathrm{cm}$ (for joule-heated melter). The waste glass would have high leach resistance $(<1 \mathrm{~g}$. $\mathrm{m}^{-2} \cdot \mathrm{d}^{-1}$ in the $28-\mathrm{d} \mathrm{MCC}-1$ test), it would be homogeneous, and it would not devitrify during cool-down. A glass that simultaneously satisfies all of these attributes is unlikely. However, these targets provide a preliminary criteria for glass developers to use. Precise requirements for glasses to be applied for various waste streams will likely be specified by the sites responsible for the vitrification treatment.

The initial part of glass development can serve as a feasibility study for vitrification or as a treatability study. In this stage, observations of homogeneity and the required glass formers to achieve a glass can be determined quickly and inexpensively without detailed or extensive analysis. A decision as to whether to proceed with more extensive development can be made after this phase of study.

The primary variables controlled in the glass development activity are glass composition and melting temperature. Melter operating temperature for waste vitrification is generally 1150 $1550^{\circ} \mathrm{C}$. This provides a reasonable melting range for glass development. The higher temperature can provide for higher melting rates and higher waste loading. However, high temperature can also result in increased volatility and greater wear on melter materials. These factors should be considered when selecting vitrification equipment and developing waste glass compositions.

The results of treatability studies and glass development need to be documented in a comprehensive report for peer review and technology transfer purposes. An example is a document prepared for the Fernald OU-4 vitrification studies by Merrill and Janke (1993).

\subsubsection{Decision Points}

The principal decision is selection of preferred glass formulations for mixed waste. The decision is based on the degree to which the parameters described in Section 3.2.4 can be optimized. If an acceptable glass cannot be made in terms of waste loading and leach resistance, etc., then the applicability of vitrification should be questioned before further investment is made. Aside from the technical requirements, there may be economic or schedule requirements that affect the decision or selection process. 
Table 3. Data Needs: Waste Form Development and Treatability Studies

\section{Data Obiectives}

Glass former composition

Glass composition

Effect of compositional variability

Melt glass viscosity

Melt glass electrical conductivity

Metal retention in glass melt

\section{TCLP of glass}

Leaching characteristics of glass

Mctals dropout in crucible melts

Melting temperature of glass

Glass homogeneity, phase separation

Foaming tendency

\section{How Dilil Are Used}

\section{Formulate glass composition}

Basis for association with glass propcriics

Detcrmine ability of glass to accommodate is not always well characterized and is subject to change

Evaluatc ability to process and handle molten glass, use as criterion for glass development

Evaluate ability to process glass via joulchealting

Determine viability of glass composition or thermal process to retain metals versus volatilize in off-gas

Determine or quantify performance of giass relative to EPA criteria

Quantify glass performance relative to radionuclide leaching

Criterion for redox control, need to oxidize if metals are reduced from melt

Determine processability of glass, criterion for glass development, design of melter refractory and clectrodes

Overall quality and reliability of glass composition, criterion for glass development

Processability of glass, redox control, critcrion for glass development waste feed composition changes since wastc

\section{Method}

Chemical makcup procedures

Chemical makeup procedures and/or clemental analysis using chemical fusion and inductively coupled plasma (ICP)

Statistically design test matrix around target compositions. Conduct limited evaluations of glass properties and performance

High-temperatture viscometer

High-temperature conductivity cell

Analyze glass for metals after melting: fusion-ICP

TCLP test (EPA 1311, 6010)

Visual observations in crucible melts

Qualitative melt condition versus furnace temperiture

Visual observation, microscopic

Visual observations
MCC serics tests, PCT observation as needed

\section{Form of Dillil}

Weight percent by oxide

Weight percent by oxide or glass compound

Thermal properties, leach resistance, qualitative observations of homogencily

Viscosity versus temperature |poise vs T (in kelvin)]

Electrical conductivity versus temperature [ $1 / \mathrm{ohm}-\mathrm{cm}$ vs $\mathrm{T}$ (in kelvin)]

Parts per million metals

Parts per million heavy metals in aqueous extract

Normalized release of glass constituents or radionuclides

Mass fraction of metals in glass melts

Temperature

Phasc observations

Qualitative descriptions 


\subsection{PROCESS ENGINEERING DEVELOPMENT}

\subsubsection{Objective}

This phase of vitrification development is testing of glass compositions in small-scale or engineering-scale melters. The purpose is to run through a number of glass compositions or flowsheets at relatively low cost and on a faster schedule than possible in a full-sized or pilotscale unit. Contidence can be gained in the feasibility of the melter process on a new flowsheet before committing resources to large-scale tests. Also, it may be prudent to test new glass compositions on a small scale rather than risk large and expensive equipment on untried glasses. At the small scale, a process flowsheet for integrated testing can be developed to reliably yield an acceptable product.

\subsubsection{Methodology}

The strategy is divided into steps as follows:

- Select melter unit for testing based on glass formulation and processing constraints.

- Prepare flowsheet for the overall process including feed preparation, additive requirements, vitrification unit, off-gas system, and secondary wastes.

- Perform engineering studies to determine the effects of process parameters on vitrification reliability and glass quality.

- Characterize melter performance-off-gas emissions, melting rate, glass discharging.

In most situations MWIP will be using available melter test units. Flowsheet preparation involves calculating heat and material balances around the process operations. Key parameters to be varied in the melter tests are temperature, waste composition, and waste loading. Variables to be monitored are glass durability (TCLP and PCT); melt rate; melt behavior (formation of metal precipitates, foaming); off-gas composition and amount; organic destruction; and metals retention. These studies will result in an identification of the preferred process conditions for vitrification of the waste using the melter selected for testing.

\subsubsection{Prerequisites}

Engineering studies on small-scale melters require identification of waste compositions and glass formulations to be tested. A well-developed glass composition should result from the activity in Section 3.2; however, if this activity has not been completed, then preliminary compositions may suffice. Also, there may be iteration between the engineering-scale work and glass development activities. Unacceptable melter performance may require additional glass development work.

\subsubsection{Data Needs and Required Results}

Table 4 lists the various data needs that are addressed by the process engineering development phase. In some cases the data objective is a prerequisite to doing the experiment and has no inherent value for the treatment program. "Feed composition" is one such entry. This needs to be determined so that comparison with the glass can be made and material balances can be performed, etc. Other data are specific to the melter unit such as cooling water flow and temperature, power settings, and various other parameters. These need to be monitored and recorded so that the process can be operated and conditions reproduced. All other entries besides these have value that extends beyond the immediate need for operating the equipment.

Another discriminating factor characterizing data objectives is the distinction between independent variables and dependent variables. The term dependent variable means the factor 


\section{Table 4. Data Needs: Process Engineering Development}

\section{Data Objectives}

Feed composition

Fate of metals in fced

\section{Volatility}

Effect of combustibles

Organic compound

destruction efficiency

\section{How Data Are Used}

Compare against product composition, establish material balance for treatment process, reference data for evaluating off-gas composition and decontamination factors (DFs)

Determine ability of process to accommodate metals (i.e., oxidation, melting)

Determine viability of glass composition or thermal process to retain metals versus volatilize in off-gas

Determine how combustibles behave in the melter in terms of redox conditions and effect on volatility of other feed components. Determine combustion efficiencies

Evaluate ability to de-list hazardous waste and meet air quality regulations

\section{Method}

Sample and analyze: inductively coupled plasma, water content, density measurement

Sample and analyze glass and off-gas. Test metal withdrawal methods if needed. Inspect melting tank for metals at end of test. Perform mass balance

Collect isokinctic sample, analyze solids and compare to glass and feed material through a mass balance

Analyze glass for reduced phases, measure off-gas temperature and $\mathrm{CO} / \mathrm{CO}_{2}$ content, pyrolysis product content

Collect off-gas sample or slip stream, analyze with gas chrcmatography/mass spectrometry via EPA method if warranted

\section{Eorm of Data}

Weight percent water, wt \% solids, density, composition (wt \% glass compounds)

Weight percent recovery of metals fed to melter, condition of melting tank with metals, melting temperature of metals, composition of glass and metal withdrawn from melter

Weight percent by constituent for entrained solids, glass and feed material

Mole percent gases, wt \% composition of glass, temperature datia

Destruction and removal efficiency expressed as percent destruction of organic compound 
Table 4. Data Needs: Process Engineering Development (continued)

Data Objectives

Off-gas flow

Off-gas temperature

Off-gas solids loading

Off-gas condensable gas loading

Off-gas noncondensable composition

Specific melting rate

\section{How Data_Are Used}

Variable affecting off-gas entrainment and combustion process-control parameter, size off-gas treatment system

Variable affecting off-gas entrainment, volatilization, combustion process, and organic destruction efficiency-control parameter

Determine DF for species representing radionuclides, determine scrubber

solution recycle requirements

Determine material balance around melter, size off-gas system, determine secondary effluents (scrubber brines)

Variable depending on combustion or calcination processes in melter, indicator of reactions occurring, used to monitor or control the treatment process, select or design off-gas system for acid gases if needed

Size melter to achieve production requirements, determine feasibility of feed composition (data at small or engineering scale may not be reliable)

\section{Monitor feed rate and glass}

\section{Method}

Flow meters on inlet air or combustion air, flow meters on exhaust gas flow (orifice 1 'ates, anemometers)

Thermocouple in exit gas pipe (away from radiant shine in furnace)

Pull isokinetic sample through filter, weigh filter

Pull isokinetic sample through cold traps, weigh condensate

Pull sample into mass spectrometer production rate over sufficiently long

period to obtain average rate with

low standard deviation

\section{Eorm of Data}

Standard $\mathrm{m}^{3} / \mathrm{s}$ (scfm), mol \% condensable

Temperature $\left({ }^{\circ} \mathrm{C}\right)$

Mass per unit volume ( e.g., grains per dry standard cubic foot)

Mole percent gases

Mole percent gascs

Mass/time-area: $\mathrm{kg} / \mathrm{h}-\mathrm{m}^{2}$ 
Table 4. Data Needs: Process Engineering Derelopment (continued)

\section{Data Objectives}

Adaptability to compositional variability

Characterization of secondary waste streams

Materials compatibility

Utility requirements

\section{How Data Are Used}

Determine ability of process to

accommodate waste feed composition changes since waste is not always wel characterized and is subject to change. Evaluate glass quality as a function of feed variation

Determine the nature and extent of streams such as wastewater, spent matcrials, and contaminated equipment. Factor in calculation of plant life-cycle cost. Establish criterion for selection of treatment technology

Select materials of construction, establish thickness tolerances, establish operating temperatures

Determine heat loads and energy loads for equipment, size equipment for pilot scale

\section{Methed}

Systematically alter surrogate waste composition during melter test.

Monitor feed rate and glass

production rate versus changes in

feed. Analyze feed and glass compositions as feed is altered.

Observe cold cap or melting conditions

Analyze scrubber brine composition, identify quantities and types of contaminated equipment or materials generated

Insert corrosion coupons in glass melt, off-gas exhaust pipe, and other high-corrosion/erosion locations

Collect current, voltage, and power consumption data using

instrumentation and data logging software or equipment. Measure cooling water requirements using flow meters and thermocouples. Pcrform heat balance around treatment process

\section{Eorm of Data}

Weight percent by constituent for feed and glass versus time; foed rate and production rate $(\mathrm{kg} / \mathrm{h})$; qualitative observations of melt conditions; leach rate (normalized release) and glass properties (viscosity, electrical conductivity) versus composition

Mass, volume and composition data on wastewater and other contaminatcd material

Corrosion rate: $\mathrm{mm} / \mathrm{ycar}$, qualitative observations for pituing, erosion and corrosion

Amps, volts, watts, water flow rate $(\mathrm{kg} / \mathrm{h})$, temperature $\left({ }^{\circ} \mathrm{C}\right)$ 


\section{Data Obiectives}

Gross material balance

Glass product quality evaluation

Time to steady state

\section{Table 4. Data Needs: Process Engineering Development (continued)}

\section{How Data Are Used}

Determine retention efficiencies for heavy metals and radionuclides, evaluate secondary effluents, support production rate determinations

Determine ability of process to achicve product quality objectives. Verify glass performance as projected from glass development samples. Help determine process stability. Facilitate design of glass-handling system to minimize devitrification

Indicator of overall stability of thermal treatment process

production rate. Analyze feed and glass composition. Analyze off-gas sophisticated methods as needed

\section{Eorm of Data}

Composition fced, glass, and off-gas aerosols (wt \% by constituent) entrained solids composition

Periodically sample glass product and conduct performance tests (MCC series, PCT). Inspect glasses for homogeneity, crystallinity. Use optical microscopy or other more

Monitor temperatures, feed rate, and electrical power demand until steadystate conditions are achicved.

Constant composition will require glass tank turnover
Lcach results: normalized relcase, qualitutive results from glass inspection, percent crystallinity

Temperature $\left({ }^{\circ} \mathrm{C}\right)$; flow rate $(\mathrm{L} / \mathrm{h}, \mathrm{kg} / \mathrm{h})$; clectrical (volts, amps, watts); composition (wt \% glass compounds) 
depends on the particular experimental arrangement and is a meaningful observable. The operator has control over a limited set of parameters, such as feed rate, power setting, and off-gas blower vacuum setting. With these settings, factors such as melting rate, off-gas temperature, and off-gas flow can be influenced. Other parameters cannot be directly influenced by the operator, such as glass quality, off-gas composition, and organic destruction efficiency. These factors are govemed more by chemical reactions, thermodynamics, heat transfer, etc., and are dependent variables. For the purposes of this discussion, the entries in Table 4 are considered to be dependent variables, with the understanding that some observations can be influenced more than others by the operator. The objective is to genuinely and systematically vary the conditions of an experiment to allow for meaningful observations.

The key required results from the process engineering development phase are as follows:

- Mass balances for the preferred process sufficient to proceed to integrated testing

- Functional performance requirements for process equipment (typc of melter, required throughput, off-gas system requirements, treatment equipment for secondary wastes) sufficient for procurement

- Processing limits (precipitation of metals, solubility of salts, range of waste loading, and type(s) of waste] sufficient for safe operation of process equipment

- Identification of secondary waste streams

- Organic destruction efficiency

- Heavy metal relention

- Refined cost estimate $( \pm 25 \%)$

The extent of engineering testing and experimentation required will vary depending on the specifics of the vitrification development needs for a particular waste. It will also be constrained by schedule and resources. Thus Table 4 identifies numerous data objectives that likely need to be prioritized to meet program budgets and schedules.

\subsubsection{Decision Points}

At the conclusion of engineering development, it should be possible to make selections on the promising flowsheets and glass compositions associated with various waste streams. The decision to carry a technology and a flowsheet into integrated testing can be made.

The criteria on which to base this decision are as follows:

- Process reliability (projected uptime of process, tolerance of process to variations in feed composition and other parameters)

- Waste form quality and conformance to acceptance criteria

- Project costs (operational costs-including treatment and disposal of secondary wastes, capital costs, disposal and monitoring costs)

- Other site-specific considerations

\subsection{SPECIFICATIONS FOR TREATMENT PROCESSES}

\subsubsection{Objective}

This phase of the plan outlines how to define functional specifications for the vitrification process, prepare a material balance, define treatment processing parameters, and develop a specification of pilot-scale equipment for treatment of the subject waste. This is required for deployment of the technology in a process operation, and it is auso necessary for pilot-scale 
testing, which should simulate real plant operation as accurately as possible. To properly demonstrate the technology in a nonradioactive pilot test, it is necessary to utilize surrogate materials that are physically and chemically similar to the waste and to operate at flows and temperatures that are representative. Equipment perfornance can thus be evaluated under realistic conditions.

\subsubsection{Methodology}

The functional criteria for the vitrification process need to be defined. The following are attributes and criteria that are relevant to selection of the treatment technology and its design features.

- Convert leachable waste into nonleachable final waste form. This is necessary to generally meet the objectives of the final waste form task in MWIP.

- Provide a waste form with mechanical and biological stability. General criteria for waste forms as promulgated by DOE Order 5820.2A will require this.

- Reduce waste volume. This is a factor in cost-effectiveness and is identified in DOE Order 5820.2A.

- Meet treatment standards to allow for disposal. Certain treatments may be required in order for disposal to be allowed. For example, LDR wastes may require treatment with the best demonstrated available technology (BDAT). Treatments that provide an opportunity to "de-list" the waste will also be favored.

- Destroy toxic organic materials. The ability to destroy organic materials will ensure a waste form that is free of such agents and will improve performance for risk assessment.

- Accommodate a wide variety of feedstock. Mixed waste streams are heterogeneous, and it is generally preferable to accommodate a spectrum of wastes in one process rather than have a separate process for each waste type.

- Consistent product quality. This is important to regulators in proving that the waste form properties are consistent and thus predictable in terms of meeting waste form criteria.

- Ability to recycle rejected products. This is an important aspect of product consistency and implementation of production quality control.

- Minimal secondary streams. Considering the cost of handling potentially mixed waste streams, this is important in controlling proliferation of more waste.

- Sufficient throughput capacity. The process must be able to attain production rates so that campaign schedules are met and/or equipment sizes are manageable.

- Mature technology. Mature technologies are desirable for near-term implementation to avoid uncertainties and to minimize research and development costs ani schedules.

- Operate safely. Technologies with inherently safe features should be sought for worker and environmental safety and to facilitate compliance with stringent DOE standards. 
- Cost-effectiveness. Capital and operating costs will be a factor in the selection of technologies due to budget constraints. The technology should not be labor or capital cost intensive.

- Reliability, low maintenance requirements. This is a major factor considering the cost and downtime associated with repairing equipment in radiation zones.

- Minimal pretreatment. This is important in keeping facility, equipment, and operating costs under control.

- Minimal off-gas treatment demands. This is important in keeping off-gas equipment costs down and in minimizing atmospheric discharges.

The selection of the vitrification equipment for further consideration in pilot-scale testing should be made based on the criteria listed above.

Another aspect of specifying a process for integrated testing is identification and selection of the mixed waste streams that will be vitrified. This is discussed in Sections 3.1 and 3.2. The Enhanced Waste Forms Group in MWIP has tentatively decided to evaluate vitrification of sludges, ashes, and cement-blend wastes (pondcrete, saltcrete, and contaminated concrete). The pilot testing will be with nonradioactive material since the cost and schedule for conducting large-scale tests with radioactive materials are often prohibitive. Also, the physical and chemical properties of the waste are generally determined by "inerts," or nonradioactive and nonhazardous constituents. For example, mixed waste sludge is dominated by inorganic materials such as silica, calcium hydroxide, and magnesia. This approach assumes that the waste has been adequately characterized to allow one to prepare simulated waste.

The challenge in using simulated waste is that there may be minor constituents in the real waste that are difficult to analyze and that can complicate the treatment process. Because of inadequate sampling and analysis, these constituents would be left out of the surrogate recipe. The potential for such disruptions can be reduced, but not eliminated, by conducting treatability studies on a small scale using actual waste samples (see Section 3.2). Observations on phase formation, outgassing, foaming, devitrification, and other phenomenon can generally be made in treatability studies that provide insight to the scaled-up process. Distuptions can also be minimized by maintaining a significant percentage of glass formers in the flowsheet. Sufficient additives with favorable vitrification characteristics can overwhelm constituents in the waste that detract from glass quality and process stability. However, the use of additives has an impact on the waste form volume that is generated and that must be subsequently stored and disposed of. Soils are high in silica and can serve as a good glass-forming additive. If contaminated soils are used as an additive, then the overall waste volume impact is favorably affected.

To establish the processing parameters for the pilot-scale flowsheet, data obtained during glass development and treatability studies must be utilized. These studies should reveal target waste glass compositions, additive requirements, processing temperatures, and devitrification behavior. Decisions regarding blending waste and additives, melter operating temperature, and the design of the melter and other equipment can be made using data from treatability studies.

Establishing the flowsheet is a critical step in sizing all of the equipment to be used in the pilot process. The flowsheet defines nominal flow rates, temperatures, and energy loads for all 
streams and equipment in the process. From this, design values are established that typically account for maximum variations in the process parameters. A data sheet that includes basic information necessary to procure or design the item is then prepared for all items in the process.

The design of the melter for the pilot plant begins with knowledge of the required throughput, the physical form of the waste. the type of glass being produced, the glass temperature, and other operational constraints and criteria. For radioactive waste treatment, the design criteria for a melter is substantially different from that of the conventional industrial glass fumace. The typical industrial glass fumace uses a well-known and constant batch charge, operates at fixed power and temperature, does not have radiological protection concems, has routine and relatively well-characterized maintenance characteristics, and discharges highly viscous glass gobs into forming equipment (bottle machines, etc.). The radioactive melter must be designed to accommodate variations in glass composition, radionuclides, tramp metals, flammable feed materials, and discharge of low-viscosity glass. These differences have led the national laboratories studying vitrification down a different design path than that taken by the commercial glass melter industry. As a result, high-duty refractories are used throughout the tank, they are designed for remote (versus "hands-on") maintenance, the glass discharge section uses a trough block, and the melter shell is water cooled.

\subsubsection{Prerequisites}

The required input data to proceed with flowsheet and equipment specification are as follows:

- Definition of waste and processing rates

- Established treatment process criteria

- Waste glass composition

- Results of glass waste form development (Section 3) and vitrification process development (Section 4) studies

- Waste form criteria

- Effluent constraints

\subsubsection{Data Needs and Required Results}

With the defined waste, required processing rate, and established criteria, it should be possible to make reasonable selections regarding the vitrification equipment and the type of design features to use for further pilot-scale development and testing. Selections need to be made such as batch versus continuous, high-temperature versus low-temperature melter, stirred versus unstirred melt cavity, materials of construction, and electrode configuration. Once these basic selections are made, then technical specifications can be developed.

Technical specifications define the following: required unit process capacities, equipment sizing and duty requirements, process temperatures, definition of process material, functional requirements, and operational constraints (i.e., personnel protection requirements, maintenance constraints). Technical specifications are needed to proceed with detailed design and construction of an integrated pilot plant. After operation of the plant, the specifications may be modified based on information and experience gathered. The revised specifications will be used to design, construct, and operate the initial or prototype mixed waste treatment facility.

Associated with this equipment data package are various drawings and attachments to define the process, including the following: 
- Process flow diagram

- Piping and instrumentation diagram

- Equipment layouts

- Equipment assemblies

- Mechanical drawings of equipment

- Interface drawings showing how equipment is connected

- Facility drawings

- Catalog descriptions or vendor brochures for procured items

\subsubsection{Decision Points}

To proceed with the pilot-plant specification, the principal decisions are what technologies to demonstrate and what simulated waste to process through the pilot equipment. For the purpose of this plan, it is assumed that vitrification has been selected for pilot-plant evaluation. The wastes are specified in the "Rough Screening (1)" and the "Characterization/Analysis (2)" sections.

\subsection{INTEGRATED PILOT-SCALE DEMONSTRATION}

\subsubsection{Objective}

The integrated pilot-scale demonstration is the culmination of technology development, waste form development, and selections as to how specific wastes are to be treated. The pilot plant provides valuable data and operating experience that determines the overall feasibility and effectiveness of the proposed process scheme. Operating characteristics and process data are collected on large-scale equipment that is representative of the actual plant. The primary treatment equipment should be connected to other relevant components, such as feed systems, off-gas systems, and product-handling systems, so that interactive effects of the combined process train can be observed and characterized.

\subsubsection{Methodology}

The steps required to arrive at a pilot scale demonstration are as follows:

- Select waste types to demonstrate.

- Select treatment technologies to demonstrate.

- Select support systems (off-gas and feed system, etc.).

- Establish material balances and flowsheets.

- Select facility.

- Specify equipment.

- Design and fabricate or procure equipment. Install pilot plant.

- Prepare test plan and other required documentation.

- Conduct demonstration.

\subsubsection{Prerequisites}

The input requirements are essentially the results of Specifications for Treatment Processes (Section 3.4) and include selection of waste streams to process in the pilot plant, selection of treatment technologies, selection of off-gas system, selection of feed system, selection of facility, and definition of flowsheet.

\subsubsection{Data Needs and Required Results}

The results of the demonstration activity are an installed pilot-plant facility that has been functionally tested. Simulated waste feedstock is processed through the equipment, operational 
data are collected, equipment operation is characterized, and overall plant experience is gained. This information is used to make corrections or adjustments in equipment design and operating parameters.

The following types of data or information are collected at the pilot scale for the joule-heated melter:

- Behavior of slurry or bulk materials in melter cold cap

- Bridging or boiling phenomenon

- Melting rates versus type of feed

- Entrainment and volatilization from the melter

- Performance and failure modes of ancillary equipment (feed nozzles, glass discharge, electrode holders, power feeds, instrumentation, etc.)

- Interaction of linked process equipment

- Durability of melter tank lining and electrodes

These and other data needs are summarized in Table 5. Appendix D provides a pilot-scale test plan outline used for the HLW program (Freeman 1992). Other test plans for melter studies have been prepared by Janke et al. (1992), Pohl (1989), and Eschbach (1983).

At the end of test campaigns, equipment can be closely examined by personnel since it is nonradioactive. Materials compatibility can be evaluated, and corrosion and wear phenomena can be determined. This information allows for a more reliable full-scale plant design and minimizes maintenance problems. The risk of failure, downtime, environmental releases, and worker injury or exposure is minimized through proper pilot-scale testing and equipment operating experience on surrogate materials.

A vital part of pilot-scale testing is preparation of a report that describes the results and addresses the test and the specific data objectives. Melter test reports have been written by Cooper et al. (1993) and Perez et al. (1983).

\subsubsection{Decision Points}

Upon completion of the pilot-plant testing, there is a backlog of operational experience which allows for more informed decisions regarding selection of technologies for certain types of waste and determination of operating parameters (i.e., temperatures, throughputs) for plant equipment.

The technology selection is a key decision since it will determine which treatment processes to deploy in the prototype treatment facility. The decision will utilize information gained from the pilot plant: waste form quality, versatility of feedstock, equipment reliability, maintenance requirements, etc. The decision will also include consideration of process safety, worker exposure, and overall compatibility of the equipment with radioactive operations. 


\section{Table 5. Data Needs: Pilot-Scale Testing}

\section{Data_objectives}

Off-gas analysis

Processing rate

Glass quality

Fate of metals in feed

Dynamic system responses: power, feed rate, inlet air

Maintenance requirements

\section{How Dilli Are Used}

Select and size off-gas cquipment. Determine process flowshcet matcrial balances. Quantify destruction. Provide input data for environmental assessments or

Size melter for prototype or operational plant, develop schedulc for treatment campaigns

Detcrmine product consistency for regulatory agencies and for performance assessment purposes

Determine ability of process to accommodate metals (i.c., oxidation, melting)

Evaluate treatment unit operation as a function of controllable parameters, define operational envelope for process operation

Determine maintenance schedules and costs for melter, develop radiation protection protocols for plant workers, provide input for improved equipment designs for minimal maintenance and risk performance of melter for organic environmental impact statements

\section{Method}

EPA-approved methods for acrosol sampling and organic destruction efficiency. Sample points: after melter, after scrubber

Monitor feed rate and glass production rate over sufficienuly long period to obtain average rate with low standard deviation

Sample and analyze glass from melter

Sample and analyze glass and off-gas for metals or metal-bearing compounds. Test metal withdrawal methods at high capacity. Examine melting tank at end of testing campaign

Monitor key process parameters: melter power, feed rate, etc. Correlate perturbations and associated responses

Install instrumentation to detect failures, periodically inspect equipment for wear or pending failure

\section{Eorm of Dalia}

Particle size distribution versus mass loading for acrosols, composition of aerosols, composition of volatile materials, destruction and removal efficiency

Mass/time-area: $\mathrm{kg} / \mathrm{h}-\mathrm{m}^{2}$

Leach resistance, crystallinity, homogeneity

weight pereent recovery of metals fed to melter, condition of meling tank with metals, melting temperature of metals, composition of glass and metal withdrawn from melter

Current and voltage of secondary transformer, fced rate $(\mathrm{L} / \mathrm{h}, \mathrm{kg} / \mathrm{h})$

Service life of component,

visual observations of equipment, temperatures, flows or pressures indicating equipment performance 


\section{REFERENCES}

Bibler, N. E. and J. K. Bates. 1990. "Product Consistency Leach Tests of Savannah River Site Radioactive Waste Glasses," Mat. Res. Soc. Symp. Vol. 176, Materials Research Socicty.

Chapman, C. C. and J. L. McElroy. 1989. "Slurry-Fed Ceramic Melter-A Broadly Accepted System to Vitrify High-Level Waste." In High Level Radioactive Waste and Spent Fuel Management, Vol. Il, eds. S. C. Slate, R. Kohout, and A. Suzuki, pp. 119-127. American Society of Mechanical Engineers.

Chick, L. A. 1984. West Valley High-Level Nuclear Waste Glass Development: A Statistically Designed Mixture Study. PNL-4992, Pacific Northwest Laboratory, Richland, Washington.

Chick, L. A. et al. 1981. The Effects of Composition on Properties in an 11-Component Nuclear Waste Glass System. PNL-3188, Pacific Northwest Laboratory, Richland, Washington.

Cooper, M. F., et al. 1993. Research-Scale Melter Test Report, Hanford Waste Vitrification Program, Pacific Norhwest Laboratory, Richland, Washington.

Downing, J. H. and L. Urban. 1965. "Electrical Conduction in Submerged Arc Furnaces," Proc. of Electric Furnace Conf., Am. Inst. of Mining, Metallurgical and Petroleum Engr., pp. 93-101.

Eschbach, E. J. 1983. West Valley Melter Demonstration Run Plan-PSCM 15. Pacific North west Laboratory, Richland, Washington.

Freeman, C. F. 1992. Liquid-Fed Ceramic Melter Run 9 Test Plan, Pacific Northwest Laboratory, Richland, Washington.

Janke, D. S. et al. 1992. Liquid-Fed Ceramic Melter Run 8 Test Plan, Pacific Northwest Laboratory, Richland, Washington.

Larson, D. E. et al. 1989. Hanford Waste Vitrification Plant Technical Manual, HWVP-89IVJ0010100A, Pacific Northwest Laboratory, Richland, Washington.

Lukacs, J. M. et al. 1978. Compatibility of Two Idaho Chemical Processing Plant Glasses with Electric Melting Processes. PNL-2751, Pacific Northwest Laboratory, Richland, Washington.

Materials Characterization Center. 1982. Materials Characterization Center Test Methods Submitted for the Nuclear Waste Materials Handbook. PNL-3990, Pacific Northwest Laboratory, Richland, Washington.

Merrill, R. A., and D. S. Janke. 1993. Results of the Vitrification Treatability Study for OU 4 Residues, Pacific Northwest Laboratory, Richland, Washington.

Perez, J. M. et al. 1983. West Valley Waste Vitrification Experiment, PSCM-15 Summary, Pacific Northwest Laboratory, Richland, Washington.

Piepel, G. F. et al. 1993. First Order Study of Property/Composition Relationships for HWVP Glasses, PNL-8502, Pacific Northwest Laboratory, Richland, Washington.

Pohl, P. I. 1989. Test Plan for Defense Program PSCM-24 Run, Pacific Northwest Laboratory, Richland, Washington.

Sales, B. C. and L. A. Boatner. 1988. "Lead Iron Phosphate Glass," in Radioactive Waste Forms for the Future, eds. W. Lutze and R. C. Ewing, Elsevier, pp. 193-231.

St-Pierre, H. H. T., and L. Zikovsky. 1982. "Immobilization of Radioactive Wastes: Leachability of Glasses Containing Zirconium," J. Nucl. Mat. Vol. 107, pp. 286-289.

Wolf, M. B. 1984. Chemical Approach to Glass, Elsevier. 
Appendix A

Sample Characterization Procedure for Waste Vitrification StudiesDensity, Moisture Content, Combustible Content:

Waste Sample Characterization Procedure,

Pacific Northwest Laboratory, 1992 


\section{Unique samnle ID (AA-dummiv lihmm)}

\begin{tabular}{|r|l|l|}
\hline Contact Name | & Company \\
\hline Phone ! & Street & \\
\hline Fax: & Cily. Stale zip \\
\hline
\end{tabular}

\section{Concise title, identification and descriution of waste}

\section{Measurement of Samule's Aubarent Weight Fraction Wilter}

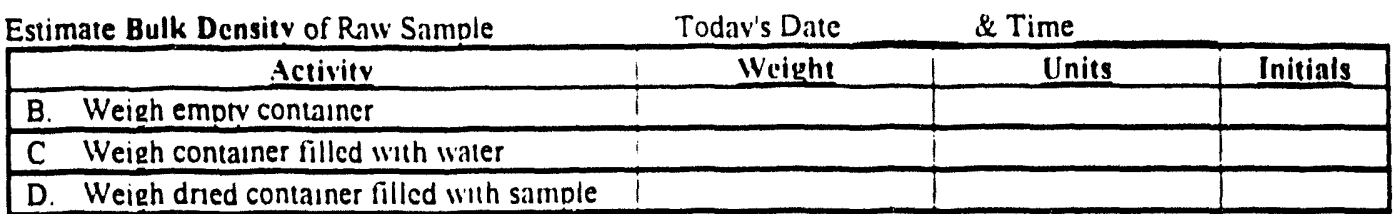

As Received Bulk densıty $\leadsto$ Weight D. - Weight B.) / (Weight C. - Weight B.)
(D. - B. $/ 1 \mathrm{C}$ - B

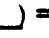
units

\section{$\Rightarrow$ Raw Bulk Density of Sample}

Take photo with samule ID \# Describe simple's appeiliance and eeneral characteristics.

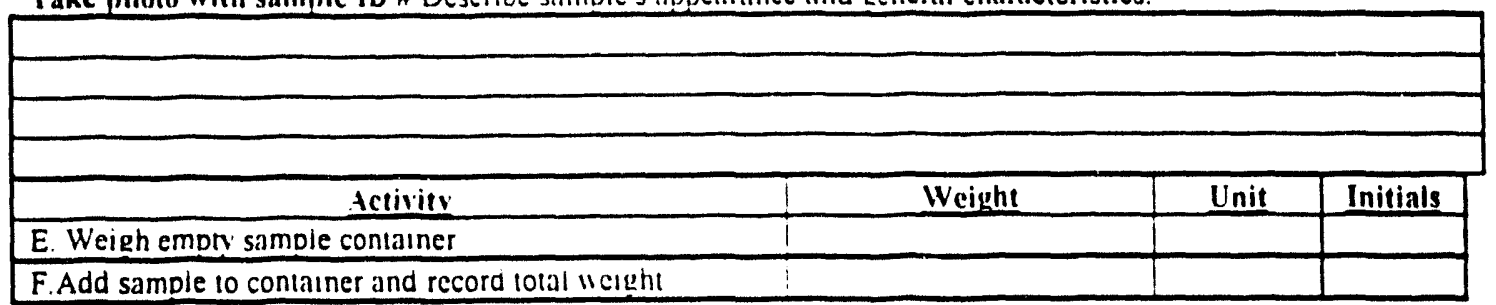

Set oven to drying temperature of $105^{\circ} \mathrm{C}$ or record different sctung here

Measure Sample plus container weight periodically. After no change in weight occurs. assume sample is dry.

\begin{tabular}{|c|c|c|c|c|c|}
\hline Activity & Date & Time & Weight & Units & Initials \\
\hline \multicolumn{6}{|l|}{ Drving ivelght \#1 } \\
\hline Drving welght $\# 2$ & & & 1 & & \\
\hline Drving welght \#3 & & & & & \\
\hline Drving welght \#4 & & & & & \\
\hline \multicolumn{6}{|l|}{ Drving weteht $\# 5$} \\
\hline Drving weight $\# 6$ & & & 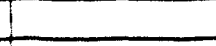 & & \\
\hline G. Final Dried Weight & & & 1 & & \\
\hline
\end{tabular}

Take photo with sample ID \# Describe sample's dried appearance and general characteristics. Add other relevant comments that were obsericd or occurred during the experiment here

(F.

- $\mathrm{G}$

$\Rightarrow$ Weight Fraction Water of Sample
IF $\cdot$ - 
Measure Drv Bulk Densitv of Sample

Todav's date \& Time

\begin{tabular}{|l|l|l|l|}
\hline \multicolumn{1}{|c|}{ Activity } & \multicolumn{1}{|c|}{ Weight } & Units & Initials \\
\hline b. Weigh emptr container & & & \\
\hline c. Weigh container filled with water & & & \\
\hline d. Weigh dried container filled with sample & & & \\
\hline
\end{tabular}

Dry Bulk density $\sim$ Weight d. - Weight b.) / (Weight c. - Weight b.)
(d. - c $/(c$ $\cdot b$ $\nu=$ units

$\Rightarrow$ Dry Bulk Density of Sample

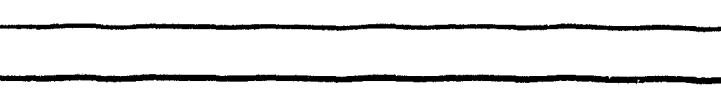

Measurement of Sample's Apparent Organic Content Todav's Date_ Time

\begin{tabular}{|l|l|l|l|}
\hline & Weight & Units & Initials \\
\hline e. Weigh empry sample container & & & \\
\hline g. Add sample to container and record total weight & & & \\
\hline
\end{tabular}

Set furnace to pyrolysis temperature of $400^{\circ} \mathrm{C}$ or record different setung here

Measure Sample + container weight penodically. When no weight change occurs. assume sample has pyrolvzed.

\begin{tabular}{|l|l|l|l|l|l|}
\hline \multicolumn{1}{|c|}{ Activitv } & Date & Time & Weight & Units & Initials \\
\hline Pyrolvzing weight \#1 & & & & & \\
\hline Pyrolvzing weight \#2 & & & & & \\
\hline Pyrolvzing weight \#3 & & & & & \\
\hline Pyrolvzing weight \#4 & & & & & \\
\hline Pyrolvzing weight \#5 & & & & & \\
\hline Pyrolvzing weight \#6 & & & & \\
\hline h. Final Pyrolvzed weight & & & & & \\
\hline
\end{tabular}

Take photo with sample ID \# Describe sample's pyrolyzed appearance and general charactenstics. Add other relevant comments that were observed or occurred during experiment.

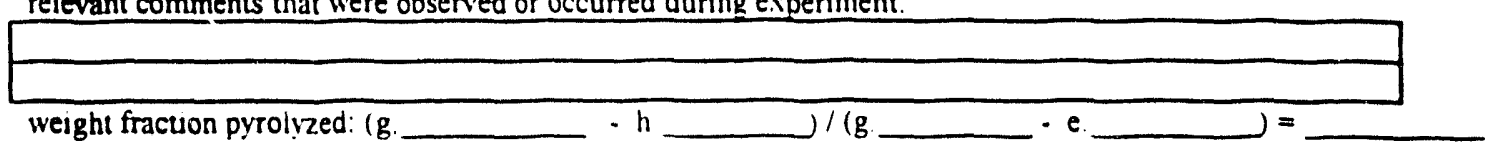

\section{$\Rightarrow$ Weight Fraction Pyrolyzed}

Measure Prolvzed Bulk Densitv of Sample Todav's date \& Time

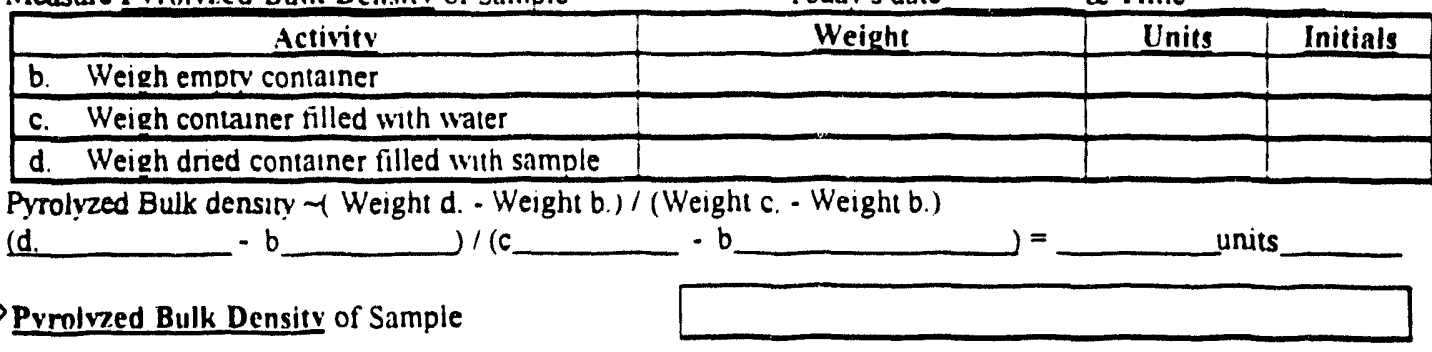




\begin{tabular}{|l|l|l|l|}
\hline & \multicolumn{1}{|c|}{ Weight } & Units & Initials \\
\hline e. Weigh empty sample container & & & \\
\hline g. Add sample to container and record total weight & & & \\
\hline
\end{tabular}

Set furnace to pyrolysis temperature of $800^{\circ} \mathrm{C}$ or record different setung here

Measure Sample plus container weight periodically. When a change in weight does not take place. assume sample has oxidized.

\begin{tabular}{|l|l|l|l|l|l|}
\hline \multicolumn{1}{|c|}{ Activity } & Date & Time & Weight & Units & Initials \\
\hline Oxidizing weight $\# 1$ & & & & & \\
\hline Oxidizing weight $\# 2$ & & & & & \\
\hline Oxidizing weight $\# 3$ & & & & & \\
\hline Oxidizing weight $\# 4$ & & & & & \\
\hline Oxidizing weight $\# 5$ & & & & & \\
\hline Oxidizing weight $\# 6$ & & & & & \\
\hline h. Final Oxidized weight & & & & \\
\hline
\end{tabular}

Take photo with sample ID \# Descrioe sample's Oxidized appearance and general characteristics. Add other relevant comments that were observed or occurred dunne expenment.

relevant comments that were observed or occurred dunne expenment.

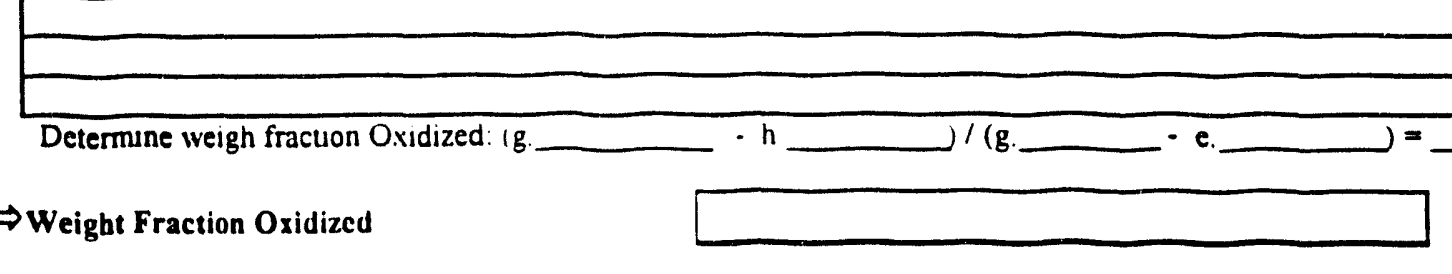

\begin{tabular}{|c|c|c|c|}
\hline Measure Samole's Oxidized Bulk Densitv & Todav's date & \multirow[b]{2}{*}{ Units } & \multirow[b]{2}{*}{ Initials } \\
\hline \begin{tabular}{|c|} 
Activity \\
\end{tabular} & Weight & & \\
\hline b. Weigh empry container & & & \\
\hline c. Weigh container filled with water & & & \\
\hline d. Weigh dried container tilled with sample & & & \\
\hline $\begin{array}{l}\text { Oxidized Bulk densıty } \leadsto \text { (Weight d. - Weight b.) } \\
\text { (d. } /(\mathrm{c}\end{array}$ & $\begin{array}{l}\text { (Weight c. - Weight b.) } \\
-b^{-}\end{array}$ & & \\
\hline
\end{tabular}

\section{Sample's Loss on Firing}

Todav's Date Time

\begin{tabular}{|l|l|l|l|}
\hline & Weight & Units & Initials \\
\hline e. Weigh emptr sample container & & & \\
\hline g. Add sample to container and record total weight & & & \\
\hline
\end{tabular}

Set furnace to finng temperature of $1200^{\circ} \mathrm{C}$ or record different setung here

Place sample in furnace for at least 1 hour

h. Final Fired weight 
Take photo with sample ID \# Describe sample's Fired appearance and general characteristics. Add other relevant comments that were observed or occurred during expenment.

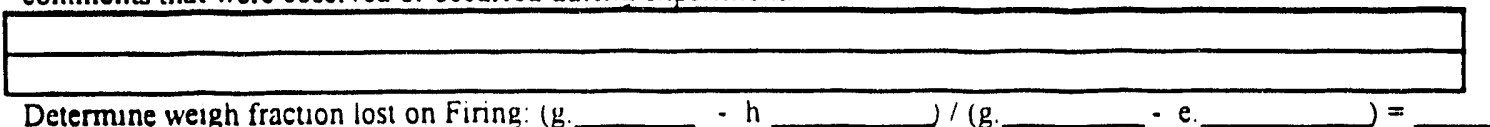

$\Rightarrow$ Weight Fraction Lost on Firing

Measure Sample's Fired Bulk Densitv Today's date \& Time

(use standard technique if not a insoluble solid piece)

\begin{tabular}{|l|l|l|l|}
\hline \multicolumn{1}{|c|}{ Activity } & Weight & Units & Initials \\
\hline b. Weigh sample & & & \\
\hline c. Weigh container filled whth water & & & \\
\hline $\begin{array}{l}\text { Weigh water filled contanner with sample } \\
\text { immersed totally in the water }\end{array}$ & & & \\
\hline
\end{tabular}

Fired Bulk density $\sim$ Weight b) / (Weight d. - Weight c.)

(b. $\quad$ _ $/(\mathrm{d}$

$\Rightarrow$ Fired Bulk Densitv of Sample

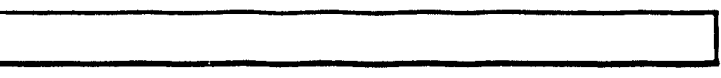

Sample's Loss on Melting

Today's Date

Time

\begin{tabular}{|l|l|l|l|}
\hline & Weight & Units & Initials \\
\hline e. Weigh empty samole container & & & \\
\hline g. Add sample to container and record total iveight & & & \\
\hline
\end{tabular}

Set furnace to firing temperature of $1400^{\circ} \mathrm{C}$ or record different setung here

Place sample in furnace for at least 1 hour

h. Final Melted weight

Take photo with sample ID \# Describe sample's Melted appearance and general characteristics. Add other relevant comments that were observed or occurred during experiment.

\begin{tabular}{|l|}
\hline \\
\hline
\end{tabular}

Weigh fractuon lost on Melting: $(g$. $\cdot \mathrm{h}$ )/(g. - e. $J=$

$\Rightarrow$ Weight Fraction Lost on Mclting

Measure Sample's Melted Bulk Densitv Todav's date \& Time

\begin{tabular}{|l|l|l|l|}
\hline \multicolumn{1}{|c|}{ Activity } & Weight & Units & Initials \\
\hline b. Weigh sample & & & \\
\hline c. Weigh container tilled with water & & & \\
\hline d. $\begin{array}{l}\text { Weigh water filled container with sample } \\
\text { immersed totally in the water }\end{array}$ & & & \\
\hline
\end{tabular}

Oxidized Bulk density $\sim$ Weight b.) / (Weight d. - Weight c.)
(b. $1 /(\mathrm{d}$ - c $\nu=$ units

$\Rightarrow$ Melted Bulk Density of Sample 


\section{Appendix B}

\section{Sample Test Plan for Bench-Scale Vitrification Studies/ Crucible Melt Studies:}

Test Plan for the Bench Scale Vitrification Testing of FEMP's Operable Unit Four-Silos 1, 2, and 3, Pacific Northwest Laboratory, 1992 
Test Number

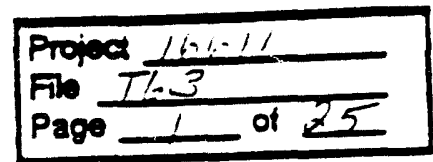

Me

Fernald Test Plan

Revision 0

May 1992

Page 0 of 24

TEST PLAN FOR THE BENCH SCALE VITRIFICATION TESTING OF FEMP'S OPERABLE UNIT FOUR - SILOS 1,2, AND 3

Prepared by: $\frac{\ln C \mathrm{CA}}{\text { sM Cote, Research Engineer }}$

Approved by:

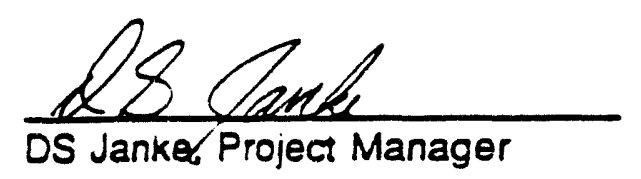
$\frac{\text { LAP eaters es CCChorman }}{\text { CC Chapman, Group Leader }}$
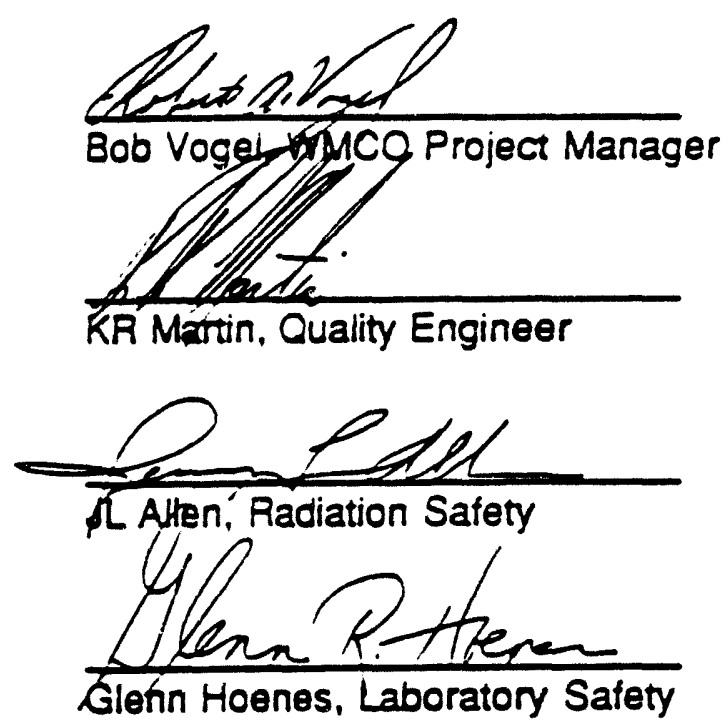

Concurred by:

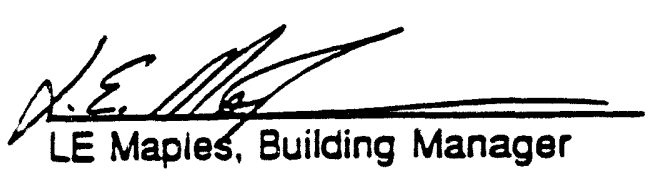

$\frac{6 / 2 / 92}{\text { Date }}$

$\frac{6 / 8 / 92}{\text { Date }}$

$\frac{6 / 9 / 92}{\text { Date }}$

$\frac{6 / 23 / 99}{\text { Date }}$

$\frac{6.5 \cdot 92}{\text { Date }}$

$\frac{6-9-92}{\text { Date }}$

$\frac{6 / 1152}{\text { Date }}$

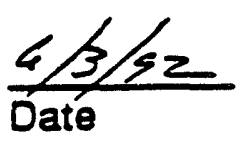

B-3 
Test Number

Femald Test Plan

Revision 0

May 1992

Page 1 of 24

TEST PLAN FOR THE BENCH SCALE VITRIFICATION TESTING

OF FEMP'S OPERABLE UNIT FOUR - SILOS 1,2, AND 3

\section{INTRODUCTION}

The Fernald Environmental Management Project (FEMP) is a contractor-managed federal facility o: $=$ ? used for the production of purified uranium metal. The FEMP has been segregated into five operable units. Operable unit 4 is defined as a geographic area that contains Silos 1 and 2 (K-65 silos), Silo 3 (metal oxide silo), and the unused Silo 4. Silos 1 and 2 were used for the storage of radium-bearing residues formed as by-products of uranium ore processing. The residues contain uranium, uranium daughter products, and some heavy metals (primanily lead). Silos 3 and 4 were designed to receive dry materials only. Silo 3 contains calcinated residues of various metal oxides while Silo 4 was never used.

Vitrification studies will be performed on the K-65 material by itself, the K-65 material with Bento-grout acded. the metal oxide by itself, and a mixture of K-65 material and metal oxide material. The objectives of these studies are as follows; determine the composition of the off-gas generated during vitrification, determine the radon emanation rate both during vitrification and from the vitrified K-65 wastes, determine the volume reduction resuiting from vitrification, determine the gamma dose rates of the vitrified wastes, and finally, determine the leachability of the vitrified wastes. The primary goal of these treatability tests is to develop a stable waste form with minimal leachability of all contaminants, including radionuclides and with reduced radon emanation.

\section{IEST DESCRIPTION}

$=$

:

The purpose of these tests is to provide a quantitative evaluation of the performance of the vitrification treatment option. As stated in the 'Operable Unit 4 Treatability Study Work Plan for the Vitrification of Residues from Silos 1, 2, and 3', four different sequences of material (A-D) will be tested. Sequence A consists of the K-65 material by itself. Sequence $B$ consists of the K-65 material with Bento-grout added.

Sequence $C$ consists of the silo 3 (metal oxide) material by itself. Lastly, sequence $D$ consists of a mixture of the K-65 material and the metal oxide material.

The first run for each of the above sequences will be pertormed using an open equipment set-up. This allows for continuous monitoring of the radon emanation during the vitrification process. The open system will be as shown in Figure 1 with valves AV2, AV6, BV4, BV5, and BV6 open. Valves AV1, BV1, BV2, and BV7 can be 
Test Number

Fernald Test Plan

Revision 0

May 1992

Page 2 of 24

either open or closed depending on whether a previous sample is being monitored for radon emanation. (The sample monitoring container is set-up as a separate system so that vitrification and sample monitoring can occur simultaneously).

The second test run for each of the sequences will be performed with a closed system set-up. This allows for collection of off-gas to determine its chemical composition. The closed system will also be as shown in Figure 1, but with valves AV2 and BV4 closed. Valves AV3, AV4, and AV5 will be opened one at a time depending on which gas sample bag is being filled.

During both the open and closed system runs, the valves on the various flow meters will be fully open unless otherwise stated. These flow meters are for measurement rather than control of flow.

After an initial pre-test waste composite preparation, $100 \mathrm{~g}$ test melts (or Sequence 0 melts) will be completed. The results of these test melts will help predict the required compositions for the Sequence A-D tests. As described below, two phases will be required to complete each test within Sequences A-D. When running the Sequence A$D$ tests, all of the open system runs will be done first. Once all of the open system runs have passed a mocified TCLP test, all of the closed system runs will be completed.

Phase I: During the first phase of the test, the material will be melted in a bench-scale furnace. Either an open or closed system will be used. depending on whether the radon emanation is being monitored or the off-gas is being collected. Condensate will also be collected for analysis.

Phase II: During this phase, the vitrified material will be analyzed for radon emanation at 7 and 30 days, volume reduction (based on the specific gravity of the glass). TCLP leachate results, conductivity, viscosity, and gamma dose rate.

\section{HAZARDOUS MATERIALS AND WASTES}

All materials used and wastes produced will be handled in accordance with the Waste Technology Center Chemical and Waste Management Plan and PNL-MA-8. All waste produced will be low-level, unmixed waste. Such waste will include gloves, paper cloths, glassware, and cleaning supplies. SDAR \# 15-11-1B-0301 (latest revision) will be used for waste disposal. All unused and vitrified test material will be retumed to Fernald. All containers will be labeled appropriately, MSOS's will be available, and personnel will be informed of the hazards present. 
Test Number

Fernald Test Plan

Revision 0

May 1992

Page 3 of 24

\section{SAEETY}

Activities associated with the tests will be in accordance with the Waste Technology Center Environmental, Safery, and Health (ES\&H) Plan and all applicable Standaro Operating Procecures (SOP's) and Radiation Work Prmits (RWP's). All personnel performing activities are required to understand the safety requirements for the work at hand.

Hazards associated with this work are the high temperature furnace and the associated electrical power, and radiation. The furnace will be continuously manned and all combustibles will be removed irum ihe area during fumace operation. All staff will be formally trained in raciation protection and will be familiar with aff applicable RWP's.

\section{QUALITY ASSURANCE}

Testing is to be conducted as Impact Level II work and will be in accordance with QA Plan WTC-060 Rev 1. Analyses of samples will be obtained through Analytical Request Forms for PNL services or through a Statement of Work for off-site services.

The procedures for the two phases of tests follow. Data sheets, which need to be initialed and dated as each step is completed, are included within this test plan. Log sheets are also attached at the back of this test plan. These are for recording any observations that are either unanticipated or which may influence the results of the test, and for recording any speculative notes. Both the data and log sheets will be taped into the laboratory noteoook (BNW 53877) once each test has been completed. Any exceptions to this test plan that, due to unanticipated events, may be required to achieve the test objectives, will need to be approved by the project manager (Dan Janke). Any major changes to this test plan will be approved by WEMCO. Once the modifications have been approved, they will be noted in the following data sheets and/or logged in the operations log attached at the back of this test plan.

Each test will be given a number that corresponds to the sequence it is under, whether it is using the open or closed system, the run number, and the start date for the test. An example test number is: $A O .1-\mathrm{mm}$.dd.yy. The ' $A$ ' is for Sequence $A$, the ' $O$ ' is for an open system run, the ' $y$ ' is for the first run, and the ' $m$ m.dd. $y y^{\prime}$ is the start date format. During each test run various items (such as crucibles, condensate bottles, gas sample tags, and sample cans) will be labeled with the test number and an explanation of the vessel's contents. 
L. RRE-TEST PREPARATION

\section{A. K-65 Composite}

PNL has been provided with samples of the $K-65$ material from three zones $(A, B$, and C) within each silo. This results in a total of six separate samples of K-65 material. Vitrification will be pertormed on a composite K-65 sample made from equal dry weight quantities of the above six samples. To complete all the required vitrification sequences, approximately $8 \mathrm{~kg}$ of composite K-65 material is required.

The required wet weight quantities from each zone will be calculated based on their moisture contents. This data will be recorded in the laboratory notebook. The proper amount from each zone will then be added to a metal can labeled 'K-65 Composite'. The exact amount added from each zone will also be recorded in the notebook. This composite will be mixed thoroughly to ensure a homogeneous mixture.

\section{B. Silo 3 Composite}

PNI received 34 cans containing the Silo 3 (metal oxide) material. To complete all the required vitrification sequences, approximately $7 \mathrm{~kg}$ (dry weight) of composite Silo 3 material is required. Material will be combined from enough of the 34 cans until $7 \mathrm{~kg}$ has been composited.

The required wet weight quantity will be calculated from the moisture content of the Silo 3 material. This data and the amount added from each can will be recorded in the laboratory notebook. The material will be added to a metal can labeled 'Silo 3 Composite'. This composite will be mixed thoroughly to ensure a homogeneous mixture.

\section{Sequence 0 Tests}

Up to three $100 \mathrm{~g}$ test melts will be conducted for each sequence A-D. The glass forming composition will be varied in these melts until a reasonable composition is found for use in the sequence A-D tests. The various compositions used and the results of these test melts will be recorded in the laboratory notebook.

During these $100 \mathrm{~g}$ test runs, the furnace will be operated as stated in SOP \#81, the Standard Operating Procedure for laboratory furnaces. 
IL PHASEL-Vitrification (Open or Closed System)

A. Complete Test System Readiness

i. The following items should be present before starting the test.

Date Initials

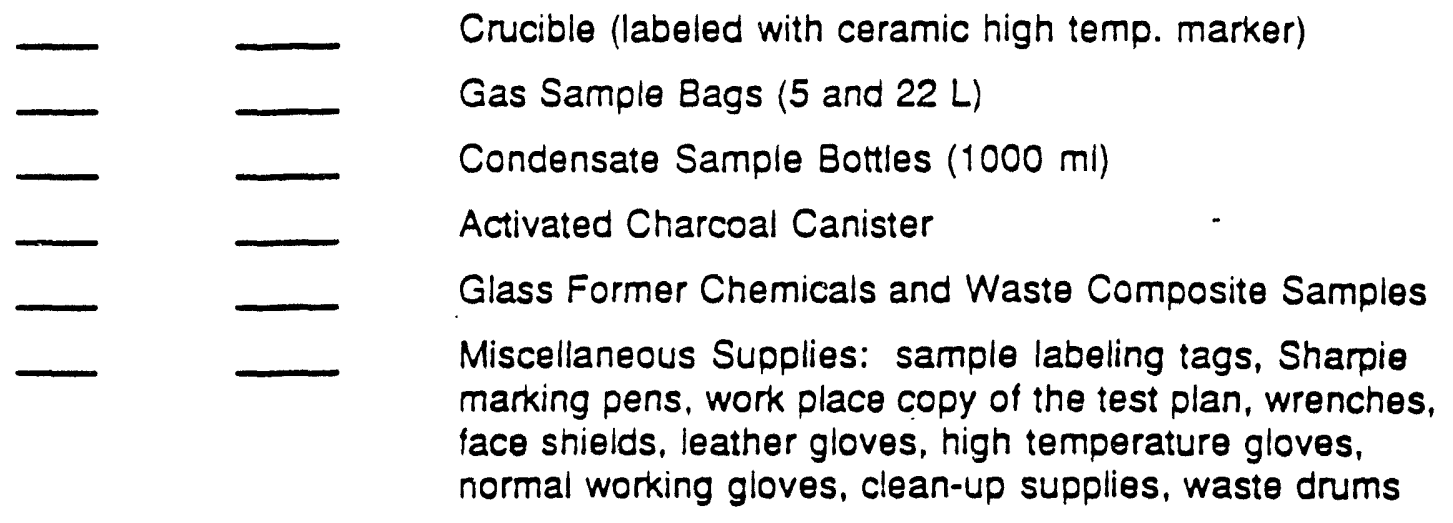

ii. The following items should be given an operability check prior to starting the test.

Date Initials

Control panel and Instrumentation
- verify that all instruments have power
- verify chan recorder settings
- verity over temperature limit setting (max of $1550^{\circ} \mathrm{C}$ )
- verity that thermocouples are closed and reading close to
ambient
- verity that furnace temp. controller is getting a signal from
the thermocouples and it is close to ambient
Furnace
- check condition of the insulation
- visually check the power cables and heaters
Off-gas Cooling System
- check water level in cooler
- check that power tums on and it pumps water
- make sure there are no leaks
Air Pre-heat before Monitors
- visually check the heating cord


- make sure the power is on for the temp. controller and that it is getting a reasonable signal from the thermocouple

Radon Gas Monitors (and Computer/Printer)

- check that power is on

- check the functionality of the monitors according to the instructions in the operating manual

- verity that there is paper in the printer

Flow meters

- verity that the valves are fully open

Electronic Balances (Mettler BB240 and Mettter PJ6000)

- verity that power is on

- verity that calibration is up to date

B. Formulate Glass for Sequence Tests

Date Initials

Add the following materials/chemicals in a stainless steel beaker and mix thoroughly. The desired amounts will have been previously calculated based on the composition results from the $100 \mathrm{~g}$ test meits. The moisture content of the rollowing chemicals will be recorded in the laboratory record book.

Chemical

Desired Quantity ial

Actual Quantity [a]

K-65 Composite

Bento-grout

Silo 3 Composite

$\mathrm{Na}_{2} \mathrm{CO}_{3}$

$\mathrm{Al}_{2} \mathrm{O}_{3}$

$\mathrm{SiO}_{2}$ 
May 1992

Page 7 of 24

Label a crucible with the test number using a high
temperature ceramic marker, number $=$
Record the weight of the empty crucible
Place the above blend in the crucible and record the weight
of the crucible and the blend

C. Perform Vitrification

1. Open System

a. Pre-Vitrification Preparation

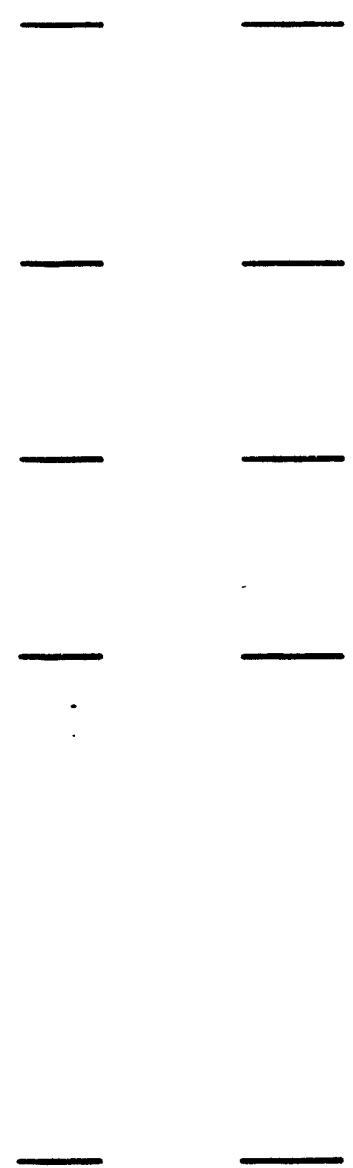

Flush the Eberiine RGM -3 and Pylon $A B-5$ portable radon gas monitors io clean out any residuals. Valves BV4, AV3, AV4, and AV5 need to be closed and valves BV3, BV5, and BV6 need to be opened. Refer to Fig. 2 for these valve positions.

Record the background count for each of the monitors.

Pylon AB-5 pCil

Eberline RGM-3 pCil

Record the flowrates from flow meters $B F 1$ and BF2

$\mathrm{BF} 1$ scin

BF2 scth

Set and record the appropriate parameters on each of the monitors

Eberline RGM-3:

Pylon $A B-5:$

Check the printer to make sure it is recording the radon emanation data 


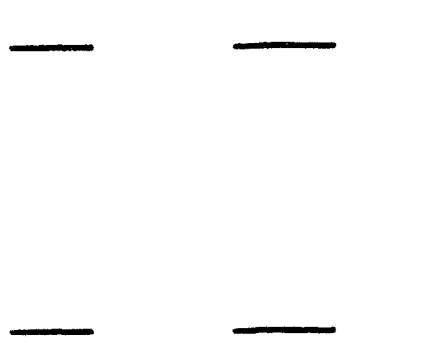

Program the temperature controller for the appropriate ramp and soak profile.

- Heat from room temp to sample melting temp at a maximum of $250^{\circ} \mathrm{C} / \mathrm{hr}$

- Record sample melting temperature

- Hold at melting temperature for ${ }^{\circ} \mathrm{C}$

Load the crucible into the furnace. Replace the door and front plate of the furnace and secure them with clamps.

b. Vitrification Test

Adjust valves to allow for monitoring radon emanation in the off-gas. Valves BV3, AV3, AV4, and AV5 shall be closed and valves BV4, AV2, and AV6 shall be opened. Refer to Figure 3

Tum on cooling water for the heat exchanger

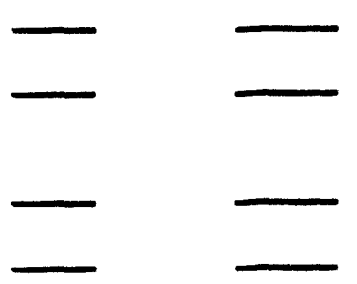

Label a $1 \mathrm{~L}$ bottle with the test number. and place it in the condensate collection trap

Open valves $\mathrm{CV} 1$ and $\mathrm{CV} 2$

Begin radon monitoring of the air flow through the furnace for a minimum of 4 hours

Set monitor inlet pre-heat temperature controller to its setpoint temperature $\left(100^{\circ} \mathrm{F}\right)$

Power up the fumace

- Tum on the breakers

$=$

- Run the ramp and soak profile on the temperature controller

Check all data acquisition equipment (temperature profile and radon concentrations) to make sure they are being recorded

Verity that the temperature profile is being followed as programmed

Periodically check and record the flowrates from flow meters BF1 and BF2. Record this data on log sheet $A$ which is attached to the back of this test plan 
Fernald Test Plan

Revision 0

May 1992

Page 9 of 24

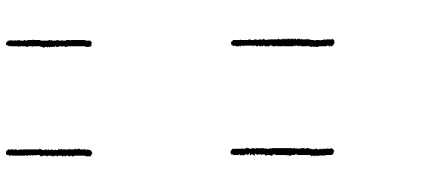

Periodically check that the off-gas temperature is being recorded

Report any out of the ordinary occurrences on $\log$ sheet $B$ which is attached to the back of this test plan

c. Post-Vitrification

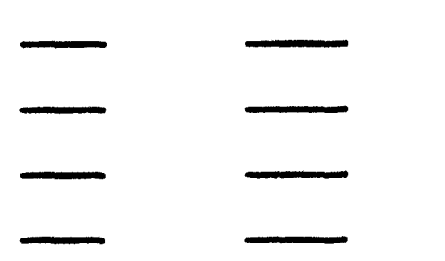

Disengage breakers

Tum off monitor inlet pre-heat temperature controller

Stop the monitors and downioad the data if required

Turn off cooling water when the off-gas has stopped (monitors off) and once the furnace temperature has fallen below $200^{\circ} \mathrm{C}$

Remove the $1 \mathrm{~L}$ bottle from the condensate collection. screw the lid on, and verity that it is labelled with the test number

Remove any condensate collected in the heat exchanger

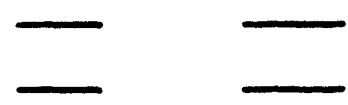

Verity that the breakers are tumed off and then remove the from of the furnace to provide access for removing the crucible

Remove all charts (fumace temperatures, off-gas temperatures, and radon concentrations) and label them with the test number

2. Closed System

a. Pre-Vitrification Preparation

Program the temperature controller for the appropriate ramp and soak profile.

- Heat from room temp to sample melting temp at a maximum of $250^{\circ} \mathrm{C} / \mathrm{hr}$

- Record sample melting temperature

- Hold at melting temperature for ${ }^{\circ} \mathrm{C}$

Verify that the temperature recorder is recording 


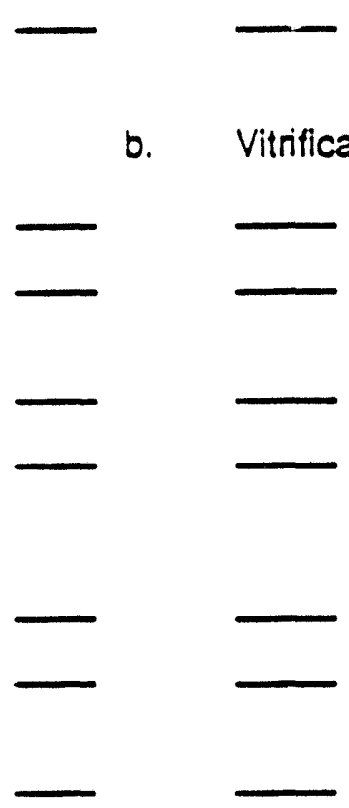

Load the crucible into the furnace. Replace the door and front plate of the furnace and secure them with clamps.

b. Vitrification Test

Tum on cooling water for the heat exchanger

Label a $1 \mathrm{~L}$ bottle with the test number and place it in the condensate collection trap

Open valves $C V_{1}$ and $C V 2$

Adjust valves for the closed system. Valves $A V 2$ and BV4 shall be closed and valve AVG shall be opened. Refer $10 \mathrm{Fig} .4$

Label a gas sample bag with the test number,

Place the gas sample bag on the gas sample manifold at position $A 3$ and open valve $A \vee 3$

Power uo the furnace

- Tum on the breakers

- Push stari on the temperature controller

Verity that the temperature profile is being followed as programmed

Periodically check that the off-gas temperature is being recorded.

Report any out of the ordinary occurrences on log sheet $B$

Observe that the gas sample bag is filling. If the bag becomes full, place another bag (labeled with the test numoer - 2 ) at position A4. Open valve AV4 and then close valve AV3. If this bag becomes full, place another bag (labelled with the test number - 3 ) at position A5. Open valve AV5 and then close valve AV4.

When the ramp and soak profile is complete (atter holding at melting temperature for specified time), close the gas sample bags and close the gas sample valves (AV3, AV4, and AV5)

Open valve AV2 to allow air in as the furnace cools 
Fernald Test Plan

Revision 0

May 1992

Page 11 of 24

c. Post-Vitrification
$\longrightarrow \quad-$
Disengage the breakers
Tum off cooling water when the off-gas has stopped (monitors off) and once the furnace temperature has fallen below $200^{\circ} \mathrm{C}$
Remove the $1 \mathrm{~L}$ bottle from the condensate collection, screw the lid on, and verity that it is labelled with the test numoer

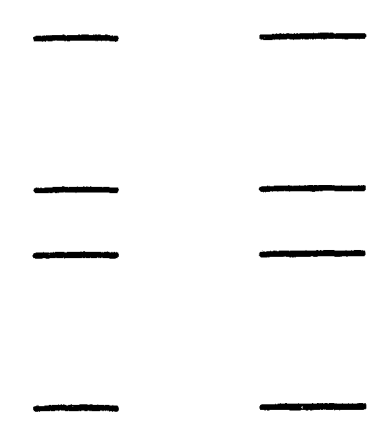
Remove any condensate collected in the heat exchanger Verity that the breakers are turned off and then remove the from of the furnace to provide access for removing the crucible
Remove all charts (fumace temperatures and off-gas temperatures) and label them with the test number

III. PHASE Il- Physical Procerty Determination

A. Complete Test System Readiness

i. The following items should be present before starting the test.

Date Initials

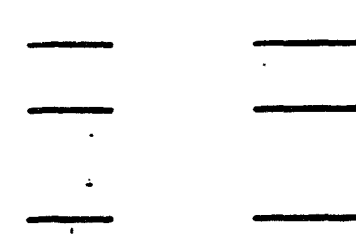

Fracture Chamber (for breaking up crucible and glass)

Stainless steel mesh basket for apparent density determination $=$

Miscellaneous Supplies: sample labeling tags, Sharpie marking pens, sample cans, fishing line, work place copy of the test plan, wrenches, face shields, leather gloves, high temperature gloves, normal working gloves, clean-up supplies, waste drums

ii. The following items should be given an operability check prior to starting the test.

Date Initials

Electronic Balances (Mettler B8240 and Mettler PJ6000)

- verity that power is on 
- verity that calibration is up to date

Hantord Cutie Pie (CP)

- verity that power is on

- verity that calibration is up to date

Pylon AB-5 Portable Monitor with Pylon Model 300A Lucas Cell

- check that power is on

- check the functionality of the monitors according to the instructions in the operating manual

B. Gamma Dose Rate of Vitrified Waste

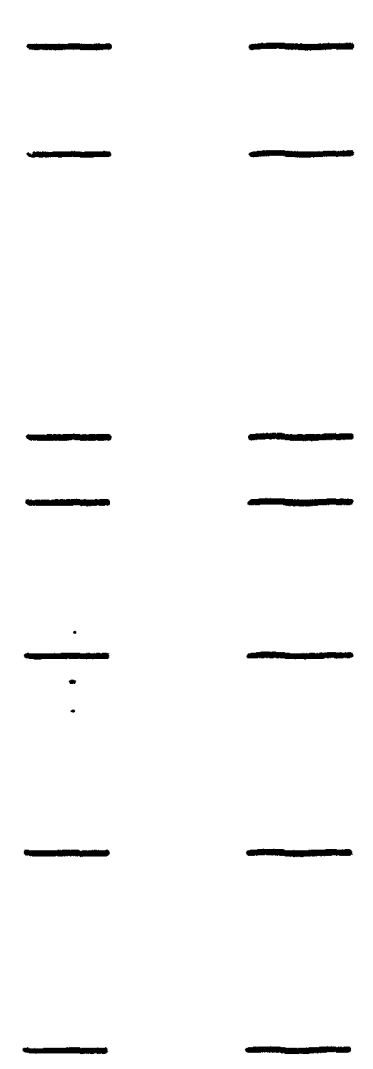

Place the cooled crucible in a plastic bag and remove it from the hood

Measure the background dose rate using the $\mathrm{CP}$ at the measurement location. This location should be away from the hood. sample storage, and other sources of radiation. The background reading should be taken just before each measurement on the vitrified waste.

Record the background dose rate $\mathrm{mRhr}$

Take the crucible to the measurement location.

Place the window of the $C P$ in contact with the bottom of the crucible with the axis of the crucible in line with the axis of the ionization chamber. Record the dose rate $\mathrm{mR} / \mathrm{hr}$

Place the window of the $C P$ at a distance of 5 Trom the bottom of the crucible with the axis of the crucible in line with the axis of the ionization chamber. Record the dose rate $\mathrm{mP} / \mathrm{hr}$

Place the window of the $C P$ at a distance of 12 from the bottom of the crucible with the axis of the crucible in line with the axis of the ionization chamber. Record the close rate $\mathrm{mP} / \mathrm{hr}$

Place the window of the $\mathrm{CP}$ at a distance of $24^{-}$from the bottom of the crucible with the axis of the crucible in line with the axis of the ionization chamber. Record the dose rate $\mathrm{mR} / \mathrm{hr}$ 


\section{Break up the Vitrified Glass}

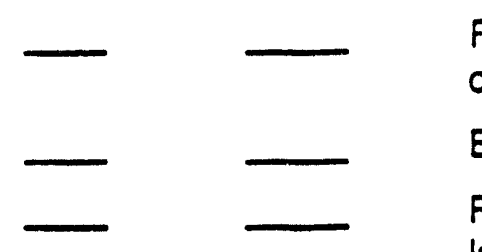

Retum the crucible to the hood and place it in the tracture chamber

Break up the crucible

Place - $100 \mathrm{~g}$ of the broken glass into a sample can labelled with the test number and an explanation of the contents. This can will be sent to the off-site laboratory for the modified TCLP test. Record the mass of glass put in the can. $g$

Place $\sim 500 \mathrm{~g}$ of the broken glass into a sample can labelled with the test number and an explanation of the contents. This can will be sent to an off-site laboratory for a full TCLP test. Record the mass of the glass put in the can 9

Place the remainder of the broken glass into a sample can labelled with the test number and an explanation of the contents. This glass will be used for the apparent density measurement and the radon emanation measurement at 7 and 30 days. Record the mass of glass put in the can 9

Place all the crucible pieces that have glass residue on them in a sample can labelled with the test number and an explanation of the contents

D. Transfer of Samples

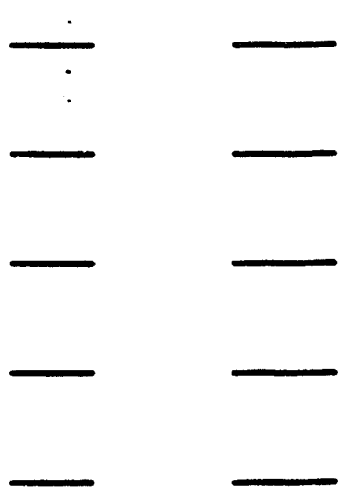

Send sample can containing $\sim 100 \mathrm{~g} \mathrm{~L}=1$ to the otf-site laboratory for the modified TCLP test

Send sample can comaining $-500 \mathrm{~g}$ 1 to the off-site laboratory for the full TCLP test

Send the $1 \mathrm{~L}$ condensate bottle to the off-site laboratory for analysis

Send the gas sample bags to the 325 building for analysis

Verity that the glass passed the modified TCLP test and then send the glass formation data to the 3720 building for conductivity and viscosity analysis 
E. Apparent Density of the Vitrified Waste

Fill a $2000 \mathrm{ml}$ beaker about three-fourths full with deionized water, place it on the electronic balance, and tare the scale

Suspend a stainless steel mesh basket from a fine wire (or fishing line) with a well defined mark to which is $\theta$ basket can be consistently submerged. Submerge the basket to this mark in the beaker and tare the scale.

Lift the basket out of the water being sure to keep it over the beaker so any water that drips off the basket falls into the beaker. Place a known mass of vitrified sample (about 50 $100 \mathrm{~g}$ ) in the basket. The pieces must be large enough to stay in the basket. Record the mass of glass placed in the basket, $m_{3}=$ $g$

Submerge the basket to the mark. Record the mass from the electronic scale, $F_{b}=$ g. This is the buoyant force.

Measure and record the temperature of the water in the beaker. ${ }^{\infty}$

Look up the density of water at the above temperature.

$p=$ $9 / \mathrm{cm}^{3}$

Calculate the apparent density of the vitrified waste as follows: apparent density $=m_{y} /(F \vee p)$

where: $=$

$m_{9}=$ mass of the vitrified sample submerged

$F_{b}=$ buoyant force

$\rho=$ density of water at neasured temperature

Apparent density $=$ $\mathrm{g} / \mathrm{cm}^{3}$

F. Radon Emanation from Vitrified K-65 Waste at 7 and 30 Days

Radon emanation data at 7 and 30 days is only required for $K-65$ waste (Sequence $A, B$, and D). This will be measured with a Pylon AB-5 monitor operating with a flow of about $0.1 \mathrm{Lpm}$. Figure 5 shows the valve positions for flushing the 
Test Number

Fernald Test Plan

Revision 0

May 1992

Page 15 of 24

monitor and sample chamber during these measurements. Figure 6 shows the valve positions required during the actual radon monitoring.

Place a known mass of the vitrified sample ( 100-200 g) into a sample can of $4^{\prime \prime}$ diameter. Label the can with the test number and an explanation of the contents. Distribute the material evenly in the can. Record the actual mass of vitrified sample g.

Place the sample can into the sample monitoring chamber and leave the lid ajar. Open valve AV7 and flush building air through the monitoring chamber

Open valves BV1 and BV7 and close valves BV2 and AV1. Flush the radon monitor with clean air and measure the background counts from the plateout of radon daughters in the sample monitoring cell. Leave for about 5-6 hours or until the background has dropped to about $1 \mathrm{pCil}$

Record the monitor's background measurement PCiL

Close valve AV6 to stop flushing air through the monitoring chamber. Open valves BV2 and AV1 and close valve BV1 to start the sampling procedure.

Seal the lid of the sample monitoring chamber

Record the flowrate at BF3 scth

Monitor the radon leveis until the concentration reaches steady state. Record the steady state concentration, pCil

Repeat the above steps at 30 days and fill in the following table 
Test Number

Fernald Test Plan

Revision 0

May 1992

Page 16 of 24

\begin{tabular}{|c|c|c|c|c|}
\hline & $\begin{array}{l}\text { Mass of } \\
\text { Samole !gl }\end{array}$ & $\begin{array}{l}\text { Background } \\
\text { Measuremnt (pCVL) }\end{array}$ & $\begin{array}{l}\text { Flowrate at } \\
\text { BF3 [scth! }\end{array}$ & $\begin{array}{l}\text { Steady-state } \\
\text { Conc. }[\text { PCViLL) }\end{array}$ \\
\hline 7 days & & & & \\
\hline 30 days & & & & \\
\hline
\end{tabular}

B-19 


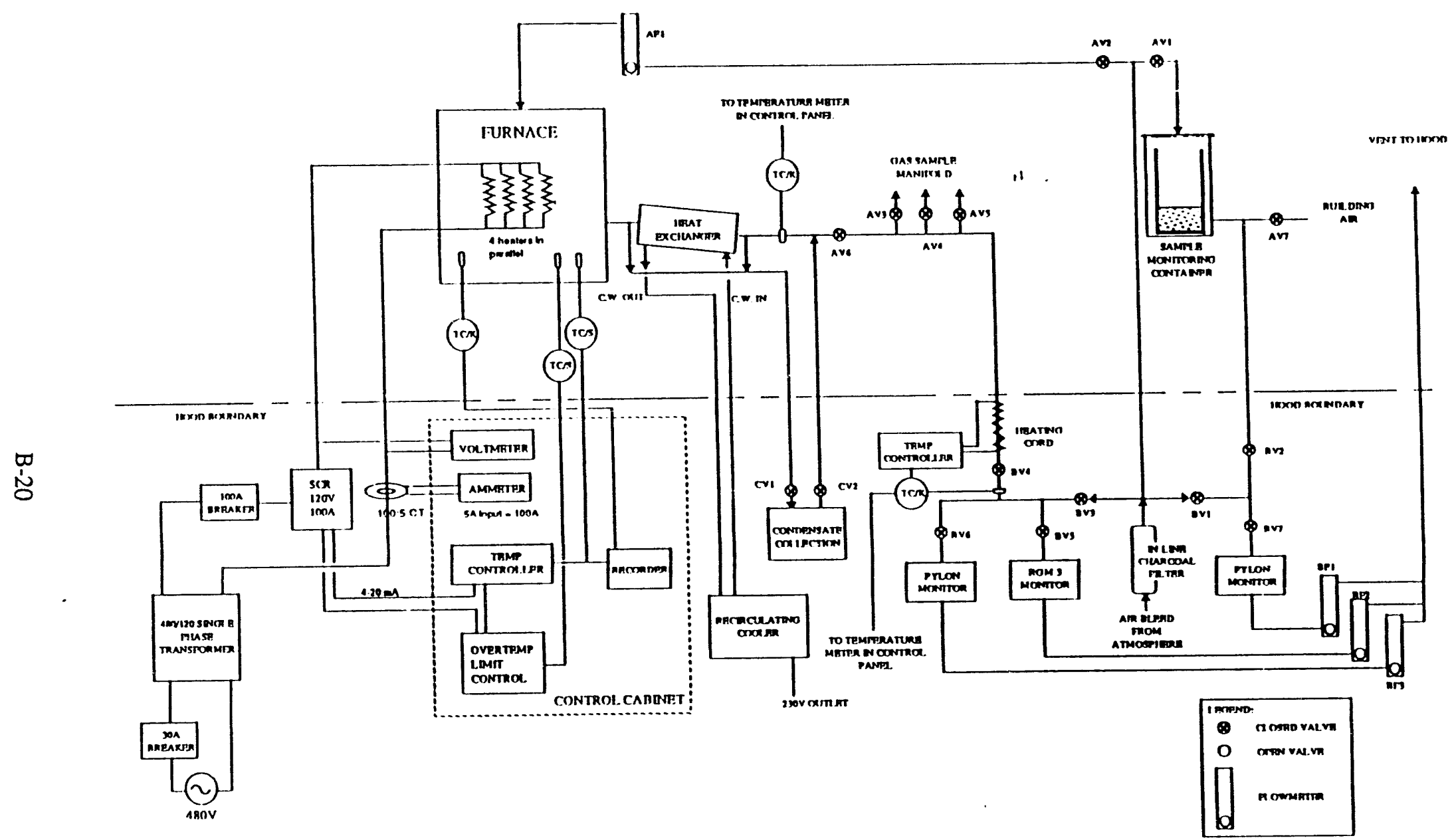

Figure 1. Bench-Scale Test System for Vitrification of Operable Unit 4 Wastes. (Figures 2-6 of original test plan show different valve positions and are similar to Figure 1.) 
Test Number

Fernald Test Plan

Revision 0

May 1992

Page 23 of 24

1

LOG SHEET A - OPEN SYSTEM VITRIFICATION

\section{Phase 1}

\begin{tabular}{|l|l|l|l|l|l|l|}
\hline Dale & Time & InIlials & BF1 Flowrale & BF2 flowrale & \\
\hline & & & & & \\
\hline & & & & & \\
\hline & & & & & \\
\hline & & & & & \\
\hline & & & & & \\
\hline & & & & & \\
\hline & & & & & \\
\hline & & & & & \\
\hline & & & & & \\
\hline & & & & & & \\
\hline & & & & & \\
\hline & & & & & & \\
\hline & & & & & & \\
\hline & & & & & & \\
\hline & & & & & & \\
\hline
\end{tabular}


Test Number

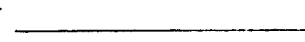

Fernald Test Plan

Revision 0

May 1992

Page 24 of 24

.1

LOG SHEET B - 'OBSERVATIONS

$\square$

N

\begin{tabular}{|l|l|l|l|}
\hline Dale & TIme & Inllials & \\
\hline & & & \\
\hline & & & \\
\hline & & & \\
\hline & & & \\
\hline & & & \\
\hline & & & \\
\hline & & & \\
\hline & & & \\
\hline & & & \\
\hline & & & \\
\hline & & & \\
\hline & & & \\
\hline & & & \\
\hline & & & \\
\hline & & & \\
\hline & & & \\
\hline
\end{tabular}




\section{Appendix C}

Sample Test Plan for Small- or Engineering-Scale

Vitrification Studies:

Research Scale Test Plan, PNL HWVP Technology Development Project, Pacific Northwest Laboratory, 1991 
PHTDP-FY91-1.2.2.04.01C

\#WTC-006-33 Mike

\section{RESEARCH-SCALE MELTER TEST PLAN}

September, 1991

Melter Performance Assessment

Equipment Adaptation \& Testing Task

PNL HWVP Technology Development Project

APPROVALS:

DATE:

Matt Coxper.

Responsible Engineer, MF Cooper

$9 / 9 / 91$

Stmetere

subtask Manager, (JM Perez

$\frac{9 / 9 / 91}{1}$

Alenew

Task Manager, GA Jensen
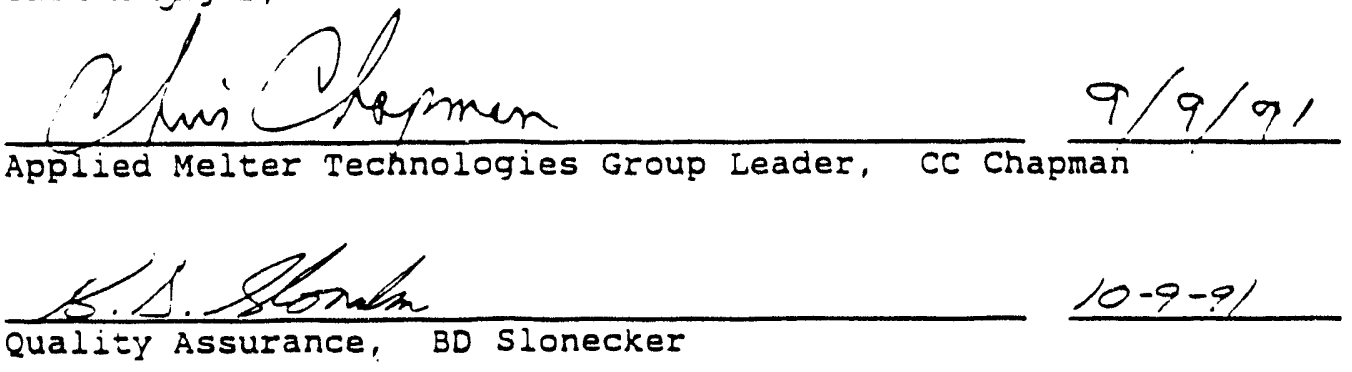

CONCURRENCE:

DATE:

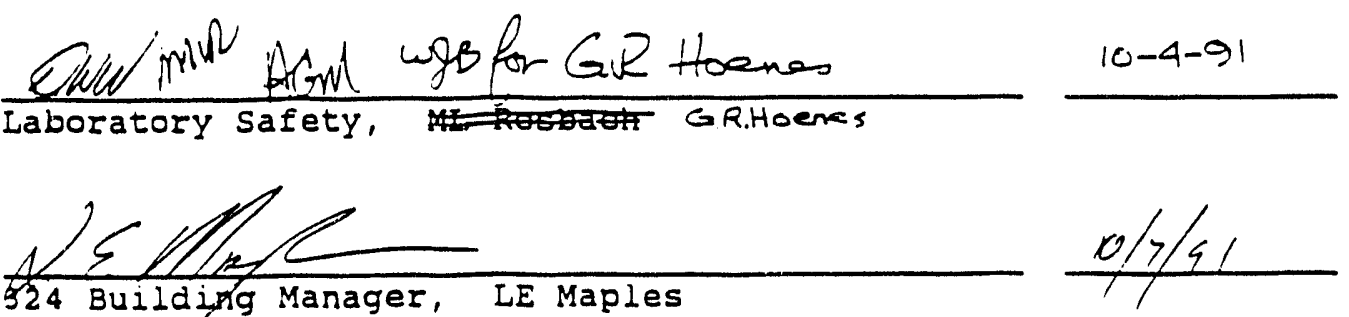




\section{1,0 INTRODUCTION}

The Melter Performance Assessment activity is responsible for determining the affect of noble metals on the HWVP melter. The melter (see Figure 1) has been designed by Savannah River to

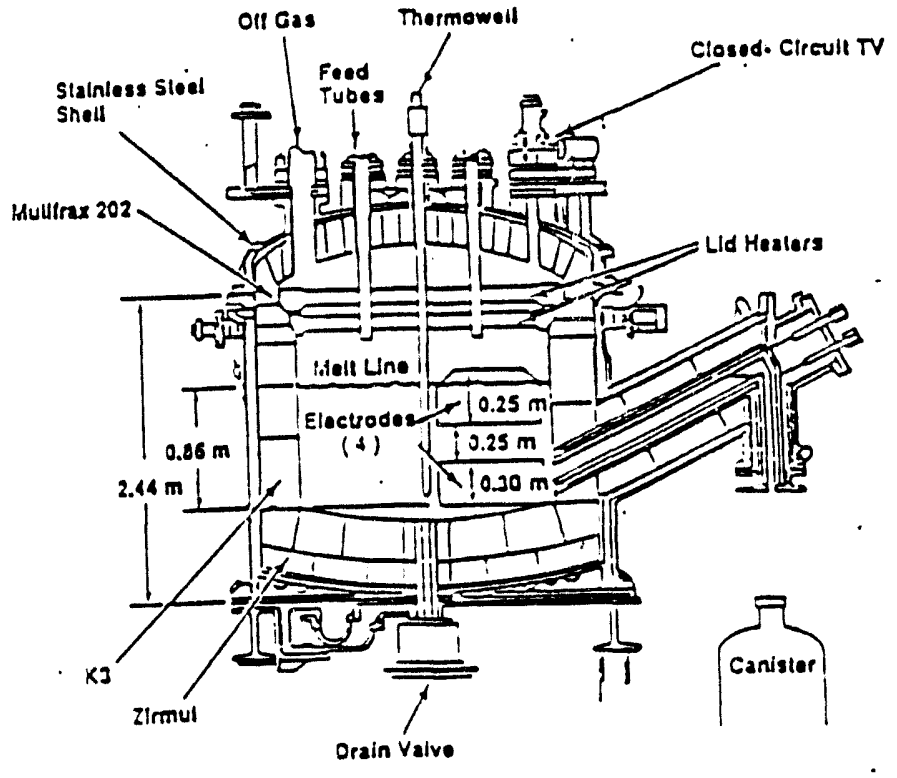

Figure 1 The HWV Melter

provide a minimum two year operating life. Therefore, nonreplaceable components, such as refractories, Inconel metal heaters, lid hearers, and electrodes have been designed to assure this minimum requirement. Unless a catastrophic failure occurs, it is reasonable to expect the melter to operate for five years or more before glass contact components fail (Koegler 1987). The presence of noble metals in NCAW feed could lead to the early failure of the first melter used within HWVP. The first double-shell tank of pretreated neutralized current acid waste will contain approximately 0.6 wtt (oxide basis) of noble metals. This will account for one to one and one-half years of plant operation, assuming a plant availability of 75\%. This is the only feed that contains sufficient concentrations of noble metals to threaten the minimum operating life of the HWVP melter.

Noble metals can be considered insoluble in the glass and will exist in the glass melt as particles. The size and behavior 
of these particles in the glass tank will determine whether a significant quantity will settle to the floor of the melter or will be carried out in the glass discharged to the canister. If a sufficient quantity of noble metals settle to the melter floor the lower electrode pair could be electrically shorted. When this occurs, either the noble metal accumulation will have to be removed or the melter will have to be replaced.

Work being conducted in FY 1991 and 1992 will define the noble metal behavior in NCAW glass and its propensity for accumulating in a ceramic melter. The work locic is shown in Figure 2. This test plan defines the scope to be performed in the Research-Scale Melter (RSM) activity. Laboratory testing that will precede RSM testing will define feed preparation methods that will be followed and analytical techniques that will give the most accurate and precise measurements of noble metals in slurries and glass. Gradient furnace testing will. study the behavior of noble metals during the decomposition, calcination, and melting stages of vitrification. RSM studies will provide more prototypic melting conditions than the GFT, i.e., true cold cap and melter conditions, and will provide data on the effects of process variations on noble metal behavior such as particle size, oxidation state, and agglomeration tendencies. process variations will span the ranges of plant melter operation, such as redox, temperature, slurry properties, etc. Computer modeling studies will be performed as a precursor to RSM testing and will utilize RSM results to further refine TEMPEST and particle tracking models. Testing will culminate with 20 to $30-$ day engineering-scale melter (ESM) tests in 1/10th-scale melter systems. ESM testing will be conducted at nominal plant conditions.

The performance assessment approach is based on a plan formulated in FY 1990 by PNL and WHC project staff. The main premise is that the noble metals assessment can not be made at a full-scale. This is due to the fact that no full-scale melter will be available until HWVP cold testing and also is due to the high costs of noble metals. For example, based on a FY 1991 cost estimate a 30-day run in a full-scale melter will require almost $\$ 4 M$ worth of noble merals alone. The approach taken then is to rely on smalier test systems and augment scale testing with laboratory and modeling work.

The KEX 1/10th-scale melter was designed to scale critical dimensions as close to the full scale as possible. The glass surface area is approximately $11 \%$ of the plant melter and the glass depth of -34 in. is within the minimum and maximum tank depths of the plant melter. Chemical and kinetic effects can not be well simulated or predicted by current numerical models. Therefore, melter parameters that will most affect particle growth were maintained as closely as possible to full-scale. Parameters which were kept as close to the plant melter as practical were heat transfer conditions, glass residence time, and the electrode placement and overflow location. The residence 
NOBLE METALS TEST PROGRAM

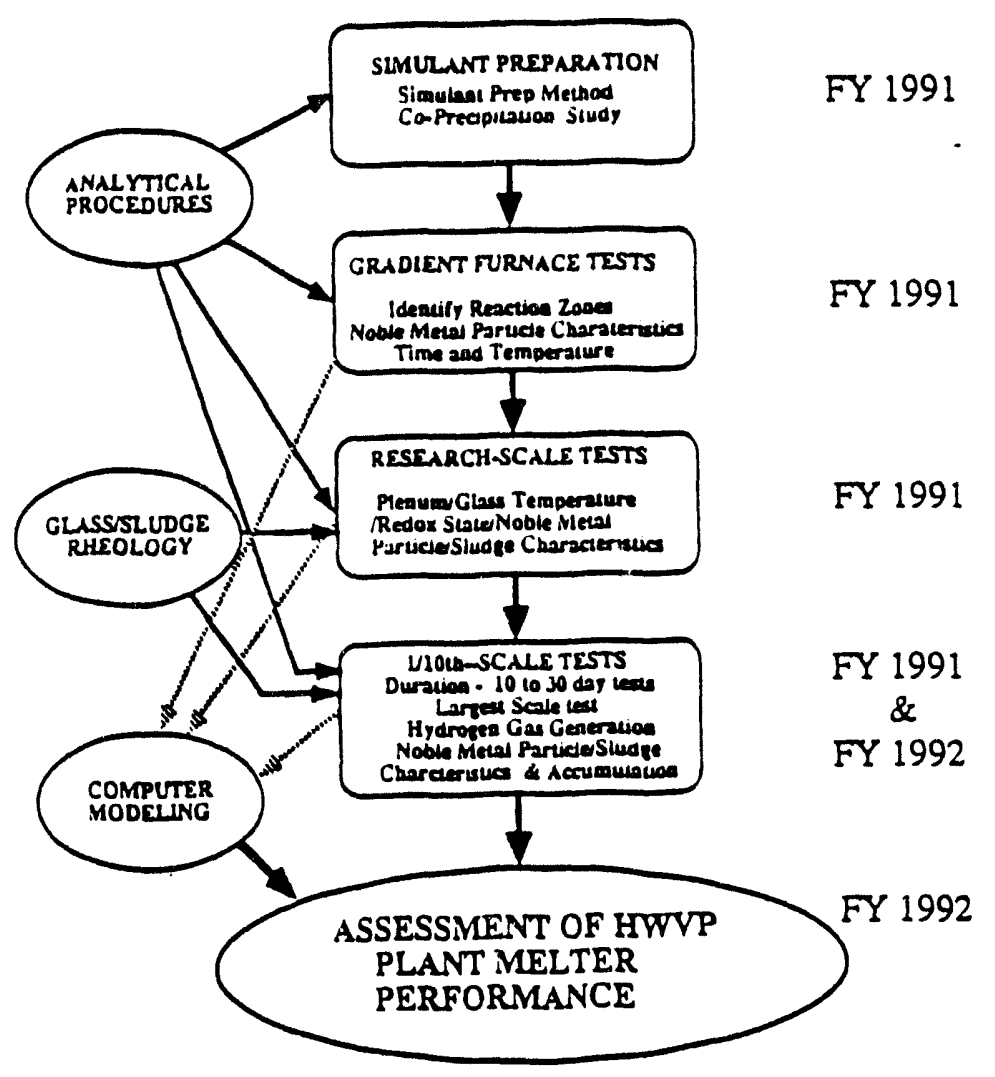

Figure 2 Noble Metals Work Logic 
time combined with the convective mixing and near surface temperatures will provide conditions as close to the plant melter as can be achieved at this scale. If a conductive sludge forms, the lower electrode current will be shorted through the sludge if a sufficient amount has accumulated. Very conductive accumulations could uitimately affect the operation of the upper electrodes. For these reasons the lower electrode height ( 12 in.) and the separation between the upper and lower electrode set (10 in.) are matched to the plant design.

The tests to be conducted at WSRC will be conducted in the integrated DWPF melter system (IDMS) melter. The two 10-day melter tests will be conducted within the schedule of testing planned to support DWPF. These tests will obtain data on off-gas compositions during feed formating and noble metal melter mass balance. Any operational effects due to the presence of noble metais that occur will also be studied.

RSM testing will provide process results of noble metal behavior as a function of process condition. Testing is planned to operate the RSM between the maximum and minimum operating inmits specified for the plant melter or, if not a plant criteria, based on achieving a measurable change. Relevant process paramerers that will be evaluaced are discussed in the objectives section of the plan. Test data will be obtained that, given the scale of the melter, will be treated as semi-

quantitative. In contrast to this testing, the ESM tests will be conducted largely within nominal conditions: i.e., reference feed composition, noble metals concentration, process temperatures, glass redox, etc. RSM tests will be correlated to ESM test results and modeling work which esgether will form the basis for the plant melter assessment.

This test plan has been prepared to direct research-scale melter testing under the Melter Performance Assessment cost account, 1.2.2.04.01. This test plan, along with the gradient furnace test plan, will satisfy PHTD FY 1991 milestone $1.2 .2 .04 .01 \mathrm{C}$. Complerion of RSM testing will be completed in accordance with milestone 1.2 .2 .04 .010 . This work will be combined with laboratory and engineering-scale testing planned in FY 2991 and FY 1992 to close HWVP Applied Technology Plan issues under section 5.1.2, "Melter Performance Assessment."

\subsection{OBJECTITES}

Per the FY 1991 PNL statement of work the objectives of RSM testing are "to establish operating parameters for engineeringscaie melter tests at $\mathrm{K} f \mathrm{~K}$ and evaluate glass containing noble metals. Obtain data that provide an understanding of noble metals behavior in conjunction with feed and glass chemistry to predict melter performance.... conduct studies of test parameters, including glass melter temperature, residence time, plenum temperature, and glass redox." (Kruger 1991). To perform this scope of work, a small joule-neated test system was designed in 
FY 1990. Approximately eignt weexs of testing will be conducted in the RSM to optain process and product data as a function of process variazles.

The relevant slury and process variables will be varied through the ranges of the Hivp operating limits. The following variables will be investigated:

- roble metals concencration.

- slurfi oxide ioading.

- redox $\left(\mathrm{Fe}^{\mathrm{T}} / \mathrm{Fe}^{-3}\right)$ of the glass.

- glass process remperatuze,

- plenum temperacure.

Process analy tical data obtained from which noble meral effects will be measured. Process data will be used to determine any measurable effects on melter operation, such as glass resistance or process rate. process data will also be used to support continued validation and refinement of the numerical codes. Aralytical data will be obtained for slurry, glass, and in-melter glass/sludge samples. In aadition, post-test examination of the melter will cccur to recover siudge or metal deposits.

\subsection{Establish $z \in K$ operating Parameters}

The 30-day ESM test planned at the Kernforschungszentrum Karlsruhe (KfK) will provide, along with testing in IDMS, the largest scale of testing tor the HWVP to evaluate noble metals effects on meiter operation. The operation parameters should reilect the expected plant conditions such as nominal composition and slurry properties and melter process condicions. However, RSM testing sould identify significant changes in noble metals behavior due $=0$ a change in one or more process conditions. Verification of this effect may be requized at the larger scale to assess the full impact on melter operation. Based on RSM results then, ESM process or slurry variations will be established. inother aspect of RSM testing trat may contribute to the ESM testing strategy is the identification of additional data needs nor currently conceived. For example, RSM analytical results may snow that smaller or larger sample sets may be required to provide the accuracy and precision for closure the mass balance. Also, process data may identify additional instrumentation needs to support nodeling efforts and melter performance assessments.

\subsection{Understarding Noble Metal Behavior}

HWVP process limits have been established for many feed and melter paramerers. These include glass temperature, plenum temperature, glass redox, and slurry oxide concentration. Variations of these parameters will alter somewhat the melting and residence time experience of noble metal particles. For example, the rate of temperature increase and the total time 
within temperature regimes within the cold cap is dependant on plenum and glass temperature, and cold cap thickness. Particle interaction and growth is known to occur in the cold cap and near glass region (Nakaoka et al 1986, Sevingy 1990). To assess the impaces of these parameters on noble metals behavior, testing will be conducted at the process ?imits. Additional variables that can have an affect on particle size and properties are the level of redox and noble metal concentration in the melter feed. More reducing glasses can lead to reduction of noble metal oxides to metal states. These metals could consolidate, alloy with other merals or act as nucleating sites for spinel growen. Higher concentrations of noble metals provides the opportunity for a greater degree of particle growth.

\subsection{Technical Approach/Test Description}

The approach to the testing is to vary the parameters considered important to noble meral accumulation over the ranges specified by HWVP Technical Data Package the feed specification (Smith 1991) or over some range designed to produce a detectable change in noble metal behavior. The parameters which will be varied during the testing are glass redox, noble metal concentration, oxide loading, glass temperature, plenum temperature. While residence time is not an independent variable parameter, it is considered an izportant parameter in noble metal particle agglomeration and therefore warrants consideration. It has been estimated that the resicence time will vary between 5.3 and 7.9 hours. This is quite short compared to the residence time projected for the plant melter of approximately $57 \mathrm{~h}$. The actual residence time in the melter will depend on the oxide loading in the feed, and the feed rate which is affected by the glass and plenum temperatures.

In addition to the measurements made during testing, after the planned testing has terminated, project staff will decide whether the melter should be turned off and sectioned to inspect the melter tank bottom for signs of noble metal accumulation or the meiter should remain operational for further testing.

\subsection{Test Matrix}

The nominal value and allowable range of the test parameters, either specified in the HWVP Technical Data Package, based on composicion revisions (Smith 1991) or selected for this test based on experience, are shown in table 1 below. The test matrix (Table 2) was designed to provide an epportunity to vary each parameter mentioned above to its extreme values as listed in Table 2. Testing is planned to occur in 5 day segments. Feeding will last approximately 100 hours per segment. At a 1 l/hr expected feed rate, approximately is melter volumes of glass will be processed during each segment. 
In addition to the parameters above, one of the later tests will increase the amount of silver and tellerium in the waste by a factor of two along with the noble metals. These metals have been seen to alloy with noble metals in the past.

\subsection{Measurements required to atzain obiectives}

The testing required to achieve the desired objectives can be divided into three separate types: process characterization, chemical characterization, and raMPEST verification.

Process Characterizarion

The measurements which will define the process are glass and plenum cemperature, electrode and heater power, glass and sludge (if measurable) electrical resistance, feed rate, glass production, zemperature profile, mass balance (feed, glass and sludge elemental analysis), glass redox.

Chemical characterization

Chemical characterization will be accomplished through mass balance measurements, sludge sample analyses, glass redox. These various measurements wili use IC?, SEM/EDX, XRF.

TEMPEST VeriEication

The TEMPEST model is being refined to suitably predict the behaviour of noble metal particles in the plant melter. To support this work RSM testing is being used to both provide data on noble meral particle characteristics (size, shape, estimated density, etc.; and giass and sludge electrical resistance. operation of the RSM is also be done to support verlfication of TEMPEST as $:=$ is being refined by comparing predicted and actual melter measurements including bulk glass temperature, glass temperature profiles, and electrode power usage. below.

The individual measurements are described in more detail

Glass Temperature - Glass temperatures will be measured using two thermocouples in a thermowell on the back of one of the electrodes. This measurement will be correlated to bulk glass temperatures by inserting a thermocouple into the glass melt to obtain a temperature profile during checkout of the melter prior to starting the test, and periodically during the testing.

Electrical Measurements - Electrical measurements will be RMS voltage and current measurements for the electrodes, plenum heater, and overflow heater. These measurements will be made continuously during the testing. Power for each of the hearers and glass resistance across the electrodes can be computed from 
Table 1

Research Scale Melter Test Matrix

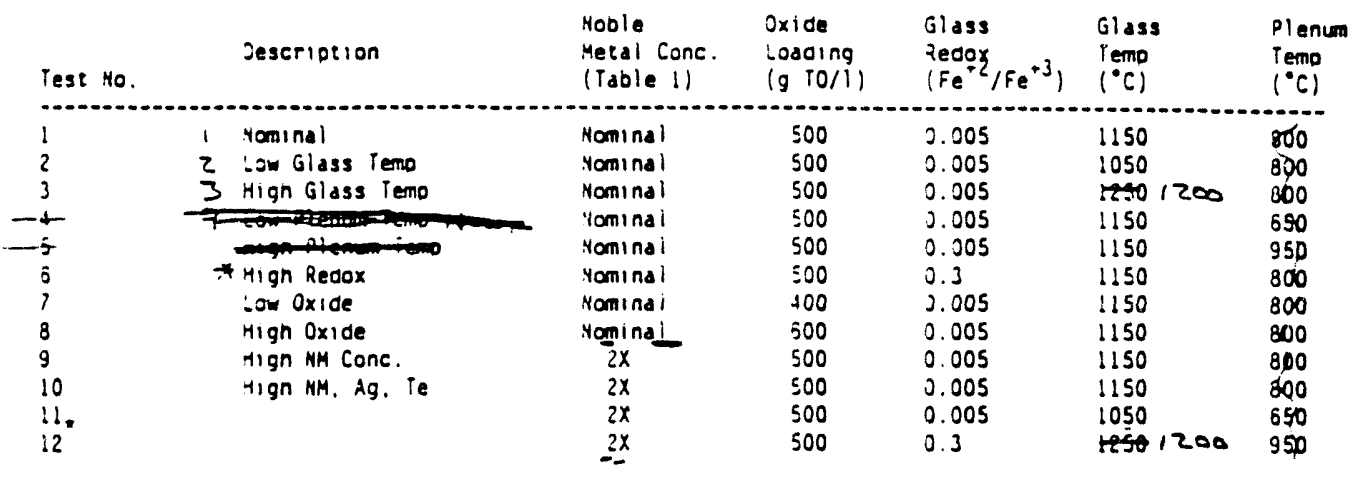

* Test number 12 will be performed only if time and noble metal stocks allow.

these measurements.

Sludge Electrical Resistance - Sludge resistance measurements fefer to measuring the resistance across the electrodes, which normally rest on the bottom of the melter, and then comparing this resistance to the resistance measured when the electrodes are raised a set amount to remove them from any accumulated sludge on the melter sottom. This measurement will be made at the beginning and end of each test period.

Feed Rate - Feed rate will be measured using the specific gravity/weight factor dip tube assembly built in the melter feed tank. A measurement of the change in feed tank depth over a period of time along with a tank depth/volume calibration curve will allow the average volumetric flow rate of feed to be calculated for that period of time.

Glass Production Rate - Glass production will be monitored by a small platform scale under the glass canister. The change in weight indicated on the scale over a period of time will allow computation of the average glass production rate.

Glass Temperature Profiles - Temperature profiles in the melter will be determined by manual thermocouple probes. Two ports are available to probe through (see Figure 9), the viewport and off gas line penetrations. 
Noble Metal Mass Balance - Mass balance measurements refer to the anaiysis of the amounc of noble merals present in the feed, melter tank glass, melter sludge and glass produce. Melter tank glass and sludge samples will be taken with a trigger activated stainless steel syringe sampler. Section 8.0 discusses the sample schedule for each of these types of samples.

Glass Redox Condition - Glass redox condition will be measured by the $\mathrm{Fe}+\mathrm{Fe}+3$ ratio.

Residence Time (Jependent variable) - Residence time will be measured by a step change in a Bao tracer, which will be added to the feed. The BaO will be added in alternating tests to produce a change in the poured glass barium concentration, which can be used to determine the-melter residence time. An addition of 0.25 wt\% BaO on an oxide basis will produce a detectable change.

\subsection{EXPECMED RESULTS}

This section discusses the expected results of the RSM tests. The bases for the expected results are laboratory tests conducted at PNL and information that has been exchanged between the project, FRG researchers, and WSRC staff. The objective of RSM testing is to characterize noble metal characteristics, such as particle size, shape, the makeup of crystali ine or metal agglomeracions, and Ezaction of setting in the RSM. The data are meant =o be compared between the various tests within the test matrix. The results will be compared qualitatively to other data obtained by $\mathrm{KfK}$, NSRC, or PNL. The semi-quantitative data that are obtained will reveal the sensitivity of noble metal behavior to the process variables studied.

\section{1 Noble Metal Concencration}

Laboratory crucible studies conducted by Geldart, et al. (1987), provided results which showed the basic effect of increasing noble metal concentration was an increasing level of particle agglomeration. No new particles or alloys were found to occur. Laboratory scudies of the behavior of ruthenium oxide particles in HWVP glass by Cobb and Hrma (1991) resulted in their proposing a mechanism for particle agglomeration. The mechanism is based on particle collisions, enhanced by mixing mechanisms, and provides an explanation for how partilles are brought into such close proximity. It is possible then that a $2 x$ increase in noble metals may result in a large population of particles above a single particle size. Subsequently, a greater fraction of the noble metals should settle in the melter based on the above data. Conversely Dr. Pentinginaus of $\mathrm{KfK}$ has supported the hypothesis that there is little particle interaction occuring in the glass 
phase. If such is the case then larger particles would not be expected as a function of noble metal concentration. If this were the case the fraction of particles settling should not be affect be concentration. This is in possible agreement with the work performed by Geldart, et al. Work pertormed at WSRC has concentrated primarily on the relationships between noble metals and mercury (Nakaoka and strachen 1990). There has been no similar work done at WSRC.

\section{2 oxide concentration}

Operating between the lower and upper limits of oxide loading will result in several changes. At the lower oxide concentration, the glass production rate will drop proportionately. This will increase the residence time of the glass in the RSM. A longer residence time provides the opportunity for a higher degree of particle settling. Longer hold times can also lead to additional spinel growth and particle agglomeration or alloying if a mechanism for particle collisions to occur exists. In discussions with Dr. Pentinghaus of KfK, (Sevigny 1990), he has the technical opinion that once the melt phase is reached there is little chance or time for particle growth. As already stated, cobb and Hrma have developed at least one plausible mechanism for continued particle growth in the melt phase. Geldart, et al (1987) found additional particle settling and some spinel growth as a function of time. Tests conducted with higher oxide loadings should have the opposite effects. That is, lower residence time should result in lower particle settling and smaller particles.

oxide concentration will also affect the cold cap melting history. That is, the time and temperature experience of the feed solids will be different. At the lower oxide concentration a thin cold cap is typical. Therefore, a high temperature profile will exist across the cold cap solids phase and quicker melting times will result. The effects on the cold cap kinetics are not known. Work being performed by the gradient furnace testing activity is intended to provide data and insight into this area.

\subsection{Glass Redox Level}

Noble metal oxides can be reduced to metal phases if a sufficiently strong reducing environment exists. The nominal redox level is near the detection level for the ferrous-to-ferric ratio analytical method used. At this value of 0.01 or less Geldart, et al. (1987) observed ruthenium oxide and palladium and rhodium oxides. Palladium and rhodium alloys with tellurlum were also observed. Typically, the palladium and rhodium behaved as nucleating sights for spinel growth. As the redox level increased, ruthenium oxide concentrations were reduced and metalic ruthenium was observed. The upper ferrous-to-ferric 
ratio level to be tested will be targeted at 0.3 . To achieve this high ievel, sugar will be added. This is below the levels required to achieve gross reduction of noble metal oxides to metals experienced in past PNL tests and at WSRC (Nakaoka and strachan :990) in which redox levels greater than 0.5 existed. Based on the laboratory data at hand it is expected that little affect of the higher redox will be observed. However, the cold cap kinetics were not simulated in laboratory tests. The presence of sugar as a reductant in the cold cap may cause more metal reduction than has been observed to date due to its strong reducing potential.

\subsection{Glass Temperature}

Geldart et al. (2987) observed higher spinel growth at lower glass temperatures than occurred at $1100^{\circ} \mathrm{C}$. This may be due to spinels being present to a high degree as the cold cap melts. As temperatures progress to $1150^{\circ} \mathrm{C}$ the spinels go into solution. If temperatures are held below $1100^{\circ} \mathrm{C}$, spinels will go into solution more slowly and be capable of reacting with noble metal oxides or metal particles which serre as nucleating sites. Conversely, the higher viscosity glass will also reduce convection currents and lead to a more stagnant tank. This effect may inhibit particle collisions and result in more plug flow and less mixing. The use of a tracer added to the feed slurry during these rests will indicate if any change occurs in tank mixing characteristics. Therefore, at this time it is not clear what the overall effect of lower glass temperacure will be.

Higher glass temperatures will decrease glass viscosity which could increase tank mixing. If the hyporhesis offered by cobb and Hra (1990) is applied there should result in a greater occurrence of particle interaction, leading to larger particle growth and settling rates will increase. These conditions should lead to a higher degree of settling. Conversely, higher convection currents, if present, may reduce somewhat the rate of settling through enhanced mixing. However, the net effect of convective mixing in a closed system will ultimately be complete settling of entrained particles. Unless mixing increases to a turbulent zegime, as would be achieved with vigorous sparging (note: a clear distinction exists between vigorous sparging and using one or two bubblers in a glass tank), all particles would be expected to settle. This fact explains why complete drop out of noble metal particles occurs in a melter once feeding has been stopped and glass ceases to be poured. These conflicting effects make it unclear precisely how higher temperature will affect noble metal behavior. 
Research-Scale Melter Test Plan Rev. 0

HWVP $1.2 \cdot 2.04 .01 \mathrm{C}$

Page 12 of 30

4.5 Plenum Tomperature

Plenum temperature changes will affect the boiling rate of water from the cold cap. is a result, lower plenum temperature will reduce feeding and glass production rates; and higher plenum temperature will increase feeding and glass production rates. Both will change the temperature history of the cold cap. As discussed earlier, the affect changing the cold cap history will have on noble metal behavior is not understood. Gradient furnace testing is expected to provide insight into this area and will be relied on heavily in drawing conclusions from this part of the RSM test.

\subsection{TEMPEST Modeling}

A simulation of the Research Scale Melter using the TEMPEST thermal/fluid analysis software package was performed by Loren Eyler of the Applied physics Center. This simulation provided an indication of the electrode power and kiln temperatures required to achieve the desired bulk glass temperatures. The simulation also produced the convective circulation patterns in the melter. Measurements made during testing will be used to improve the post test simulations.

The model used was fully three dimensional and included the melter electrodes, thermowell and the discharge tube. Because of the asymmetry of the discharge section and the melter electrodes, the model used cartesian elements to represent the geometry. This simulation did not include the effect of pouring glass. It is currenely planned to include this in the post test

simulations. The model is shown in Figure 3 .

The simulations were performed assuming that the kiln is maintaining the melter exterior at $500^{\circ} \mathrm{C}$. The TEMPEST software then used its built in control algorithm to maintain a specified portion of the melt at an average temperature of $1150^{\circ} \mathrm{C}$. The initial simulation used too large a portion of the melt as an average temperature to use as a control temperature. This resulted in the glass near the relatively cool walls and cold cap region being included in the average and forcing the electrode power up until the maximum temperature in the central core of the melt was at $1275^{\circ} \mathrm{C}$. Once the averaging region was reduced to a smaller portion of the melt, near the center, the power required to maintain the $1150^{\circ} \mathrm{C}$ average decreased and the maximum

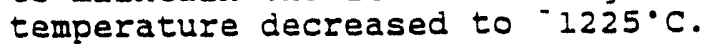

The flow pattern in the melter is comprised of two roughly cylindrical roll cells which come togerher and generate a sheet of glass moving upward between the two electrodes. The velocity vectors are shown for planes cutting through the center of the melter in Figures 4 and 5. The celis are slightly asymmetrical due to the discharge tube. The maximum velocity in the convecting glass is approximately $3.2 \mathrm{~mm} / \mathrm{s}$. These low velocities result in little energy transfer through the melt as a result of 


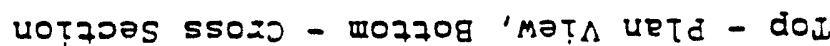
KS\& IO TәPOW ISIdhAL $\varepsilon$ axnST!
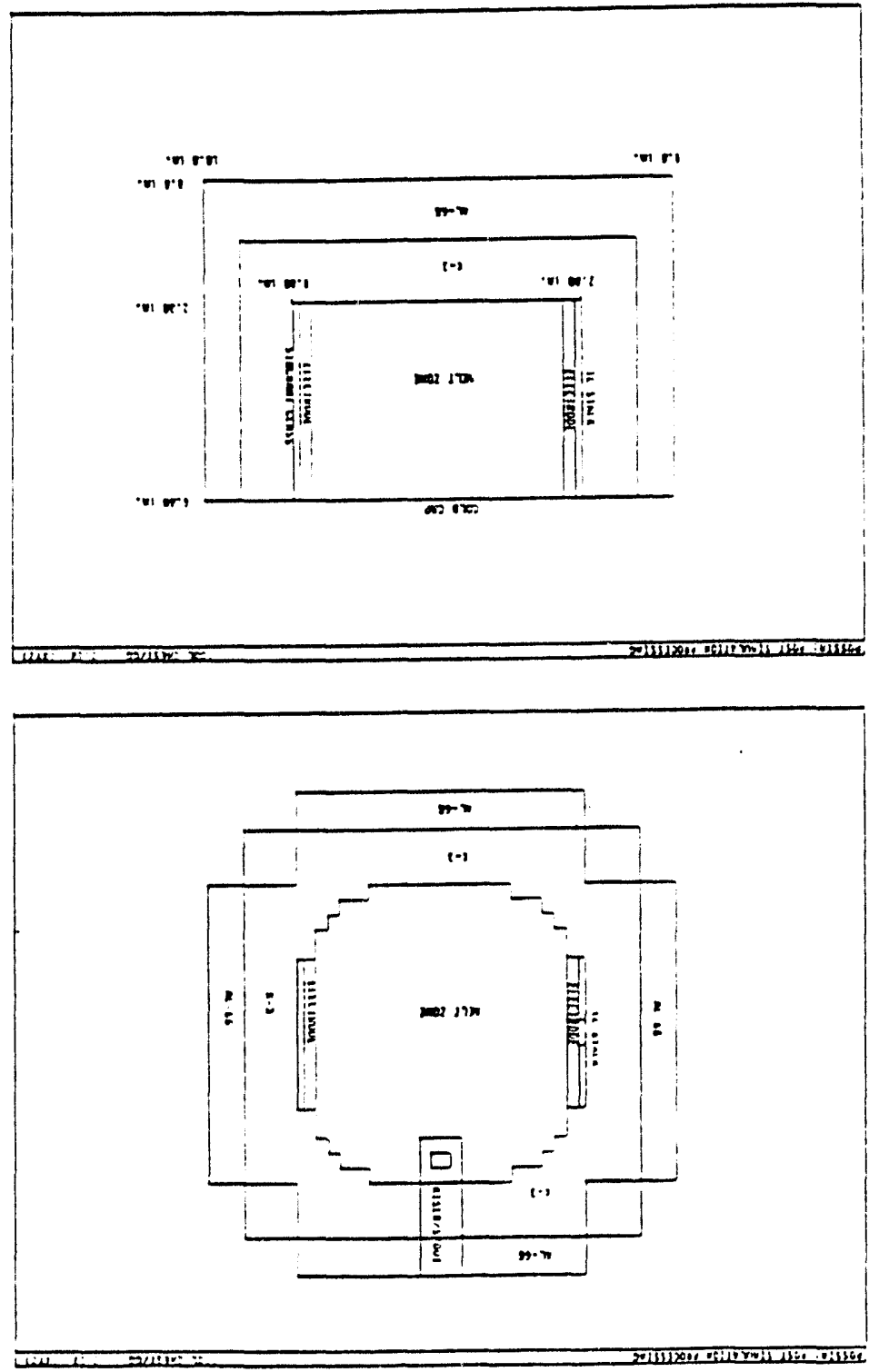

oE JO ET abed

วTO $\bullet O \cdot \tau \cdot \tau \cdot \tau$ d $\triangle M H$

$0 \cdot \wedge \partial$

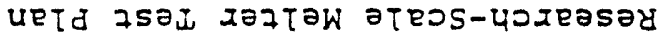


convection. Conduction is the predominant mode of heat transfer and is the reason why there is a large temperature gradient from the center of the melt to the walls.

The predicted flow patterns in the melter would tend to sweep any heavy particles settling out of the melt into a line between the two electrodes. This makes this a good location for the sampling of melter sludges along with another location which is less likely to accumulate settled particles for a comparison of the two.

\subsection{Equipment Description}

The RSM/Noble Metal Test Run will be conducted in the Engineering Levelopment Laboratory in the 324 building. The major pieces of equipment used in feed storage, vitrification, and off-gas treatment are described in this section.

The RSM System consists of an electrically joule heated melter, placed within an electrically heated firebrick kiln, and the equipment associated with the delivery of feed and discharge of glass.

\subsection{RSM METTER}

The research scale meleer is $10^{1} / 4$ inch OD (by 15 1/2 inch high) and possesses an Inconel 601 shell. Ceramic paper and Alfzax ${ }^{2} 66$ line the melter tank refractory as principle insulators.

The glass melt cavity refractory is an 8 inch $O D \times 6$ inch high cylinder of $\mathrm{K}-3$ block. The melt cavity is a 6 inch ID $x$ $4 \%$ inch deep cylindrical volume with a nominal capacity of 1.33 I (with a plenum vacuum of 2 inches $\mathrm{H}_{2} \mathrm{O}$ ). The configuration of the RSM's refractories and insulation are shown in Figure 6 . Both electrodes for the RSM are fabricared from $1 / 4$ inch Inconel 690 plate. The electrodes have a square face with dimensions measuring 3 inch $x 3$ inch. The arms of the electrodes extend $173 / 4$ inches and measures 1 inch in width. Detailed dimensions are presented in Figure 7 .

The electrodes are allowed to rest on the bottom surface of the $\mathrm{k}-3$ refractory melt cavity. They are located $43 / 8$ apart. The arms of the electrodes extend out of the melt region, through the plenum space, penetrate through the lid, and terminate in direct connection to the electrode power supply wiring. Isolation of the electrodes from the lid is achieved by providing oversized lid penetrations through which the electrodes protrude and filling the unoccupied space with Alfrax 66. This provides sufficient electrical isolation in addition to stabilizing the

\footnotetext{
IInconel is a registered trademark of Ineo Alloys International.

2 Alfrax is a registered tracemerk of Carborunam corporation.
} 


\section{VELOCITY VECTORS}

Approx Cyin model: full 3d w/spout/

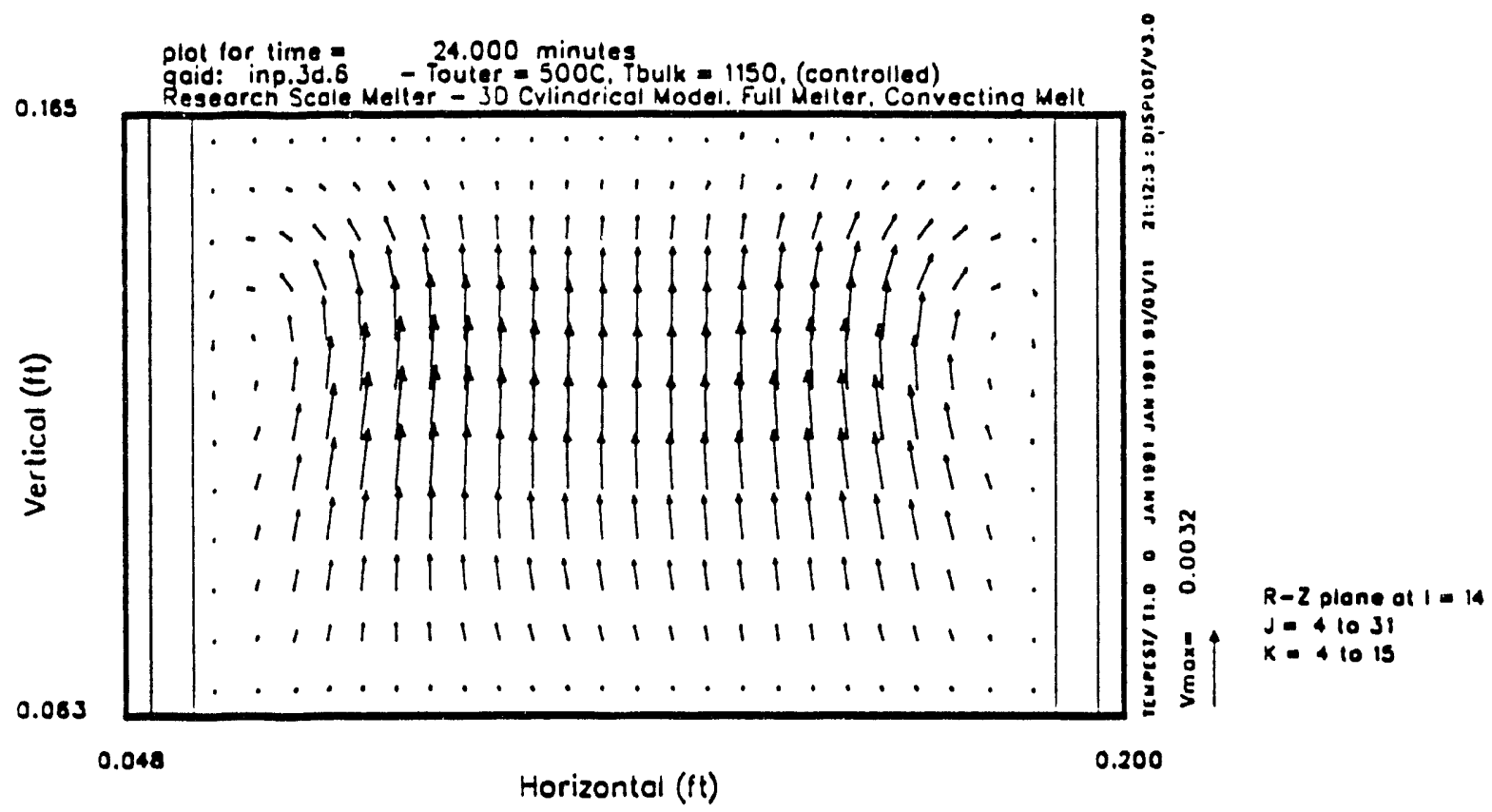

Figure 4 TEMPEST Velocity Vector plot plane Perpendicular to Electrode Faces 


\section{VELOCITY VECTORS}

Approx Cyln model: full $30 \mathrm{w} / \mathrm{spout} /$

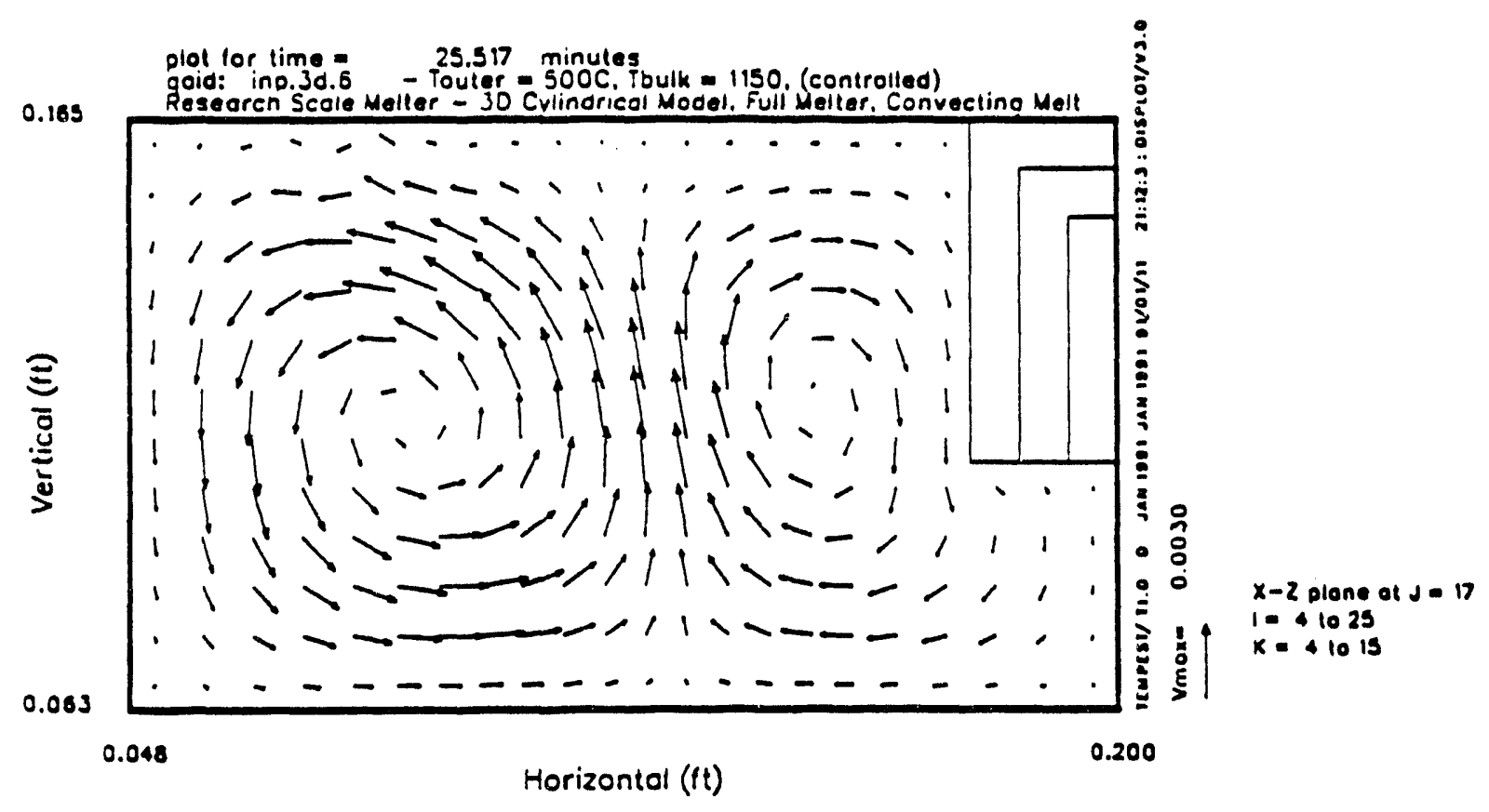

Figure 5 TEMPEST Velocity Vector Plot

Plane Parallel to Electrode Faces 

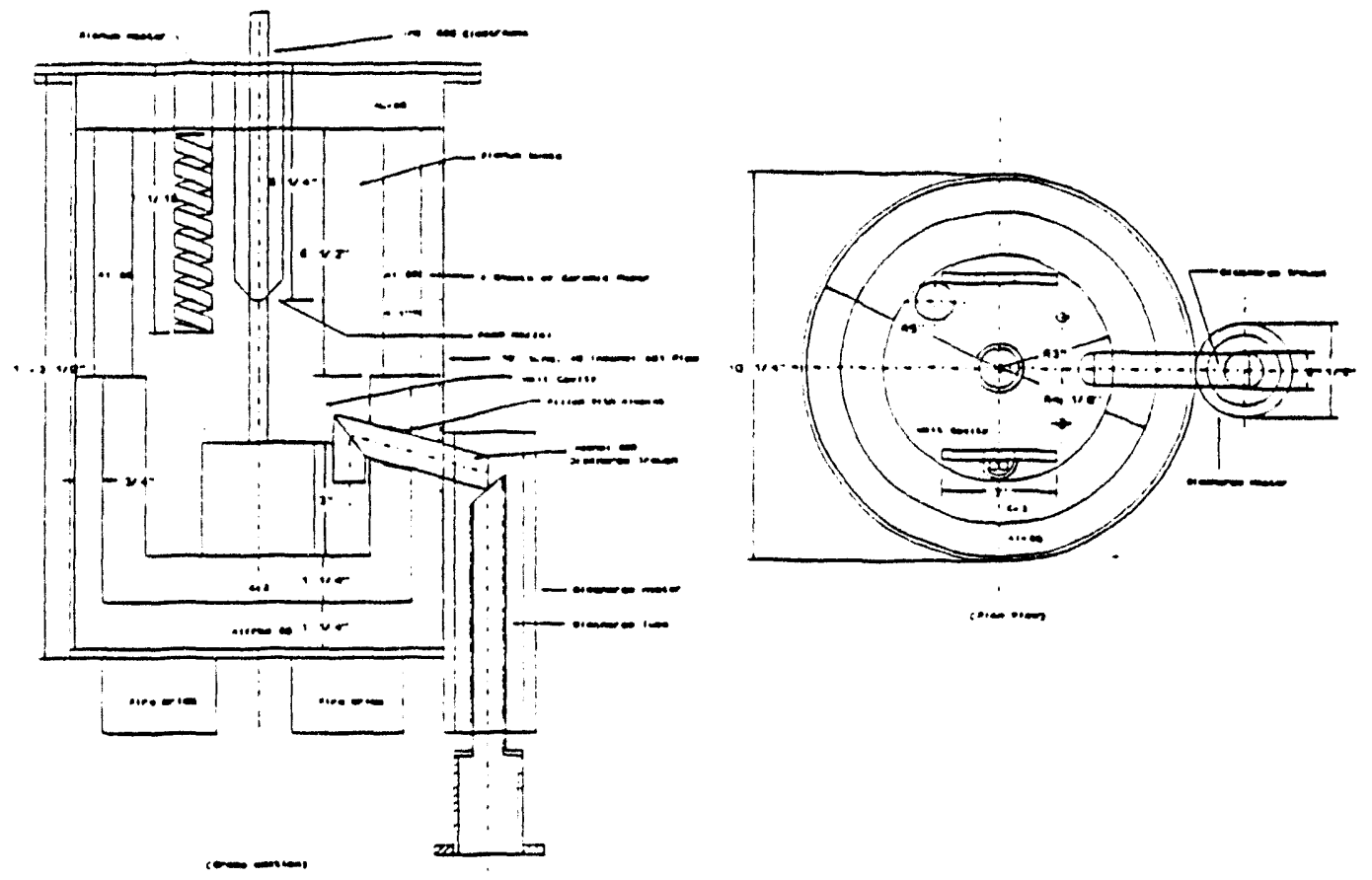

Figure 6 Research Scale Melter

electrodes.

Another significant heat contribution is the presence of a plenum heater. The heater is a 1 inch diameter, is inches long silicon carbide bayonet style heater with an effective heating length of 5 inches. The element is supported off the lid through a 9 inch length of 2 inch schedule 80 pipe. A ceramic sleeve is utilized to isolate the heating element from the pipe. The end of the heater length sits 2 inches above the melt level.

The RSM sits inside an electrically heated firebrick kiln. The inner geometry of the kiln is an octagon with a diameter of $16^{1 / 2}$ inches and a height of 18 inches. This kiln will be operated and maintained at approximately $500^{\circ} \mathrm{C}$. The melter will sit on 2 firebricks. This configuration is presented in Figure 8 .

The melter lid is a one piece unit which covers the melt cavity. It is 12 inches in diameter, $1 / 4$ inch Inconel 601 plate. All services to the RSM run through the f.id. The locations of specific services for the test are indicated in Figure 9. The feed port is located in the center of the lid.

To monitor the glass and plenum temperatures $1 / 8$ inch type $\mathrm{K}$ Inconel 601 sheathed thermocouples will be used to measure the glass temperature in the melter. Two thermocouples will be in an 

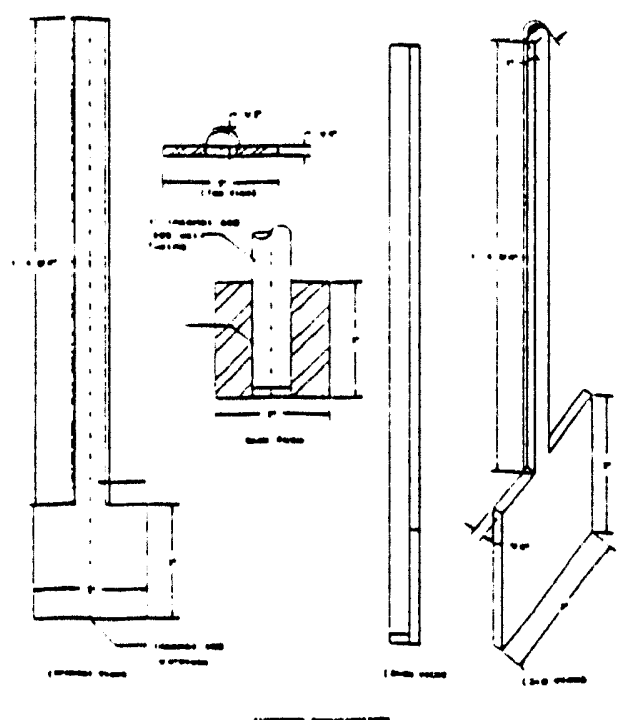

Figure 7 RSM Electrode Details

Inconel 690 thermowell. This thermowell is welded to the back side of one of the electrodes. The thermocouples will be $1 / 2$ inch and $21 / 4$ inch from the floor of the melt cavity. Bulk glass temperatures will be correlated to the thermowell measurements. one Inconel 601 sheathed thermocouple will be fixed in the plenum space at $6 / / 4$ inches from the 1 id. An additional Inconel 601 sheathed thermocouple will be used to periodically determine temperature profiles in the melt region. This thermocouple will be inserted through an opening in the off-gas port or through the viewport.

Pressure in the melter will be maintained at 2 inches $w . c$. through the use of a vacuum regulating valve attached to the EDL 102 Vessel vent system.

\subsection{Feed Delivery system}

During the test the feed slurry will be stored in a stainless steel, agitated tank located on 2 nd floor EDL-102 in Module 18. The tank has an ID of 24 inches, a height of $363 / 4$ inches and a nominal capacity of 250-270 liters. Primary delivery of the feed is gravity induced head. Feed levels in the tank will be monitored via weight factor/specific gravity 


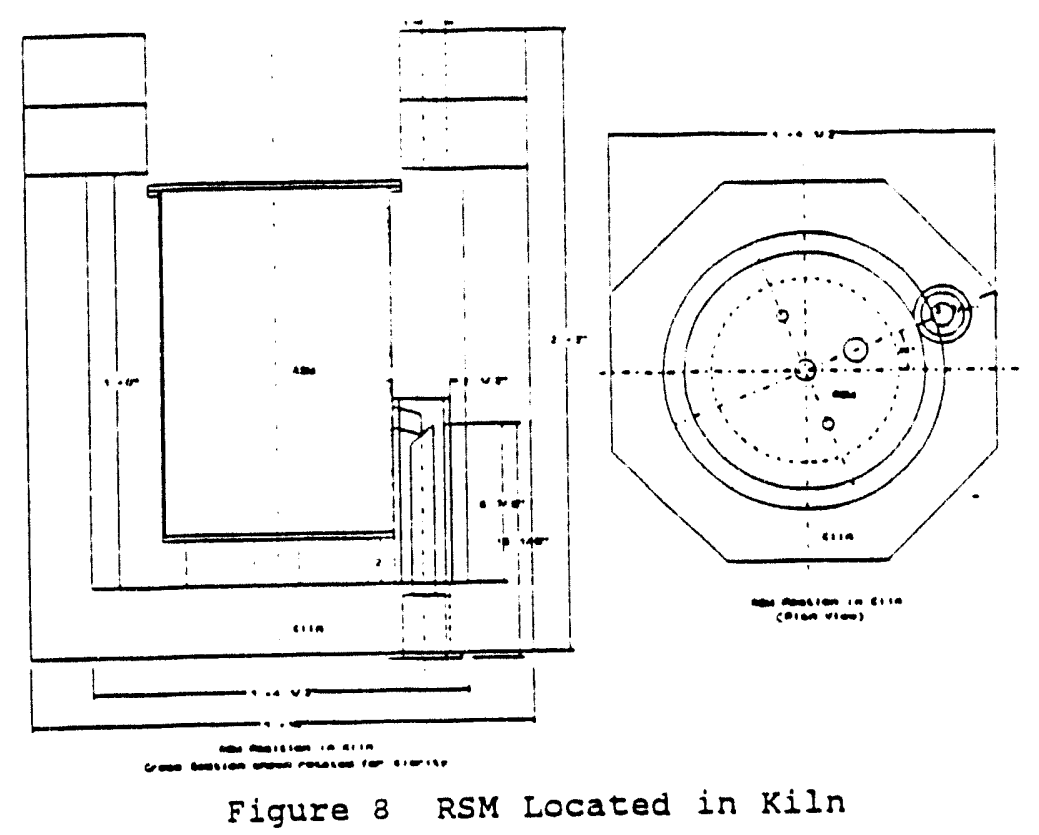

instrumentation. A peristaltic pump will regulate the feed rate to the feed nozzle. The rate of feed to the melter will be established by maintaining a 50 - $70 \%$ cold-cap coverage of the melt surface. The actual feed rate will be measured by the rate

of drog in the feed tank. the feed tank on the second floor to the peristaltic pump: located on a shelf above the RSM. At this point the $3 / 8$ inch stainless steel tube terminates and connects to $3 / 8$ inch Norprene flexible tubing which runs through the pump. The Norprene tube then connecrs to $1 /$ inch stainless steel tube which, in turn, connects to the feed nozzle. The feed nozzle extends $61 / 2$ inches into the plenum from the top. During the operation of the melter the feed nozzle will be water cooled to prevent premature drying of the feed while still in the nozzle. Water flushing and nozzle cleanout capabilities are designed into the feeding system. The feed nozzle is shown in Figure 10. 


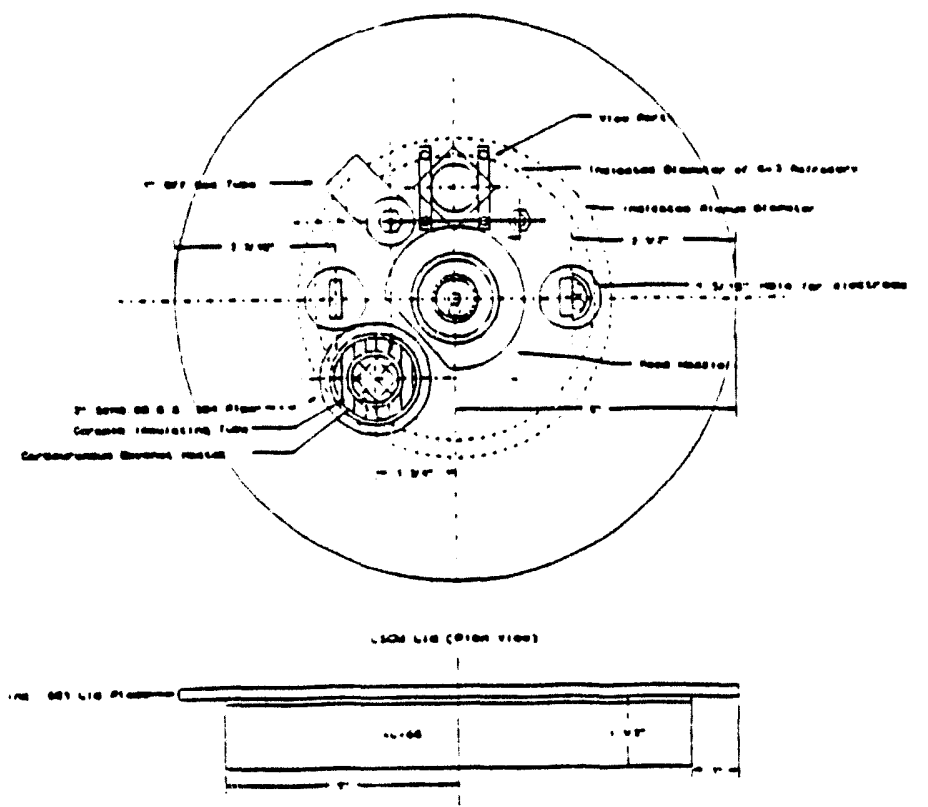

Figure 9 RSM Lid Detail

\subsection{Glass Discharge system}

A continuous gravity controlled overflow is used for simplicity, and because the discharge rate is small. The design is intended to provide a gas-tight transfer line between the melter and the discharge. No consideration for enhancing of inhibiting particulate transfer was intended.

The discharge trough (see Figure 11) is constructed entirely of Inconel $690 \mathrm{l} / 2$ inch schedule 160 pipe. It has an overall length of $4^{3} / 8$ inches and has a $15^{\circ}$ slope. The vertical portion of the discharge trough is submerged in the glass. Once the level of glass rises to the point which corresponds to the highest point of the trough slope then glass discharge will occur. The exterior face of the discharge trough is chamfered at a $15^{\circ}$ angle to prevent molten glass from clinging to the trough. The discharge trough is presented in Figure 11. The trough protrudes from the melter body by $1 \frac{1}{4}$ inches. The glass flows from the end and falls $10^{1 /} 4$ inches into a 4 liter stainless steel canister. To prevent the glass from solidifying in the pour tube it falls through an Inconel 690 1" tube which is surrounded by a $2 \frac{1}{2}$ inch $x 8$ inch electrical clam shell style heater. The heater will be operated at approximately $1000 \mathrm{C}$. A type $K$ thermocouple will be placed inside the heater to monitor the temperature of the discharge region. To determine glass pour 


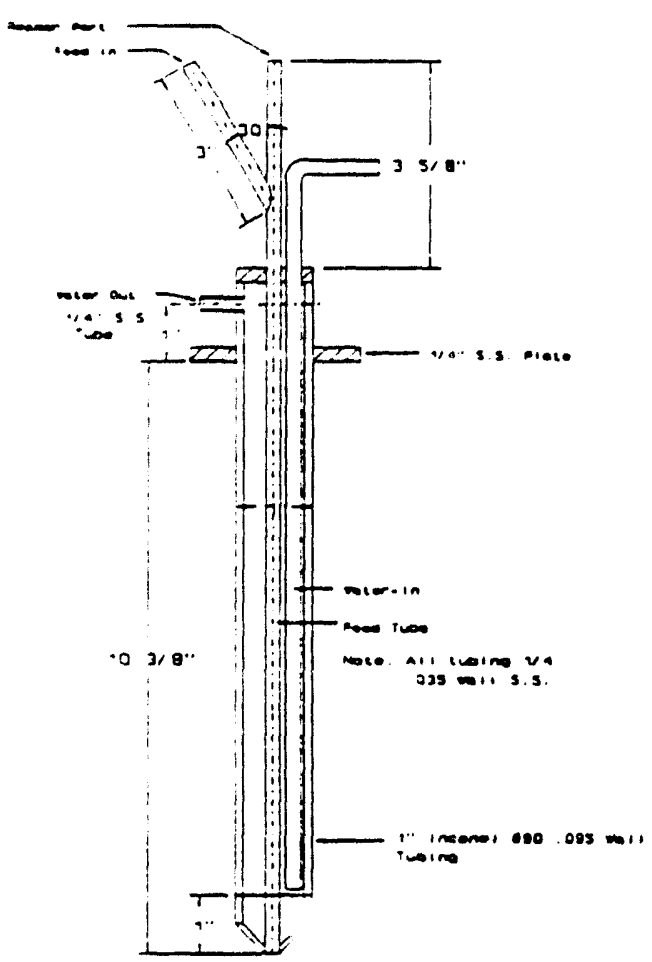

Figure 10 RSM Feed : tuzzle Detail

rate the 4 liter stainiess steel canister will be located on a small platform scale to measure the weight of glass being poured.

\subsection{Power control System}

The electrode, plenum heater, and discharge tube heater power are all controlled by silicon controlled rectifiers (SCR's). The SCR's act as a switch to turn the line voltage on and off to the load at an extremely fast rate. The longer fraction of time they are turned on, the more power is going to the load. The power output is controlled by a signal from an external process controlier. This controller can operate in a manual mode or automatic mode. In the automatic mode the temperature of the specific point which that heater is controlling is fed back to the process controller and it adjusts the output of the SCR accordingly. It is anticipated that thu melter power and hearers will be operated in an automatic temperature controlled mode for the majority of the testing. 


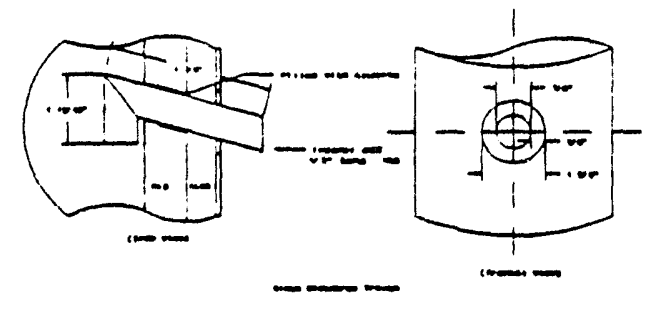

Figure 11 RSM Discharge Tube Detail

\section{5 off-Gas Treatment system}

The gases and airborne effluent generated by the RSM vitrification process are exhausted through and treated by an off-gas system. An insulated 1 inch stainless steel tube is extended from the melter and is routed through a venturi scrubber to provide initial cooling and remove the majority of the condensable and particulate material. The liquid for the scrubber is recirculated in a continuous loop which passes through a small shell and tube heat exchanger to remove the heat from the melter off-gas. As condensate accumulates, it will be drained down into Tank 20 in the Tank Pit below EDL 102. From the scrubber, the off-gas is run through a High Efficiency Mist Eliminator (HEME). The HEME will remove condensed phase aeroso.s. All accumulated waste liquids will be drained to Tank 20.

\subsection{Data Accuisition}

Data acquisition and melter control are performed with a Computer Data Acquisition and Control system capable of acquiring data, computing values based on the data and controliing the 
melter including all alarm functions associated with the melter. In addition, some critical data (glass temperatures, melter power) will be sent to chart recorders.

\subsection{Feed Description}

The composition of the simulated NCAW waste is shown in Table 3 below. This composition is based on the latest information communicated to PNL from WHC (Letter, R.A. Smith to J.M. Creer). Table 3 shows the deletions and substitutions of constituents which will not be included in the simulated waste either due to the small amourt of the constituent which is present or to avoid a radioactive element. The composition after deletions and substitutions is normalized to $100 \%$.

Based on this composition, a chemical form for each of the cations was determined to use in the melter feed makeup. This is shown for each of the oxides in Table 4 . Table 4 also shows the weight percent on an oxide basis for each of the simulated waste components and the grams/liter of each of the feed makeup chemicals in the melter feed.

Some of the chemicals are added in multiple forms to meet the anion specifications $(5, C 1, N 03 \ldots)$ called for in the NCAW feed specifications. Sodlum is primarily used for this function due to the availability of these sodium salts and the relatively high sodium concentration in the feed.

The noble metal chemicais will be supplied as nitrates as listed in Table 4, but will be neutralized along with the other minor constituents and less soluble components using $\mathrm{NaOH}$. These are the components in Table 4 other than aluminum, iron, manganese, nickel and zirconium. This is done to more accurately simulate the chemical processes taking place in the waste tanks. When the hydroxide forms of these chemicals have precipitated, the solution will be washed to remove most of the $\mathrm{Na}$ and $\mathrm{NO}_{3}$ and the minor constituents will be added in their hydroxide forms. Feed preparation and formateing requirements will be based on work yet-to-be conducted under the 1.2 .2 .03 .02 subtask.

\subsection{Data Acouisition and Sample Schedule}

\subsection{M\&IE}

The Research Scale Melter Measurement and Test Equipment Iist is shown below. Accuracy of the M\&TE is as fol.lows:

Temperarure: $t /-20^{\circ} \mathrm{C}$

pressures : $+/-2$ in.WC

voltage : $+/-5$ volts

current : $+/-5$ amps

Power $:+/-200$ watts 
Table 2

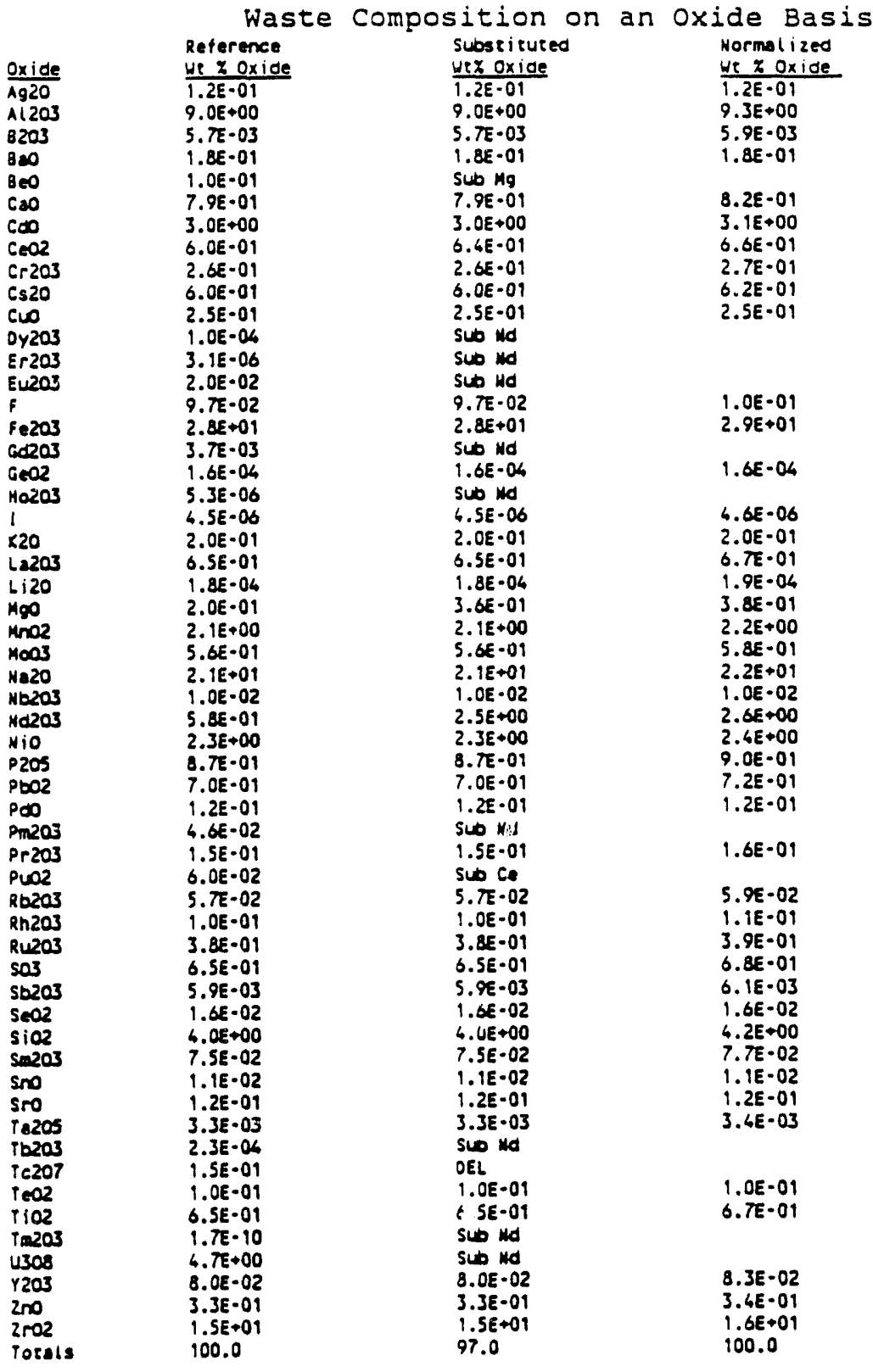




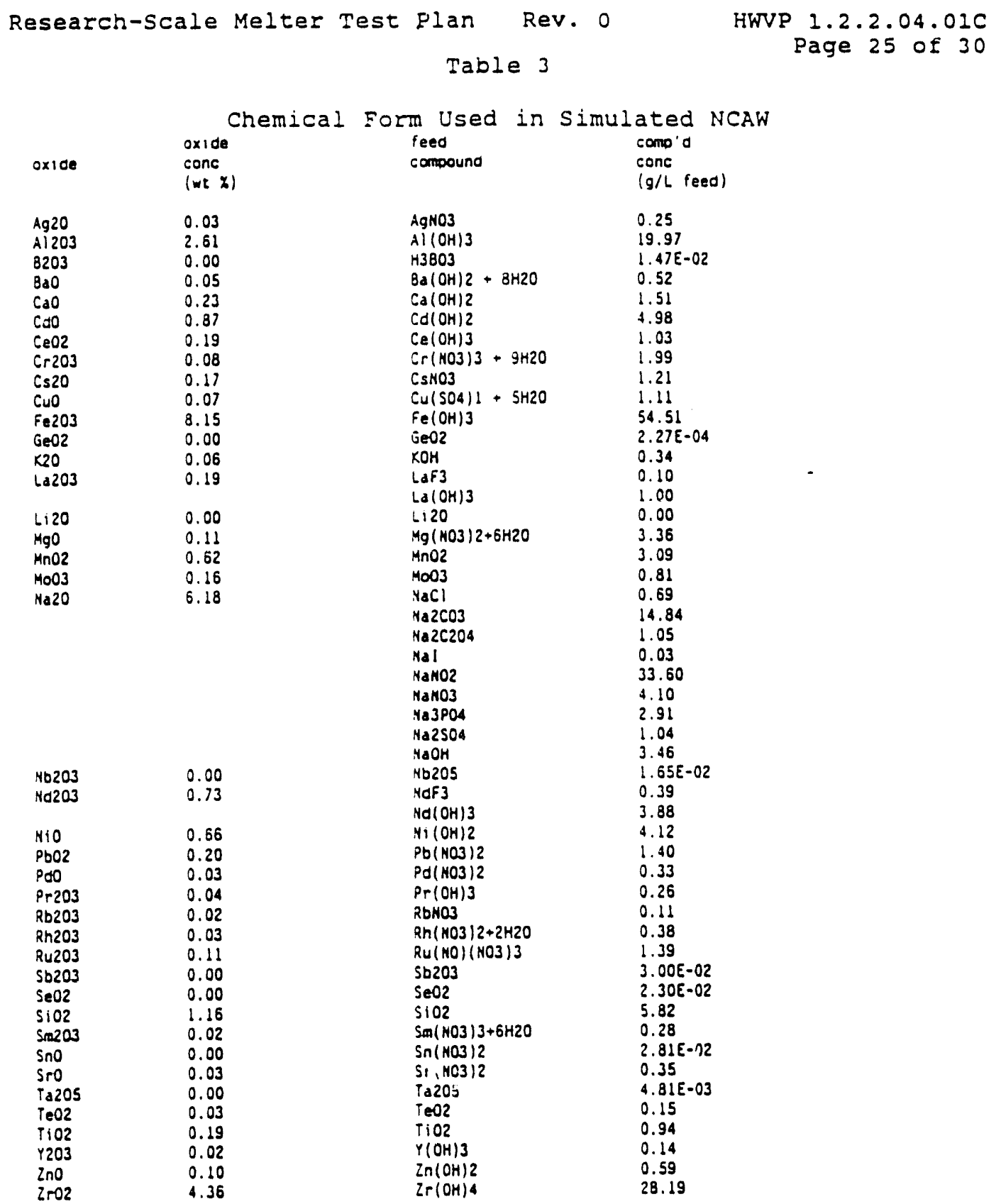




\subsection{Sample Schedule and Required Analyses}

Sampling during RSM testing will be required during feed preparation and testing. Slurry and glass samples will be obtained to support mass balance calculations and compare the compositions to the target values. In addition, post test inspection of the RSM will potentially retrieve sludge samples from the melter which will also be analyzed. Table 5 identifies the type and minimum number of samples and analyses that will be performed.

Minimum sample requirements require that at least one slurry and two glass samples be obtained each day. A typical slurry analysis requires less than $25 \mathrm{ml}$ of slurry. To assure an adequate archive of samples will exist, all of the glass that is produced will be retained. In addition, two 100-ml slurry samples will be taken each day. Samples will be stored in the $3718 \mathrm{G}$ warehouse located behind the 324 bldg. Additional 125-ml samples will be obtained specifically for slurry redox measurements. The final glass and slurry samples will be taken at the end of each test. At the start of each. test and immediately following cold cap melting at the end of each test, the melter tank glass and sludge samples will be obtained.

\section{0 schedule}

The dates for the major events in the Research Scale Melter subtask are shown below.
Date
$5 / 31$
$5 / 31$
$6 / 24$
$7 / 24$
$8 / 5$
$9 / 27$

\author{
Event \\ Start up Melter \\ Approve Test Plan \\ Start Feed Makeup \\ Finish Feed Makeup \\ Start Testing \\ Conclude Testing \& Decide \\ Whether to Destructively \\ Examine the RSM
}

\section{0 rest Procedures/Requirements}

All of the preparation for testing and testing associate.' with the Research Scale Melter vill be done in accordance with the plans and procedures listed below. 


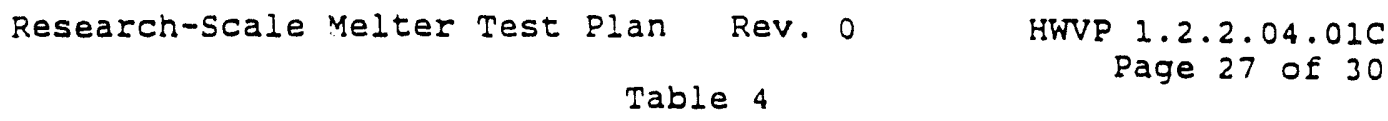

Table 4

Minimum Sample and Analytical Requirements

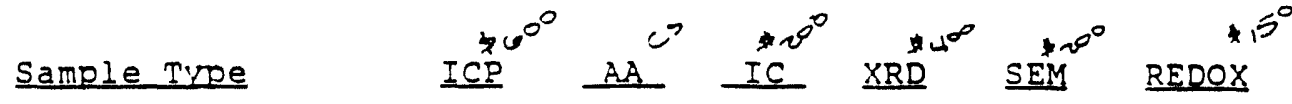

\section{Feed Preparation}

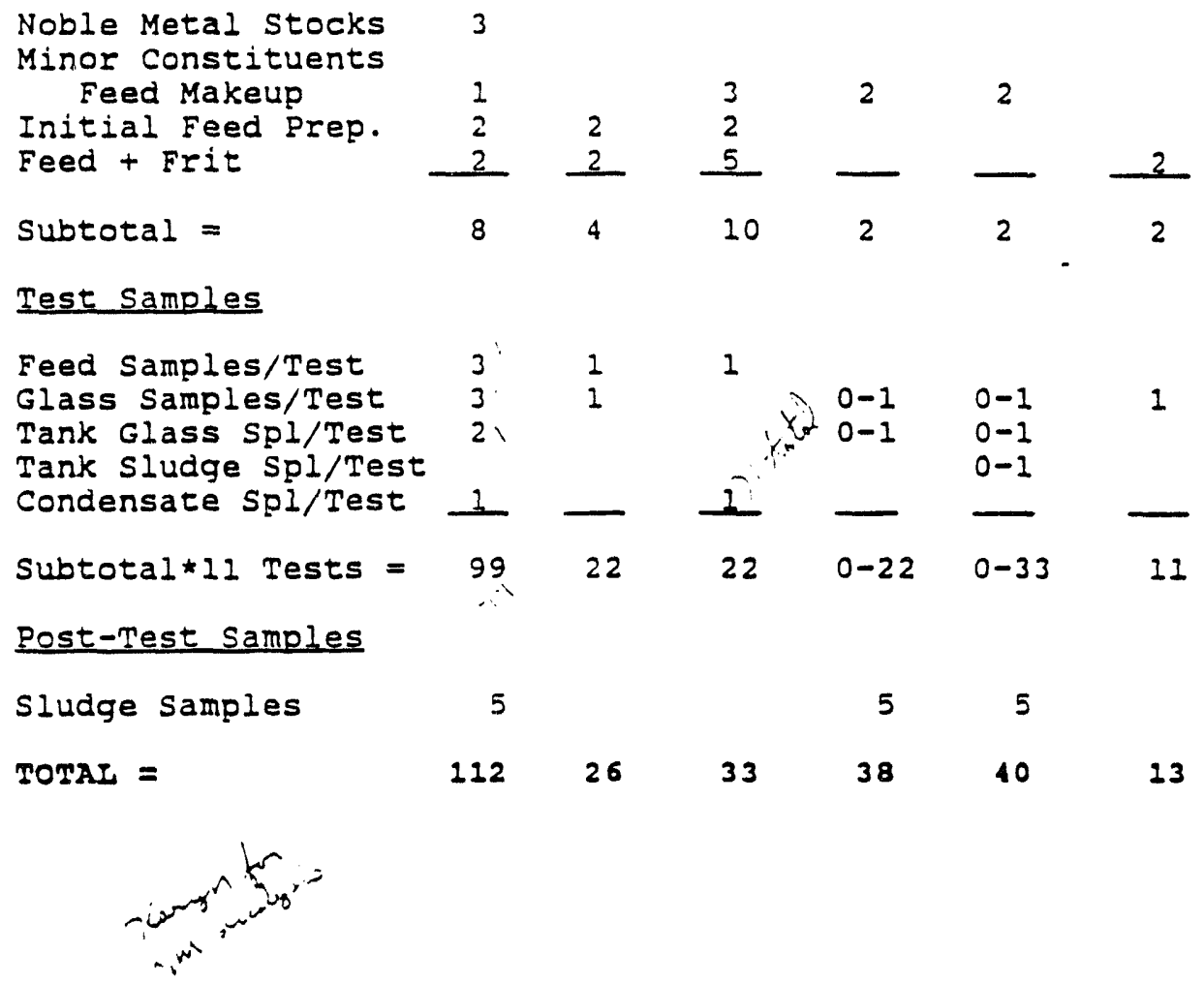

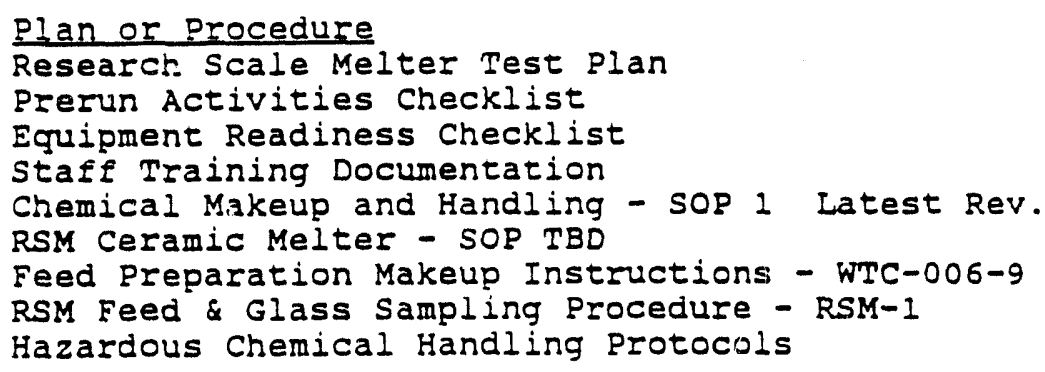


Research-scale Melter Test Plan Rev. 0

HWVP $1.2 .2 .04 .01 \mathrm{C}$

Page 28 of 30

\subsection{OA Requirements, Training, Safety and waste Handing}

\subsection{A Requirements}

The RSM tests are being conducted as a QA Impact Level II activity. It is important that all data records, calculations, and anaiyses reported from this test be documented in a sufficient manner to be traceable from the primary data and the methods and equipment used, through the assumptions and/or interpretations made, to the corresponding results reported in the summary report. Where applicable, error analyses will be performed to support data reporting.

Samples and analytical work will be tracked using the Analytical Request Form (ARF) provided in PNL MA-70/PAP-404 as Exhibit 3 and a sample log. Calibrated measuring and test equipment (M\&TE) will be used during testing and data reported to support TEMPEST to assure the accuracy and reliability of the reported data can be substantiated. Data obtained for preliminary study or to assist in the melter operation may include data obtain by uncalibrated instrumentation. This data and instrumentation will be clearly identified in any reporting of the data. The M\&TE that will be used during this test will be recorded per PNL MA-70/PAP-70-1201.

The majority of data will be collected on data and status log sheets and test instructions. Additional observations, data, and remarks will be placed in a PNI laboratory record book (LRB). The RSM operations LRB is BNW 50265.

\subsection{Records}

Project records (e.g., test data, LRB copy, etc.) pertaining to this work will be maintained in the FY 1991 records inventory and disposition schedule (RIDS) file T.5 - Research-Scale Melter, for WBS 1.2 .2 .04 .01 .

\subsection{Change control}

The desk copy of the run plan will be the controlled document copy in which notations and changes in the run will be recorded. Changes may be entered only by the shift leader, responsible engineer (M.F. Cooper), and 1.2 .2 .04 .01 subtask leader ( $J$. M. Perez). Any changes will be countersigned by the responsible engineer (can be after the fact) to indicate cognizance of the change. Any change to run activities which will affect the primary test objective must be approved additionally by G.A. Jensen, and the cognizant WHC HWVP staff prior to the change. Test modification forms will also be available at the operations desk for initiating and recording changes. 


\section{4 operator mraining}

Training will be accomplished through the implementation of PNL MA-70 PAP 201. Staff responsible for operating test equipment, recording data, and making process changes will be required read and understand the following as a minimum: i) this RSM test plan, 2) the RSM safe operating procedure, 3) the chemical handing SOP, 4) material safety data sheets contained in the run book, and 5) applicable PNL-MA-70 PAP's and activity procedures also copied and placed in the run book. Training will be documented by sign-off of reading and training instruction record sheers.

\subsection{Safety}

The operation of the RSM system will comply with all of the normal safety rules for operating in EDL 102. In addition there are specific burn and electrical hazards associated with the operation of the melter. These specific hazards are addressed in the Research Scale Melter Safety Operating Procedure (Waste Treatment Technology Department SOP \# TRD).

\subsection{Waste Handling}

All wastes generated during the course of tisis test will be disposed of per PNL's safety manual, PNL-MA-8. A PNL waste management specialist will review the quantities and types of waste expected to be generated during this study to verify that proper storage and disposal methods are known and can be implemented. 


\subsection{References}

Geldart, R. W., S. O. Bates and S. J. Jette. 1987. "Preliminary Evaluation of Noble Metal Behavior in the Hanford Waste Vitrification Plant Reference Glass, HW-39." Final Technical Report. HWVP-87-V110202F. Pacific Northwest Laboratory, Richland, Washington.

Cobb, W. T. and P. R. Hrma. 1991. "Behavior of Ruthenium Oxide Particles in Nuclear Waste Glass," to be presented at the American Ceramic Society Conference, April, 1991. Cincinnati, onio.

Koegler, S. S. 1987. Pilot-Scale Ceramic Melter 1985-1986 Rebuild. PNL-6259. Pacific Northwest Laboratory, Richland, Wasnington.

Kruger, 0. W. 1991. Fiscal year 1991 statement of work for Apolied Technology Tasks to be Performed by Pacific Northwest Laboratory in support of the Hanford waste Vitrification plant Project. WHC-SP-0638. Westingnouse Hanford Company, Richland, Washington.

Nakaoka, R. K., J. M. Perez, Jr., W. C. Buchmiller, R. W. Goles and $S$. O. Bates. 1986. Hanford Waste Vitrification Plant Nonradioactive Liquid-Fed Ceramic Melter Testing for Fiscal Year 1986. RHO-RE-CR-17 P. Prepared for Rockwell Hanford operations by Pacific Northwest Laboratory, Richland, Washington.

Nakaoka, R. K. and D. M. Strachan. 1990 "Draft: Melter Performance Evaluation Report." HWVP-90-1.2.2.04.08b. Pacific Northwest Laboratory, Richland, Washington.

Sevigny, G. J. 1990. "Foreign Trip Report." Trip taken June 21June 29, 1990 to KfK Center, FRG.

Smith, R. A. Letter to J.M. Creer, "Revision of Pretreated Neutralized Current Acid Waste Composition for FY 1991 Pilot Testing --Errata Correction," 9150151, dated January 31, 1991. 


\section{Appendix D}

Sample Test Plan Outline for Pilot-Scale Melter Studies:

Liquid-Fed Ceramic Melter Run 9 Test Plan, PNL HWVP Technology Development Project,

Pacific Northwest Laboratory, 1992 
Process Development Task: Vitrification Testing Cost Account

Approva1s:

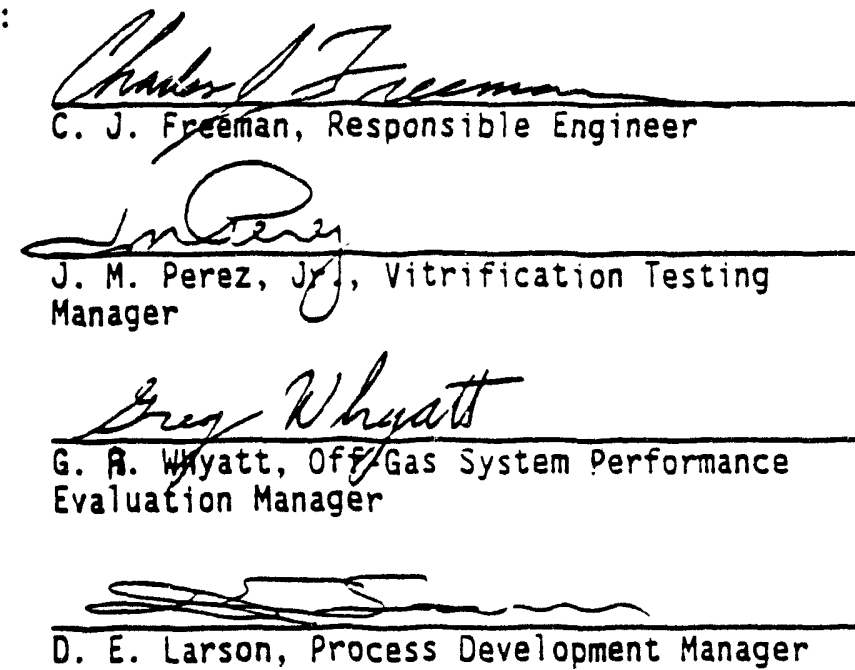

D. E. Larson, Process Development Manager

$$
\begin{aligned}
& \frac{8 /-8 / x-}{\text { Date }} \\
& \frac{8-2 \varepsilon-92}{\text { Date }}
\end{aligned}
$$

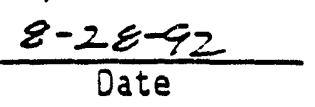

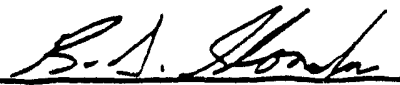

Concurrences:

B. D. STonecker, Quality Engineer

$$
\frac{8 / 17 / 92}{\text { Date }}
$$

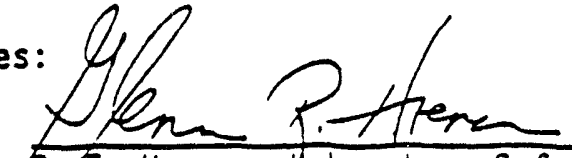

G. R. Hoenes, Laboratory Safety Dept. Mgr.

$\frac{8 / 20 / 92}{\text { Date }}$

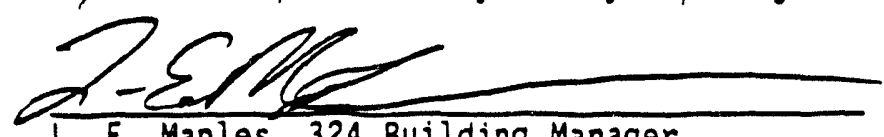

L. E. Maples, 324 Guilding Manager

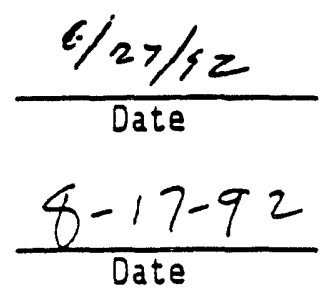

D-3 


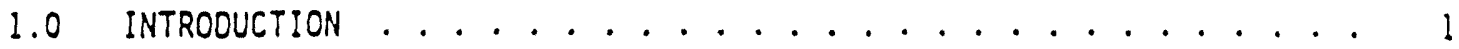

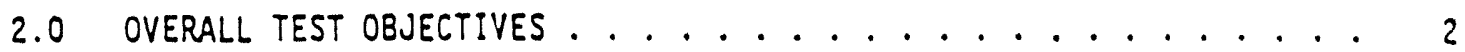

3.0 BACKGROUND .......................... 6

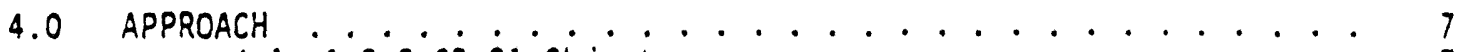

4.1 1.2.2.03.01 object, es.............. . . 7

$4.2 \quad 1.2 .2 .03 .02$ objectives.............. 8

$4.3 \quad 1.2 .2 .03 .03$ objectives .............. . 9 9

4.4 1.2.2.03.04 objectives............. 10

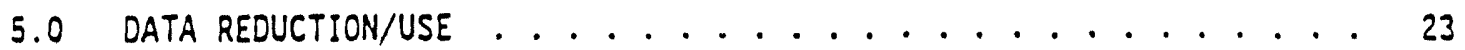

6.0 TEST SCHEDULE . . . . . . . . . . . . . . . . . 27

7.0 EQUIPMENT OESCRIPTION ......... LFCM-8 Test PIan (sect. 4)

8.0 FEED DESCRIPTION ..................... . . . 28

9.0 SAMPLE AND DATA COLLECTION SCHEDULES ............... . . . 31

9.1 Sample Schedule .................. 3 ! . . .

9.2 Sample Labeling and Archive Storage . . . . . . . . 3

10.0 QA REQUIREMENTS, TRAINING, SAFETY, AND WASTE HANDLING . . . . . 34

11.0 REFERENCES ...................... 37 

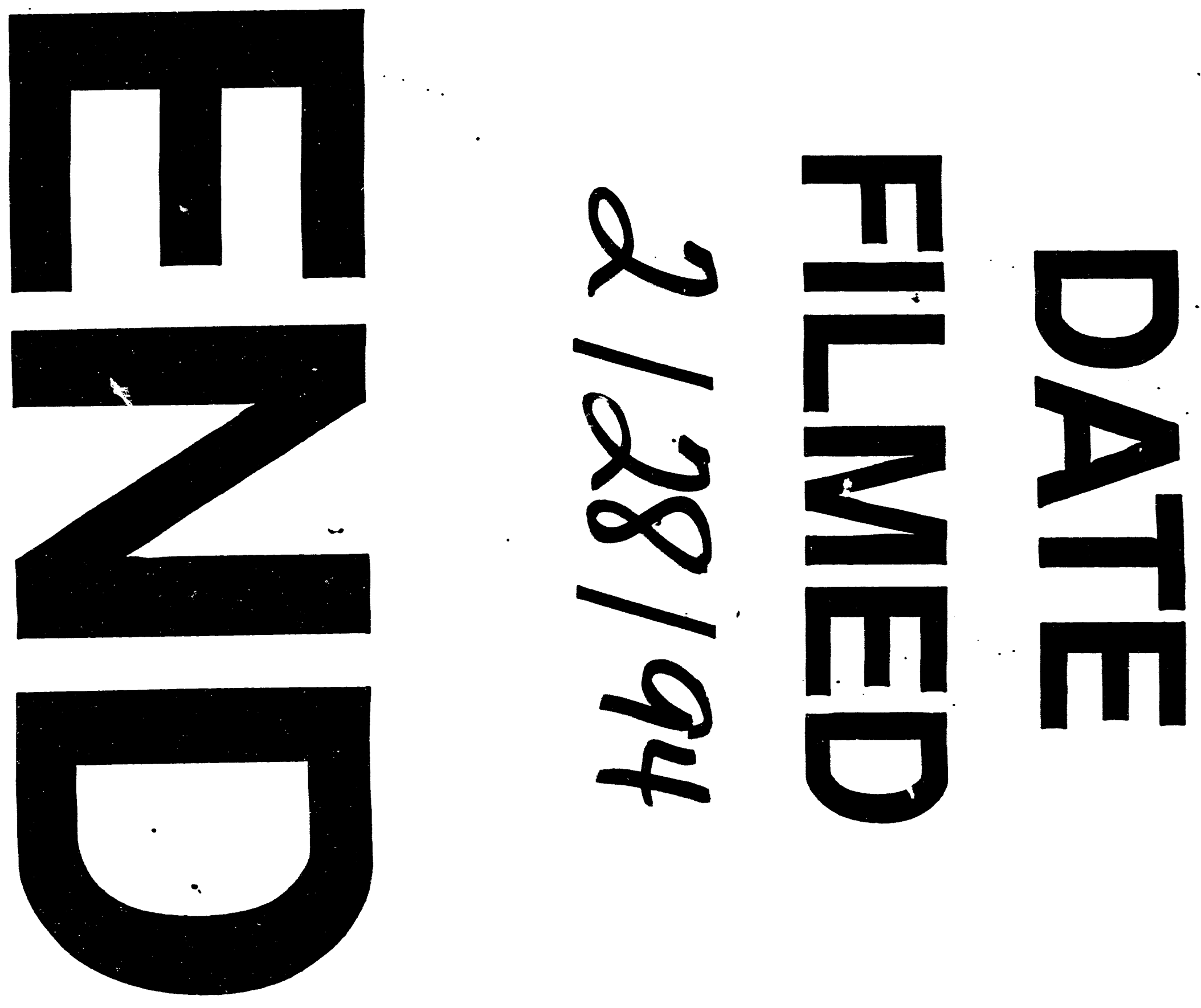